\title{
Essays on Consumer Credit Markets and Debtor Protections
}

\author{
Nathaniel John Pattison \\ Newport News, Virginia
}

M.A. Economics, University of Virginia, 2012

B.S. Mathematics and Economics, Christopher Newport University, 2011

A Dissertation presented to the Graduate Faculty

of the University of Virginia in Candidacy for the Degree of Doctor of Philosophy

Department of Economics

University of Virginia

May, 2017 


\begin{abstract}
This thesis studies the costs, benefits, and welfare impact of laws that protect debtors when they default. The first chapter evaluates the welfare impact of one of the main debtor protections in the United States: asset exemptions. Asset exemptions shield debtors' assets from seizure by unsecured creditors, and so provide insurance that increases consumption when debtors default. This default insurance is financed by higher interest rates when debtors repay. I derive a sufficient statistic formula for the welfare impact of increasing exemptions, which captures the benefits to debtors who default either in or out of bankruptcy. I then estimate the key components of the formula. First, using the PSID, I estimate the change in consumption that occurs when debtors default, which determines debtors' willingness to pay for default insurance. The estimated 5.5\% consumption drop upon default implies that debtors are willing to pay, at most, $16.5 \%$ over the actuarially fair rate for default insurance. Second, using credit union data and changes in state exemption levels, I show that higher exemptions increase interest rates and decrease recoveries on charged-off debt. The estimates imply that exemptions generate default insurance, but the higher interest rates are marked up $320 \%$ over what is actuarially fair. Ultimately, since the actual markup substantially exceeds what debtors are willing to pay, lower exemptions would increase welfare.

The second chapter investigates whether borrowers file more bankruptcies when asset exemption are higher. A higher exemption makes bankruptcy more attractive, but also reduces the supply of credit, so the equilibrium effect on bankruptcy filings is uncertain. The reduced-form literature finds conflicting evidence, generally using cross-sectional variation in exemptions across states. I use panel variation in exemptions, combined with state- and county-level data on bankruptcies, and find that a median-sized exemption increase raises Chapter 7 bankruptcy rates by 3-7\%. Event study regressions show that bankruptcy rates rise immediately after an exemption increase and remain high for at least six years, so it is
\end{abstract}


not a temporary effect. I also estimate the effect of exemptions after the Bankruptcy Abuse Prevention and Consumer Protection Act of 2005, a major reform of the bankruptcy system.

The third chapter, coauthored with Leora Friedberg and Richard M. Hynes, examines the labor market effects of limiting employers' use of credit reports. Eleven states limit employers' use of credit reports, and the primary arguments for the bans are that the use of credit reports hinders the financial recovery of those who suffer financial hardship and has a disparate impact on minority employment. Recent papers provide limited evidence that credit report bans help Americans with bad credit, while suggesting that the bans harm minority employment. We use the Survey of Income and Program Participation (SIPP) because it reveals some people who might directly benefit from credit report bans - those who have had recent trouble meeting their essential expenses. The SIPP also reports unemployment spells, so we see job-seeking status. We use double- and triple-difference specifications and find that banning credit checks reduces the unemployment duration of people who have had trouble meeting their expenses by about $25 \%$; we fail to find a statistically significant effect of these laws on people who have not had such trouble. We do not find a statistically significant effect on the unemployment duration of minorities.

JEL Codes: D14, K35, H0, G0, D61

KEYWORDS: CONSUMER CREDIT, HOUSEHOLD FINANCE, SUFFICIENT STATISTIC, DEBT COLLECTION, BANKRUPTCY 


\section{Acknowledgements}

I am deeply indebted to my advisors for their invaluable guidance and encouragement. I benefited immeasurably from Leora Friedberg's mentorship and continuous guidance in research and writing. I thank Sarah Turner for emphasizing the big picture, transferring her excitement about research, and providing resources and guidance throughout the program. I thank Bill Johnson, who was always willing to discuss research and several versions of models, and pushed me to develop better economic intuition.

The research community at the University of Virginia has been wonderful, and many other faculty members and staff have contributed to this work. Rich Hynes has been an extremely valuable resource and I learned so much about bankruptcy from him and his work. Many others, including Andrew Barr, Dotan Oliar, John Pepper, and Eric Young, gave generous feedback and guidance over the last several years. I am also grateful for the support of the economists at the Federal Reserve Bank of New York, especially Rajashri Chakrabarti, who were critical in developing my research agenda and providing advice and resources. I also wish to thank my fellow graduate students, who have made this experience incredibly fun.

I also thank the Bankard Fund for Political Economy, the Quantitative Collaborative Bynum Grant, the Steer Family Endowed Fund, and Karen and Brad Radulovacki. Their generous financial support granted me the research time and resources needed to complete this thesis.

Lastly, I wish to thank my family, who provided unending support and encouragement. And this would not have been possible without my incredible wife, Dawn. Her patience, generosity, and friendship were unmatched. 


\section{Contents}

1 Consumption Smoothing and Debtor Protections 1

1.1 Introduction . . . . . . . . . . . . . . . . . . 2

1.2 Institutional Background $\ldots \ldots \ldots \ldots \ldots$

1.3 Model: Exemptions as Social Insurance . . . . . . . . . . . . . . . . . . 10

1.4 Willingness to Pay for Default Insurance . . . . . . . . . . . . . . . 16

1.4.1 Data: Panel Study of Income Dynamics _ . . . . . . . . . . . . . 18

1.4.2 Empirical Strategy: Consumption Change upon Default . . . . . . . . 20

1.4 .3 Results . . . . . . . . . . . . . . . . . . . . . . . . 21

1.4.4 Robustness, Anticipation, and Heterogeneity . . . . . . . . . . 22

1.5 The Cost of Exemption-Generated Default Insurance . . . . . . . . . . . . 25

1.5.1 Data: Credit Union Call Reports . . . . . . . . . . . . . . . 25

1.5.2 Empirical Strategy: The Effect of Exemptions on $r(m)$ and $q(m) \ldots 28$

1.5 .3 Results . . . . . . . . . . . . . . . . . . . . 30

1.5.4 Explaining the Markup: The Role of Default . . . . . . . . . . . . 31

1.6 Calculating the Welfare Impact $\ldots \ldots \ldots \ldots$

1.6.1 Computing the Welfare Gain . . . . . . . . . . . . . . . . . . 33

1.6.2 Sensitivity of the Welfare Gain . . . . . . . . . . . . . . . 35

1.7 Conclusion . . . . . . . . . . . . . . . . . . . . . . . . . . . . . 36

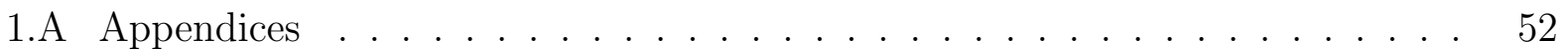

1.A.1 Dynamic Model . . . . . . . . . . . . . . . . . . . . . . . 52

1.A.2 Multiple Loan Types and Implications for Welfare Gain . . . . . . . 57

1.A.3 Comparison with Calibration of Dávila (2016) . . . . . . . . . . 61

\section{New Evidence on Asset Exemptions and Consumer Bankruptcies}

2.1 Introduction . . . . . . . . . . . . . . . . . . . . 66

2.2 Bankruptcy Law and Related Work . . . . . . . . . . . . . . . . . 69

2.2 .1 Exemptions in Bankruptcy . . . . . . . . . . . . . . . . . . . 69

2.2 .2 Related Work . . . . . . . . . . . . . . . . . . . . . . . 71

2.3 Data and Variation in Exemption Levels . . . . . . . . . . . . 73

2.3 .1 Data . . . . . . . . . . . . . . . . . . . . 73

2.3.2 Variation in exemption levels . . . . . . . . . . . . . . . 75 
2.4 Empirical Strategy _ . . . . . . . . . . . . . . . . . . . . . 76

2.5 Results . . . . . . . . . . . . . . . . . . . . . . . . . . . . . . 79

2.5.1 Main Results . . . . . . . . . . . . . . . . . . . . . . . . . 79

2.5.2 Impact of Exemptions After BAPCPA: Monthly Data . . . . . . . . . 82

2.5.3 Comparison with Cross-Sectional Estimates . . . . . . . . . . . 84

2.6 Discussion and Conclusion . . . . . . . . . . . . . . . . . . . 85

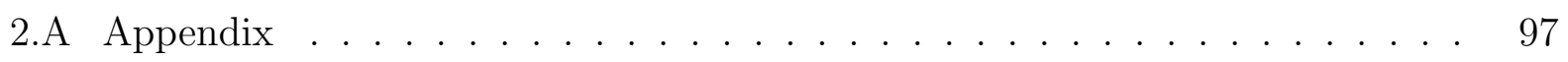

\section{Who Benefits from Credit Report Bans? (with Leora} $\begin{array}{lr}\text { Friedberg and Richard M. Hynes) } & 104\end{array}$

3.1 Introduction . . . . . . . . . . . . . . . . . . . . . . 105

3.2 Background . . . . . . . . . . . . . . . . . . . . . . . . . . . . 108

3.3 Empirical Strategy . . . . . . . . . . . . . . . . . . . . . . . . . . . 111

3.4 Data . . . . . . . . . . . . . . . . . . . . . . . . . . . . . . . . 114

3.4 .1 State Laws . . . . . . . . . . . . . . . . . . . . . . . . . 114

$3.4 .2 \quad$ SIPP Data . . . . . . . . . . . . . . . . . . . . . . . . . . . 114

3.4.3 Corroborating Information on Financial Distress . . . . . . . . . 117

3.5 Estimation Results . . . . . . . . . . . . . . . . . . . . . . . . . 118

3.5.1 Baseline Results . . . . . . . . . . . . . . . . . . . . . . . . . 118

3.5.2 Additional Estimates . . . . . . . . . . . . . . . . . . . 120

3.6 Conclusion . . . . . . . . . . . . . . . . . . . . . . . . . . . . . . . . 124

3.A Appendix . . . . . . . . . . . . . . . . . . . . 134

$\begin{array}{lr}\text { Bibliography } & 136\end{array}$ 


\section{Chapter 1}

Consumption Smoothing and Debtor Protections 


\section{$1.1 \quad$ Introduction}

Debtor protection laws can be viewed as one of the largest social insurance programs in the United States. These laws provide consumption insurance by protecting debtors' assets, income, and privacy from creditors attempting to collect on debts. But, this insurance comes at a cost, as creditors compensate for additional losses by raising interest rates. Thus, debtor protections form a government-mandated default insurance program that is financed by higher interest rates. The default insurance program for unsecured credit, which is the focus of this paper, is large. Around $10 \%$ of households have filed for bankruptcy and a greater percentage have defaulted informally. ${ }^{1}$ At the same time, total credit card debt exceeds $\$ 700$ billion and consumers pay more than $\$ 100$ billion in credit card interest each year. ${ }^{2}$ Given the frequency of default and the size of consumer credit markets, the design of debtor protections can have important effects on welfare.

This paper evaluates the welfare impact of a key form of debtor protection in the United States: asset exemptions. When a debtor defaults, states' asset exemptions protect certain property from seizure by unsecured creditors. The level of protection varies widely across states, with the total value of state exemptions ranging from less than $\$ 10,000$ to over $\$ 500,000$. In this paper, I derive a sufficient statistic formula for the welfare impact of varying the exemption level. Guided by this formula, I estimate the key determinants of the welfare impact and find that, at the current levels, the cost of additional default insurance substantially exceeds what borrowers are willing to pay. The policy implication is that lower exemptions would increase welfare, even in states with already low exemptions.

\footnotetext{
${ }^{1}$ Stavins (2000) reports that $8.5 \%$ of households have filed for bankruptcy, and more recently, Dobbie et al. (2016) reports that $15 \%$ of individuals have filed for bankruptcy based on their calculations in the Federal Reserve Bank of New York's Consumer Credit Panel/Equifax Data. VISA reports that 55-60\% of charge-offs occur without a bankruptcy filing (NBRC, 1997).

${ }^{2}$ The $\$ 100$ billion in interest rate payments, reported in Akerlof and Shiller (2015), is obtained by multiplying the total credit card debt in 2009 (886 billion) by the average interest rate on revolving credit (0.134). These figures are from tables 1188 and 1190 of the 2012 US Census Bureau Statistical Abstract of the United States.
} 
I begin by adapting a standard model of social insurance from Chetty (2006) to the case of asset exemptions, and use this model to derive a Baily-Chetty sufficient statistic formula for the welfare impact of raising exemptions. I focus on a two-period model, but show that a similar sufficient statistic holds in a general, dynamic setting. A borrower can be in one of two states: repayment or default. Raising the exemption level transfers resources from the repayment state to the default state by increasing interest rates and decreasing debt collection in default. The value of this transfer, i.e borrowers' willingness to pay for it, depends on the relative marginal utility of consumption in the two states. The cost of the transfer depends on how much raising exemptions causes 1) interest rates to increase (the additional "premium" payments) and 2) repayment rates in default to decrease (the additional "payout" to those who default). If borrowers' willingness to pay exceeds the cost of higher interest payments (relative to the decrease in debt collection), then raising exemptions would be welfare-improving. The welfare gains formula compares what borrowers are willing to pay for default insurance against the actual cost of generating this insurance with exemptions. ${ }^{3}$

This welfare gains formula guides my two-part empirical analysis. In the first part, I estimate what borrowers are willing to pay for default insurance. The willingness to pay for insurance can be expressed as borrowers' coefficient of relative risk aversion multiplied by the drop in consumption that occurs upon a shock (Baily, 1978, Chetty, 2006). Beginning with Cochrane (1991) and Gruber (1997), a number of papers use panel data on household consumption to estimate the drop in consumption that occurs upon job loss or illness. ${ }^{4}$ Using

\footnotetext{
${ }^{3}$ I maintain the assumption that exemptions do not affect lenders' profits. Later, I provide empirical evidence that, supporting this assumption, the magnitudes of the interest rate, debt collection, and default responses are consistent with a model of competitive loan pricing. Specifically, my estimates of the reduction in recovery rates and the increase in the probability of default generate losses that exactly offset the additional revenue from higher interest rates.

${ }^{4}$ Several papers use this approach to study unemployment insurance (Gruber, 1997, Browning and Crossley, 2001, Kroft and Notowidigdo, forthcoming, East and Kuka, 2015). Bronchetti (2012) studies workers' compensation.
} 
data on food consumption and default from the Panel Study of Income Dynamics (PSID), I apply this technique to determine the drop in consumption that occurs upon default. On average, consumption is $3.6 \%$ lower during the year that a borrower defaults, relative to the prior year. The decline is somewhat larger in low-exemption states (5.5\%) and smaller in high-exemption states $(1.9 \%)$, though these differences are not statistically significant. The estimated consumption drop among defaulters is similar when non-defaulters living in the same state and year are used to control for state-year shocks. Additionally, I find no evidence that borrowers anticipate default, since there is no decline in consumption during the years before they default.

Scaling the largest estimated consumption drop, $5.5 \%$, by a coefficient of relative risk aversion of 3 , implies that borrowers are willing to pay up to a $16.5 \%$ markup over the actuarially fair rate for additional default insurance. ${ }^{5}$ One potential concern is that exemptions may not affect all defaulters. I test for heterogeneity in the consumption drop among subsets of PSID defaulters who may be more affected by exemptions: homeowners and those with more serious forms of default. The consumption drop upon default among these subgroups is smaller, implying that they place a lower value on additional default insurance. Therefore, the $16.5 \%$ willingness to pay for default insurance likely overstates the value of default insurance among those that asset exemptions target. For comparison, the consumption drop upon unemployment is $7-10 \%$, which implies a willingness to pay of $21-30 \%$ for unemployment insurance (Gruber, 1997, Kroft and Notowidigdo, forthcoming).

To evaluate the welfare impact, I need to compare this $16.5 \%$ willingness to pay to the actual markup (over the actuarially fair rate) of the default insurance generated by raising exemptions. In the second part of the empirical strategy, I estimate the markup. This requires causal estimates of the effect of exemptions on 1) interest rates and 2) recovery rates

\footnotetext{
${ }^{5} \mathrm{~A}$ coefficient of relative risk aversion of 3 is in the conventional range of estimates, and I later show that the policy implication of the paper holds over a wide range of values for the coefficient of relative risk aversion.
} 
on defaulted debt. The effect on interest rates captures the additional payments by debtors in the repayment state (insurance premium), and the effect on the recovery rate captures the reduction in payments made in default (insurance payout). These effects, when scaled by the relative probability of repayment, determine the expected increase in premiums relative to payouts, i.e. the markup. If the insurance were actuarially fair, the ratio of premium increases to payout increases would equal one. I construct annual, state-level credit card interest rates and recovery rates on defaulted debt from Credit Union Call Reports for 1994-2004. ${ }^{6}$ I estimate difference-in-differences regressions that exploit 65 changes in state exemption levels. These regressions show that a $10 \%$ increase in exemptions raises interest rates by 4 basis points and reduces recovery rates by 42 basis points, both significant at the $1 \%$ level. Supporting the identification strategy, estimates from event-study regressions show that interest rates and recovery rates in treatment and control states followed parallel trends and then diverged sharply once exemptions increased.

With the sample mean default rate of $2.2 \%$, these estimates imply that borrowers must pay a markup of $320 \%$ over an actuarially fair transfer for default insurance generated by exemptions. That is, in expectation, debtors pay $\$ 4.20$ more in higher interest payments for $\$ 1$ of default insurance generated by raising exemptions. Such a large markup raises concerns that exemptions may affect lenders' profits, which would violate a key assumption used to derive the welfare gains formula. I address this concern by showing that the markup can be fully explained by moral hazard and adverse selection within a model of competitively priced loans. Specifically, I show that higher exemptions increase the probability of default, and the corresponding losses are large enough to completely offset the additional revenue from the interest rate markup.

\footnotetext{
${ }^{6}$ I use data from credit unions because, unlike large commercial banks, credit union data contain interest rates and credit unions are often local lenders, so their financial information reflects state laws. The recovery rate is the share of charged-off non-real estate debt that is eventually recovered through debt collection. These data on interest rates and recovery rates were first used in Fedaseyeu (2015) to examine regulations on debt collectors, such as licensing requirements and criminal penalties.
} 
The final section of the paper calculates the welfare impact of increasing exemption levels. The $5.5 \%$ consumption drop, when scaled by a coefficient of relative risk aversion of 3 , indicates that individuals are willing to pay a maximum markup of $16.5 \%$. The estimated responses of interest rate and recovery rates, however, imply that the actual markup generated by raising exemptions is $320 \%$. Since the cost of this form of default insurance exceeds borrowers' willingness to pay, the policy implication is that lowering exemptions would increase welfare. I conduct a sensitivity analysis and show that this policy implication is robust to variation within the $95 \%$ confidence intervals of the estimates. Moreover, this analysis likely understates the costs of raising exemptions, since it ignores other potential creditor responses, such as lowering credit limits or rejecting applicants.

This paper contributes to the literature studying the welfare impact of asset exemptions. Papers in this literature develop structural or quantitative models to examine the welfare impact of bankruptcy and exemptions, but different modeling choices and parameterizations generate conflicting results (Athreya, 2006, Li and Sarte, 2006, Pavan, 2008, Mitman, 2016, Hintermaier and Koeniger, 2016). ${ }^{7}$ In the sufficient statistic approach that I adapt here, the welfare impact depends on only a few high-level statistics and holds in a general class of models. Dávila (2016) derives a sufficient statistic for the optimal level of asset exemptions in bankruptcy and shows that the formula holds in more realistic and general settings. This paper differs in two key ways. First, my model and new formula allow exemptions to benefit debtors who default in or out of bankruptcy. This is critical, as most default and debt collection occur without a formal bankruptcy. ${ }^{8}$ Second, I estimate the key determinants of the welfare impact, and some of these estimates differ dramatically from the calibrated

\footnotetext{
${ }^{7}$ For example, Athreya (2006) finds that higher exemptions increase welfare, while Li and Sarte (2006), which allows for Chapter 13 bankruptcy and general equilibrium effects, finds the opposite. See Livshits (2015) for a recent review and discussion of the dispersion of findings in the literature evaluating the welfare impact of default policy.

${ }^{8}$ In Section 1.2, I provide evidence that the major impact of exemptions is on debt collection outside of the formal bankruptcy system.
} 
values chosen in Dávila (2016). These differences are large enough to reverse the policy implications.

By estimating borrowers' willingness to pay for default insurance, this paper also contributes to the empirical literature examining the benefits of exemptions and bankruptcy. While I focus on the tradeoffs for consumer credit markets, Mahoney (2015) shows empirically that exemptions provide a form of health insurance and examines the implications for optimal health insurance mandates. Other papers in this literature focus on the benefit of filing for formal bankruptcy (Filer and Fisher, 2005, Dobbie and Song, 2015, Yang, Dobbie, and Goldsmith-Pinkham, 2015). Grant (2010) demonstrates that exemptions provide insurance by showing that increasing exemptions reduces state-level inequality in consumption growth. Adding to this, I separately estimate the drivers of the exemption insurance, higher interest rates and reduced debt collection, and estimate the willingness to pay for this insurance. It is separately estimating these components that allows me to compute the welfare impact of raising exemptions. An additional contribution is that the estimated willingness to pay can be used in cost-benefit analyses of other forms of debtor protections. Since the willingness to pay of $16.5 \%$ reflects the value of transferring resources to those in default, regardless of how those resources are transferred, any form of debtor protection (e.g. garnishment restrictions, statutes of limitations on debt) must generate default insurance that is marked-up less than $16.5 \%$ for it to be welfare-improving.

Finally, this paper adds to the empirical literature studying the effect of asset exemptions on interest rates. Several papers have found that auto loan and small business interest rates are higher in states with more lenient exemptions (Gropp, Scholz, and White, 1997, Berkowitz and White, 2004, Berger, Cerqueiro, and Penas, 2011). ${ }^{9}$ My paper differs in that it provides estimates of the effect on credit card interest rates, which are more affected by

\footnotetext{
${ }^{9}$ Fedaseyeu (2015) includes exemptions as a robustness check, but since his paper focuses on the regulation of third-party debt collectors, these coefficients are not discussed.
} 
exemptions than are interest rates on secured loans (e.g. auto loans) since exemptions only protect borrowers from unsecured creditors. ${ }^{10}$ Additionally, while those studies rely on crosssectional variation, I use panel variation in exemption levels and examine the timing of the interest rate changes using event-study regressions. My estimates are consistent with recent work in Severino, Brown, and Coates (2015), which also uses panel variation in exemption laws. They find a positive effect of exemptions on unsecured consumer loan interest rates and a generally positive but imprecise effect on credit card interest rates.

The paper proceeds as follows. Section 1.2 describes the role that exemptions play inside and outside of bankruptcy. Section 1.3 derives the welfare gains formula, which compares borrowers willingness to pay for default insurance to the cost of the insurance generated by raising exemptions. Sections 1.4 and 1.5 estimate the components of the welfare gains formula. Section 1.6 calculates the welfare effect using these estimates and conducts a sensitivity analysis. Section 2.6 concludes.

\subsection{Institutional Background}

When debtors default, exemption laws protect specific assets from seizure by unsecured creditors. While federal exemptions are available, the large majority of states have opted out or set their own exemption laws alongside the federal exemptions. This generates substantial variation across states. For example, for an unmarried debtor, Virginia exempts $\$ 5,000$ in home equity and $\$ 6,000$ in vehicle equity, while Texas exempts an unlimited amount of home equity and one vehicle, regardless of the value.

The state exemptions generally apply in both the formal bankruptcy system and the collection process outside of bankruptcy in the state courts. Consumer bankruptcies can

\footnotetext{
${ }^{10}$ I show this empirically in Appendix 1.A.2 by estimating the effect of exemptions on auto loan interest rates.
} 
be filed under Chapter 7 or Chapter 13. In Chapter 7, which accounts for $70 \%$ of consumer bankruptcies, the bankruptcy court sells the debtor's non-exempt assets and gives the proceeds to creditors. In Chapter 13, exemptions apply indirectly, since creditors must receive at least as much as they would under Chapter 7. Bankruptcy is not the only method of default, however, and there is growing evidence of the importance of default outside of bankruptcy (Dawsey and Ausubel, 2004, Fedaseyeu and Hunt, 2014, Fedaseyeu, 2015). For debtors defaulting outside of bankruptcy, the majority of exemptions still protect debtors' assets from the collection efforts of unsecured creditors (Hynes and Posner, 2002). If an unsecured creditor sues in state court, he can obtain a judgment that allows special collection actions, including the right to seize assets as payment. Court judgments are common, with almost 5\% of credit reports containing a record of a court judgment (Avery et al., 2003). But unsecured creditors with a judgment can only seize assets that are not protected by state exemption laws.

The actual seizure and sale of assets, either through the bankruptcy system or state courts, is rare. 93-96\% of Chapter 7 filers have no assets seized, and of the small share that do, the most commonly seized asset is a tax refund (Flynn, Bermant, and Hazard, 2003, Jiménez, 2009). Less is known about seizure outside of bankruptcy, but the available evidence suggests that it is also relatively rare. Hynes (2008) reports that asset seizure, at least in Virginia, is seldom used. A popular guide to dealing with collection actions reports that while collectors may threaten to seize household goods, this threat is rarely carried out (NCLC, 2016). The most important exemption for many households is the homestead exemptions, and while unsecured creditors with a judgment lien can theoretically foreclose, they usually will not (Loftsgordon, n.d.). Instead, to avoid losses from a foreclosure sale, unsecured creditors will often wait to collect on a judgment lien until the property is sold by the borrower (Leonard, 2015).

Although asset seizure is rare, exemptions can still have a meaningful impact on repay- 
ment. Since the deadweight costs of bankruptcy or asset seizure can be high, debtors and creditors have the incentive to negotiate a settlement. The view taken in this paper is that seizable assets serve as a threat-point in this negotiation. Consistent with this, a consumer guide advises delinquent debtors that when settling, the "amount you offer to pay should be directly related to what the collector could seize ..." (NCLC, 2016). Similarly, creditors are more likely to accept partial payment if the debtor has few seizable assets (Finlay, 2010). Mahoney (2015) provides empirical support for the importance of these laws in the negotiation process of medical debt, showing that uninsured individuals with fewer seizable assets repay less of the debt. These settlements, asset seizures (or the threat of seizure), and other collection efforts recover a nontrivial share of defaulted debt, particularly when done outside of the formal bankruptcy system. Visa reports that the average recovery rate on debt charged-off without a bankruptcy is $18 \%$, compared to only $3 \%$ when a bankruptcy is filed (NBRC, 1997). ${ }^{11}$ In summary, although assets are rarely seized, they still affect debt collection, especially debt collection that occurs outside of the bankruptcy system. Therefore, to assess the impact of exemptions, it is critical to consider their impact on default and collection both inside and outside of bankruptcy.

\subsection{Model: Exemptions as Social Insurance}

In this section, I adapt the social insurance of Chetty (2006) to the case of asset exemptions and derive a sufficient statistic formula for the welfare impact of raising exemptions. Raising exemptions reduces the amount borrowers repay in default. This payment reduction is financed through an increase in the interest rate, which reduces consumption when borrowers

\footnotetext{
${ }^{11}$ As another example of the efficacy of collection outside of bankruptcy, in 2013, the bankruptcy courts collected $\$ 3.2$ billion from Chapter 7 asset cases, while third-party debt collection agencies alone, which excludes in-house collection, recovered over $\$ 55$ billion (United States Trustees Program Annual Report, FY 2013 and (Ernst \& Young, 2014)).
} 
repay. In this way, exemptions smooth consumption by transferring resources from the repayment state to the default state. The model produces a formula for the welfare impact of this transfer that compares borrowers' willingness to pay for default insurance against the cost of generating this insurance by increasing asset exemptions.

This basic trade-off between partial default insurance and the cost of credit is central to most papers examining the welfare impact of default policy. ${ }^{12}$ Dávila (2016) was the first paper to apply the sufficient statistic framework to evaluate asset exemptions. He develops a sufficient statistic in a two-period model, then extends it to additional choice variables, multiple contracts, borrower heterogeneity, asymmetric information, and dynamics then calibrates the model to determine the optimal exemption level. My model differs from Dávila (2016) in two main ways. First, while Dávila (2016) focuses on bankruptcy filers, I use a broader measure of default and allow exemptions to affect borrowers who default without filing a formal bankruptcy. This changes the population that benefits from raising exemptions and requires additional reduced form parameters to evaluate the welfare impact, in particular, the consumption drop among informal defaulters and the effect of exemptions on repayment in informal default. Second, while Dávila (2016) is based on the model of borrowing with default risk in Eaton and Gersovitz (1981), my model adapts Chetty (2006) and so produces a Baily-Chetty sufficient statistic formula that is analogous to those in the optimal social insurance literature. Since the purpose of my model is to guide the empirical analysis, I focus on a simple model that demonstrates the intuition. In Appendix 1.A.1, I use the arguments of Chetty (2006) to show that a similar welfare gains formula holds in a more general setting with multiple periods and additional choice variables.

Borrower's Problem There are two periods, $t=0,1$, and a single consumption good. Two periods are necessary to include both borrowing and repayment. In the first period, income

\footnotetext{
${ }^{12}$ This literature mostly consists of macroeconomic models and a recent review of these papers is Livshits (2015).
} 
is certain and borrowers choose how much to borrow, $d$. Borrowers also exert costly effort, $e$, that determines the probability that they will repay their debts in the second period. This effort choice reflects actions that borrowers can take to increase their ability to repay debt, such as purchasing insurance against shocks or adjusting work effort. The units of effort, $e$, are normalized so that $e$ is equal to the probability of repayment in the second period. The cost of effort, given by $f(e, d)$, can depend on the amount of debt one holds. I assume $f_{e e}, f_{d d}$, and $f_{e d}>0$ because it is more costly to avoid default as the level of debt $d$ increases.

In the second period, borrowers enter one of two states: default (low state) or repayment (high state). If borrowers enter the default state, they earn income $y_{l}$ and repay some share of their debt at the rate $q<1$. This recovery rate $q$ reflects that creditors collect some portion of what is owed even when borrowers are unwilling or unable to repay the full amount. For example, Visa eventually recovers $18 \%$ of credit card debt charged-off without a bankruptcy filing. ${ }^{13}$ If borrowers enter the repayment state, they earn income $y_{h}$ and repay their full debt plus interest at the rate $r>0$. I do not model assets and asset seizure, but instead allow exemptions $m$ to influence the recovery rate $q(m)$. This focus on the recovery rate, which captures post-charge-off settlements, is motivated by the evidence that the threat of asset seizure is often used to coerce debtors to repay, but actual asset seizure is rare. Through the response of creditors, exemptions also influence the interest rate $r(m)$.

Borrowers take the interest rate $r(m)$ and the recovery rate $q(m)$ as exogenous and choose their effort and debt to maximize state-independent utility. Indirect utility $V(m)$, written as a function of the exemption level $m$, is equal to the utility from consumption in period 0 plus the expected utility in period 1 , minus the cost of effort.

$$
V(m)=\quad \max _{e, d} \quad u\left(c_{0}\right)+\left\{e u\left(c_{h}\right)+(1-e) u\left(c_{l}\right)\right\}-f(e, d)
$$

\footnotetext{
${ }^{13}$ This statistic is from NBRC (1997).
} 
where

$$
\begin{aligned}
& c_{0}=y_{0}+d, \\
& c_{h}=y_{h}-(1+r(m)) d \\
& c_{l}=y_{l}-q(m) d .
\end{aligned}
$$

In period 0 , borrowers consume the income endowment, $y_{0}$, plus the amount borrowed, $d$. In period 1 , borrowers the repayment state with probability $e$ and consume income $y_{h}$ less the amount it takes to repay the debt plus interest $r(m) d$. Alternatively, borrowers default with probability $(1-e)$ and consume income $y_{l}$ less the portion of the debt that repaid in default $q(m) d$. I assume the regularity conditions that generate an interior solution with borrowers holding a positive level of debt. Also, note that for default insurance to potentially have any value, it must be that $c_{h}>c_{l}$. In Section 1.4, I test whether this condition holds.

\section{Interest Rates and Recovery Rates}

I make four assumptions about creditors and interest rates. First, changes in asset exemptions do not change lender profits. This simplifies the welfare analysis by allowing the social planner to consider only borrower welfare. In Section 1.5, I provide empirical support for this assumption by showing that exemptions do not affect expected returns on credit card loans from credit unions and that the magnitudes of the estimated credit market responses are consistent with a model of competitively priced loans. Second, creditors do not use information on individual effort or the amount borrowed to set interest rates in the interval over which effort and debt respond to changes in exemptions. That is, the interest rate and recovery rate are market prices, so they are not affected by individual effort and debt, but can depend on aggregate demand and effort. Third, I assume that creditors respond to exemptions only by changing the interest rate. This rules out creditor responses that change denial rates, credit limits, or other terms of credit card contracts. The second and 
third assumptions are needed because of the available data on interest rates and recovery rates, which do not contain borrower characteristics or other lending terms. At the end of this section, I discuss the how relaxing these assumptions will affect the implications of this analysis. Finally, I assume that $r(m)$ and $q(m)$ are smooth.

\section{Planner's Problem and Welfare Implications}

The social planner chooses an exemption level $m$ to maximize the borrower's expected utility $V(m)$. In standard social insurance problems, such as unemployment insurance, additional benefits are financed through an increase in the tax rate required by the government's balanced budget constraint. In the asset exemptions setting, additional benefits to defaulters are financed through increased interest rates, with the size of the interest rate increase determined by how creditors respond to changes in exemptions levels.

The change in expected utility from increasing the exemption level is obtained by differentiating $V(m)$ with respect to $m$. Using the envelope conditions,

$$
\frac{d V(m)}{d m}=\left\{-e r^{\prime}(m) u^{\prime}\left(c_{h}\right) d-(1-e) q^{\prime}(m) u^{\prime}\left(c_{l}\right) d\right\}
$$

This welfare change is in units of utility. To obtain a money-metric measure of the welfare gain, I normalize the effect of exemptions by the marginal utility of an additional dollar in the repayment state $u^{\prime}\left(c_{h}\right)$, so that $\frac{d W(m)}{d m}=\frac{d V(m) / d m}{u^{\prime}\left(c_{h}\right)}$.

$$
\frac{d W(m)}{d m}=\left[\left(\frac{u^{\prime}\left(c_{l}\right)}{u^{\prime}\left(c_{h}\right)}-1\right)-\left(-\frac{e}{1-e} \frac{r^{\prime}(m)}{q^{\prime}(m)}-1\right)\right] T
$$

where $T=-(1-e) q^{\prime}(m) d>0$ is a scaling factor equal to the total amount of money transferred to those in default. The first term in equation $(1.2), \frac{u^{\prime}\left(c_{l}\right)}{u^{\prime}\left(c_{h}\right)}-1$, is the maximum markup (over the actuarially fair rate) that a borrower would be willing to pay in expected interest payments for a marginal increase in the expected payout in default. For example, 
if $\frac{u^{\prime}\left(c_{l}\right)}{u^{\prime}\left(c_{h}\right)}-1$ equaled 0.2 , the borrower would be willing to pay $\$ 1.20$ in expected interest payments to reduce the expected repayment in default by only $\$ 1 .^{14}$

The second term, $-\frac{e}{1-e} \frac{r^{\prime}(m)}{q^{\prime}(m)}-1$, is the actual markup of the default insurance generated by increasing asset exemptions. The numerator $\mathrm{er}^{\prime}(m)$ is equal to the expected increase in interest payments (the insurance premium) and the denominator $(1-e) q^{\prime}(m)$ is equal to the expected reduction in payments made when in default (the insurance payout). If there were no behavioral distortions and creditors set competitive interest rates, the increase in interest rates would exactly offset the reduction in payments, $-\frac{e}{1-e} \frac{r^{\prime}(m)}{q^{\prime}(m)}$ would equal one, and since the transfer would be actuarially fair, it would be optimal to provide full insurance. Factors such as moral hazard or administrative costs could cause the actual markup to exceed the actuarially fair rate, even while lenders' profits remain unchanged. ${ }^{15}$

The terms inside the brackets in equation (1.2) give the welfare effect of transferring an infinitesimal amount to the default state by increasing exemptions. Whether the welfare impact is positive or negative depends on whether the borrower's willingness to pay exceeds the cost of the transfer. $T$ scales this welfare effect by the expected size of the transfer generated by increasing exemptions, $T=-(1-e) q^{\prime}(m) d$, which is the probability of default $(1-e)$ multiplied by the change in default payments $\left(-q^{\prime}(m) d\right)$. Since $T>0$, it will affect the magnitude, but not the sign, of the welfare impact of exemptions.

\section{Discussion of Extensions and Critical Assumptions}

The key features of this welfare formula hold in a much more general setting. In Appendix 1.A.1, I use the arguments of Chetty (2006) to show that a very similar formula holds in a

\footnotetext{
${ }^{14}$ To see this, consider the welfare effect of an insurance policy that pays out an infinitesimal amount in the default state in exchange for premium payments $t$ in the repayment state: $\left.\frac{\partial}{\partial b}\right|_{b=0} e u\left(c_{h}-t(b)\right)+(1-e) u\left(c_{l}+b\right)$. The change in utility will be positive if and only if the increase in expected premiums relative to payout, $\frac{e t^{\prime}(0)}{(1-e)}$, is less than $\frac{u^{\prime}\left(c_{l}\right)}{u^{\prime}\left(c_{h}\right)}$.

${ }^{15}$ If creditors face the zero-profit condition $(1-e) q(m)+e(1+r(m))=1+\tilde{r}$, where $\tilde{r}$ is the market rate of return, and there is no moral hazard $\left(\frac{\partial e}{\partial m}=0\right)$, then differentiating with respect to $m$ yields $-\frac{e}{1-e} \frac{r^{\prime}(m)}{q^{\prime}(m)}$ $=1$. However, if exemptions cause moral hazard $\left(\frac{\partial e}{\partial m}<0\right)$, then it could be greater than 1 .
} 
setting that allows dynamics, additional constraints, and additional choices by the borrower. The only major change to the formula is that the marginal utilities $u^{\prime}\left(c_{h}\right)$ and $u^{\prime}\left(c_{l}\right)$ in equation (1.2) are replaced by the average marginal utilities in the two states, and these marginal utilities are weighted by the level of debt. This weighting is because, in the more complicated model, debt varies over time and states, so the impact of raising exemptions in each state will be proportional to the amount of debt held.

The welfare gains formula is somewhat sensitive to altering the assumptions about credit markets, but in many cases the direction of the resulting change can be signed. A more flexible model of interest rates and recovery rates would not dramatically alter the welfare gains formula, but it would change the particular empirical objects $r^{\prime}(m)$ and $q^{\prime}(m)$ needed for the formula. In this model, I assume that, in the interval over which borrowers behavior responds to exemptions, interest rates $r(m)$ are not a function of individual choices of effort and debt. This assumption is motivated by the available data, which consists of averages of interest rates and recovery rates. If interest rates depend on how individual actions $a$ respond to exemptions, then the appropriate interest rate response for equation (1.2) would be the change in interest rates holding these actions constant, i.e. $\frac{\partial r(a, m)}{\partial m}$. Similarly, if repayment in default is a function of individual actions, the term in the welfare gains formula would be $\frac{\partial q(a, m)}{\partial m}$. With regard to changes in the repayment rate, as long as higher exemptions change actions in a way that decreases payment conditional on default, the $q^{\prime}(m)$ that I estimate will overstate the benefits to consumers. ${ }^{16}$ Additionally, this model assumes that creditors respond to changes in exemptions only by altering interest rates. If creditors respond by increasing loan denials or altering other loan terms, the welfare gains formula will not capture these additional costs and, as a result, will understate the true costs of increasing exemptions.

In addition to these assumptions that are particular to the asset exemptions setting, there

\footnotetext{
${ }^{16}$ I estimate $\frac{d q(a, m)}{d m}$. If $\frac{\partial q(a, m)}{\partial a} \frac{\partial a}{\partial m}<0$, then $\frac{d q(a, m)}{d m}<\frac{\partial q(a, m)}{\partial m}$ and my estimates would overstate the benefits to borrowers in default.
} 
are the critical assumptions that underly the sufficient statistic approach to social insurance. In having the social planner maximizes the agent's indirect utility $V(m)$, I assume that the borrower's problem reflects the true costs and benefits to society. That is, there are no externalities in any of the choices affected by changes to exemption levels. This is violated if, for example, changes in exemptions affect the take-up of other social insurance programs or agents do not make financial decisions optimally.

In the remainder of the paper, I calculate the welfare gain by estimating the key components of equation (1.2). Section 1.4 estimates the gap in marginal utility between the default and repayment states using the approach of Gruber (1997). Section 1.5 estimates $r^{\prime}(m)$ and $q^{\prime}(m)$ using data on interest rates and debt collection from credit unions.

\subsection{Willingness to Pay for Default Insurance}

This section estimates borrowers' willingness to pay for a marginal increase in default in-

surance. As discussed in Section 1.3, the term $\frac{u^{\prime}\left(c_{l}\right)}{u^{\prime}\left(c_{h}\right)}-1$ captures the maximum markup over the actuarially fair rate that borrowers are willing to pay for default insurance. Baily (1978) and Chetty (2006) show that taking a Taylor expansion of $u^{\prime}$ around $c_{h}$ yields the approximation:

$$
\frac{u^{\prime}\left(c_{l}\right)}{u^{\prime}\left(c_{h}\right)}-1 \approx \gamma \frac{\Delta c}{c_{h}}(m),
$$

where $\gamma=-\frac{u^{\prime \prime}\left(c_{h}\right)}{u^{\prime}\left(c_{h}\right)} c_{h}$ is the coefficient of relative risk aversion evaluated at $c_{h} \cdot{ }^{17}$ The intuition for this approximation is that the value of additional insurance depends on the utility value of smoothing consumption $(\gamma)$ and the size of the consumption drop being insured $\left(\frac{\Delta c}{c_{h}}\right)$. Since this expression is derived by applying envelope theorem, the consumption drop needed to evaluate this expression is the drop in consumption that occurs among the pool of people

\footnotetext{
${ }^{17}$ This approximation assumes that the higher order terms (e.g. $\left.u^{\prime \prime \prime}\right)$ are negligible.
} 
currently choosing to default (i.e. holding their actions constant). In this section, I estimate the consumption drop upon default. I do not estimate risk aversion, but evaluate the welfare calculations in Section 1.6 over a range of values for the coefficient of relative risk aversion. The normative implications are not sensitive to variation within the conventional range of estimates $(\gamma \leq 5)$.

According to this willingness to pay formula, it is only necessary to estimate the average drop in consumption upon default. A causal estimate of the effect of exemptions on consumption is not needed. ${ }^{18}$ The intuition is that the value of additional default insurance depends on the consumption drop upon default, given the existing methods borrowers have of smoothing across this drop. For example, if borrowers already perfectly smooth shocks causing default with private insurance or borrowing, there is no value of providing additional insurance by raising exemptions. Thus, the drop in consumption upon default captures the extent to which borrowers are currently under-insured against shocks causing default, and this determines their willingness to pay.

\subsubsection{Data: Panel Study of Income Dynamics}

The Panel Study of Income Dynamics (PSID) from 1991-1996 is well-suited to study changes in consumption upon default, as it contains information about instances of financial distress and a measure of consumption. In 1996, the PSID asked families about financial distress that occurred between 1991 and 1996. Each family reports the year that they missed a bill payment, had a debt collector call, dealt with judicial collection actions (repossession, garnishment, lien), or filed for bankruptcy. In the main analysis, I count the occurrence of any of these events as default, though I later test for heterogeneity using different definitions of default and subsamples of defaulters. Since the goal of the analysis is to estimate the

\footnotetext{
${ }^{18}$ Kroft and Notowidigdo (forthcoming) highlight a similar point for the case of unemployment benefits.
} 
change in consumption upon default, the unit of observation is an instance of default. The main defaulter sample consists of all household heads that report defaulting in some year $t$ but did not default in year $t-1 .^{19}$

The measure of consumption available in the PSID is each family's annual food expenditure. While focusing on food consumption seems limiting, Chetty (2006) shows that as long as agents make optimal consumption choices, nothing is lost by estimating changes in a single good (food) as long as the risk aversion parameter reflects curvature in utility for that good. This is because, although food consumption will experience smaller changes than other goods, this relatively inelasticity is reflected in a higher coefficient of relative risk aversion, so that the product of the percentage change and risk aversion is similar across goods. Following Gruber (1997), I measure consumption as the sum of at-home food expenditure (including food stamps) and out-of-home food expenditure, deflated by the corresponding component of the CPI for the month of the interview. I exclude households with imputed food consumption and households that report a change in food consumption over $300 \%{ }^{20}$

I combine these data from the PSID with states' asset exemption levels collected from state statutes and various editions of Elias, Renauer, and Leonard (1996-2013), a popular consumer bankruptcy guidebook. For each individual, I sum the homestead and personal property exemptions available in the state during the year he defaulted. If the household head is married and lives in a state that allows married couples to double their exemptions, I double the exemption value. ${ }^{21}$ Ideally, I would estimate the drop in consumption upon default

\footnotetext{
${ }^{19}$ The PSID only asks about default in years 1991-1996. I drop households that report default in 1991, since I cannot know whether they were in default in 1990.

${ }^{20}$ Following Zeldes (1989) and Gruber (1997), I drop households where $\log \left(c_{t} / c_{t-1}\right)>1.1$ or $<-1.1(4 \%$ of the sample). Including these households does not affect the results.

${ }^{21}$ I thank Jeffrey Traczynski for generously sharing data on exemptions from Traczynski (2011), and in particular, the property exemptions used in this analysis. I collected data on homestead exemptions from editions of Elias, Renauer, and Leonard (1996-2013) and corrected the timing of the changes by referencing historical state statutes. For states that allow individuals to choose between the state homestead exemption and the federal homestead exemption, I use whichever is higher. I code states with unlimited homestead exemptions as $\$ 550,000$, the maximum exemption level among states without unlimited exemptions during the period 1991-2014. I ignore lot size restrictions. I assume the filer is not a senior citizen. For personal
} 
separately for each state. However, the relatively small sample and difficulties associated with measuring consumption (e.g. noise, recall error) generate noisy estimates. For this reason, I group individuals into exemption terciles based on the total amount of homestead and personal property exemptions available to them. ${ }^{22}$ I refer to these groups as individuals living in low-exemption, mid-exemption, and high-exemption states, although the exemption tercile is a function of both state and marital status.

Table 1.1 reports descriptive statistics for two groups: PSID respondents who never report an instance of financial distress (non-defaulters), and the analysis sample, which consists of the 1,123 instances of default (defaulters). The first row shows the average change in log food consumption. In the sample of non-defaulters, the average change in food consumption is basically zero. In the defaulter sample, however, food consumption drops by $3.6 \%$ (0.036 $\log$ points). One concern is that this drop may be due to shocks that change the food requirements of the family and are correlated with default, such as divorce or death of a spouse. The second row rules this out by showing that food needs, the PSID's measure of the household's food requirements based on household size and composition, does not change among defaulters. The remaining rows of Table 1.1 show that the sample of defaulters tends to be younger and are more likely to be female, non-white, unmarried and have more unsecured debt than non-defaulters.

\subsubsection{Empirical Strategy: Consumption Change upon Default}

The sample statistics in Table 1.1 show that borrowers experience an average drop in consumption of $3.6 \%$ upon default, which would be sufficient to determine the average willing-

property exemptions, I use the coding of Traczynski (2011).

${ }^{22}$ Low-exemption states have total exemptions less than $\$ 12,700$, mid-exemption states range from $\$ 12,700$ 45,200 , and high exemption states have total exemptions above $\$ 45,200$ (including the unlimited exemption states). To allow for robustness checks on the sample of non-defaulters, the tercile thresholds are determined using the full PSID sample, including both defaulters and non-defaulters. 
ness to pay for default insurance. The purpose of the additional analysis in this section is to investigate how the consumption drop varies with the exemption level and to investigate the sensitivity of the result to additional controls. The sample consists of 1,123 instances of default, indexed by $i$. I estimate regressions of the form:

$$
\Delta \log C_{i}=\alpha_{L} \text { exempt }_{i}^{L}+\alpha_{M} \text { exempt }_{i}^{M}+\alpha_{H} \text { exempt }_{i}^{H}+\delta X_{i}+\tau_{i}+\varepsilon_{i}
$$

$\Delta \log C$ is the change in the $\log$ of consumption and exempt ${ }^{L}, e^{e x e m p t} t^{M}$ and exempt ${ }^{H}$ are indicators for whether an individual is protected by low-, middle-, or high-exemption levels (there is no intercept). $X$ is a set of individual characteristics (discussed below) and $\varepsilon$ is the error term. The $X$ variables are de-meaned so that the $\alpha$ coefficients capture the average drop in consumption upon default for borrowers in low-, middle, or high-exemption states. I also include (de-meaned) year fixed effects $\left(\tau_{i}\right)$ in all regressions.

The $\alpha$ coefficients do not capture the causal effect of exemptions on consumption smoothing. Instead, they capture the combined effect of exemptions' consumption smoothing benefits and any other factors (e.g. social or private insurance) correlated with exemptions that affect changes in consumption upon default. It is this combined effect, not a causal effect, that is needed to calculate borrowers' willingness to pay, as it reflects the extent to which borrowers remain imperfectly insured, given existing methods of smoothing consumption in default.

It is possible that differences in the consumption drops across exemption levels are due to changes in the composition of defaulters. This is not a problem, since the goal is to capture the drop in consumption among the group of borrowers that choose to default. For example, if lenient exemptions cause borrowers to default after even minor consumption shocks, this compositional change decreases the value of providing default insurance. This will be reflected in a smaller average drop in consumption upon default in lenient exemption 
states. Still, while it is not needed to determine the willingness to pay, I investigate the role of observable compositional changes by including controls for individual characteristics in some regressions. The individual characteristics $X_{i}$ include the age, sex, years of education, an indicator for white, marital status, number of children, and the change in the log of the food needs of the family. In some specifications, I also add controls for the state unemployment rate and $\log$ of state median income at the time of default. All results report standard errors clustered by state.

\subsubsection{Results}

Table 1.2 reports the results from estimating specification (1.3) on the default sample. The key coefficients are $\alpha_{L}, \alpha_{M}$, and $\alpha_{H}$, which capture the average (log) consumption change upon default in low-, mid-, and high-exemption states. Column 1 includes only the exemption tercile indicators and year fixed effects. The estimate of $\alpha_{L}$ indicates that, in the lowexemption states, consumption drops by an average of $5.6 \%$. For comparison, the mean drop in consumption upon unemployment is 7-10\% (Gruber, 1997, Kroft and Notowidigdo, forthcoming). The $\alpha_{M}$ and $\alpha_{H}$ estimates indicate that the average drop in consumption is $2.8 \%$ in mid-exemption states and $1.9 \%$ in high-exemption states, though neither are statistically different from zero. That consumption drops upon default (at least in lowexemption states) demonstrates that borrowers are not fully insured against shocks causing default, so there is potentially a benefit to increasing insurance by raising exemptions. Scaling a $5.5 \%$ consumption drop by a coefficient of relative risk aversion $\gamma=3$ implies that borrowers would be willing to pay up to a $16.5 \%$ markup for this insurance

Again, the differences in the $\alpha$ estimates capture the combined effect of exemptions, compositional changes, and other factors correlated with exemptions. The remaining columns investigate the role of compositional changes and economic conditions in explaining these es- 
timates. Column 2 adds controls for individual characteristics and column 3 adds controls for state-level economic conditions during the year that the default occurred. If the results were driven by differences in the observable characteristics of borrowers or economic conditions, the estimates of the average consumption drop across exemption terciles would converge after controlling for these variables. Instead, columns 2 and 3 show little change. The estimates in column 3 indicate that the average consumption drop is $5.5 \%$ in low-exemption states, $3.2 \%$ in mid-exemption states, and $1.9 \%$ in high-exemption states, though the drop is only statistically significant in low-exemption states.

\subsubsection{Robustness, Anticipation, and Heterogeneity}

In this section, I run a series of robustness checks designed to address three potential concerns. The first concern is that there may be omitted variables correlated with exemptions that affect the consumption of all borrowers, not only borrowers in default. The regression in equation (1.3) already controls for omitted variables that are constant within a household, since the outcome variable is the change in consumption, but there may be state consumption trends or unobserved shocks correlated with the exemption tercile that could bias estimates of changes in consumption. For example, consumption could be trending downward in lowexemption states, and this trend would make it appear as if defaulters were experiencing large drops in consumption. To test this, columns 1-3 of Table 1.3 report results from regressions on the sample of non-defaulters. If there were general consumption trends or shocks, they would also be apparent in the sample of non-defaulters. Instead, columns 1-3 show that consumption changes among the group of non-defaulters are small and insignificant. Figure 1.2 presents the estimates of the consumption change for defaulters and non-defaulters living

in the three exemption terciles. Columns 4-6 pool the samples of non-defaulters and defaulters and compares the consumption changes among defaulters to the consumption changes 
among non-defaulters in the same state and year. The specification interacts an indicator for default with the low-, mid-, and high-exemption terciles to capture the drop in consumption among defaulters relative to non-defaulters, and also includes state $\times$ year fixed effects. ${ }^{23}$ These results show that the declines in consumption occur only among individuals reporting default.

A second concern is that there is uncertainty about the timing of the changes in consumption and default. One source of uncertainty is the ambiguity about the reference year of the food expenditure questions in the PSID (East and Kuka, 2015). In most years, the PSID asks about food consumption in the average week, and the question is asked immediately after a question about food stamp use in the prior month. For this reason, I follow prior research in assuming that individuals report their consumption during the year of the interview (Zeldes, 1989, Gruber, 1997, East and Kuka, 2015). A second source of uncertainty is that the data on default was asked in 1996 and only contains the calendar year that default occurred, which will not correspond exactly to the timing of the PSID interviews in those years. A third source of uncertainty is due to the potential for borrowers to anticipate default and reduce consumption in advance. For example, Hendren (2015) shows that households reduce consumption in the year prior to a job loss. I show that these issues are not a concern by testing for consumption changes in the years around default. Table 1.4 reports estimates of the drop in consumption in the years before and after the reported instance of default. Columns 1-3 show that, for borrowers defaulting in year $t$, there is no change in consumption between years $(t-2$ to $t-1)$ or $(t$ to $t+1)$. Due to missing data and sample attrition, the sample of defaulters included in columns 1-3 changes slightly. To ensure that this is not driving the results, columns 4-6 limit the sample to the 931 defaulters who have full data for the surrounding years and the results are unchanged.

\footnotetext{
${ }^{23}$ Columns 4-6 estimate $\Delta \log C_{i}=\alpha_{L}$ exempt $_{i}^{L} \times$ Default $_{i}+\alpha_{M}$ exempt $_{i}^{M} \times$ Default $_{i}+\alpha_{H}$ exempt $_{i}^{H} \times$ Default $_{i}+\delta X_{i}+\tau_{s(i), t(i)}+\varepsilon_{i}$, where $\tau_{s(i), t(i)}$ represents the set of state $\times$ year fixed effects. There are multiple years for each household, so $i$ indexes household-year observations.
} 
A third concern is that the impact of exemptions may differ across defaulters. If the defaulters more affected by exemptions have a different willingness to pay, it could change the value of exemption-provided default insurance. To investigate this concern, Figure 1.3 reports the average consumption drop for various subsets of defaulters. First, since the benefit of exemptions is proportional to the amount of debt held, a positive covariance of debt and consumption drops could increase the value of insurance. The (unsecured) debtweighted average consumption drop, however, is similar to the average consumption drop, so heterogeneity in the amount of debt will not affect the value of raising exemptions. ${ }^{24}$ Second, it may be that only those with severe delinquencies or those with non-exempt assets benefit from exemption protection. ${ }^{25}$ The figure shows that the groups likely to be more affected by exemptions - severe defaulters (those reporting debt collector calls, judicial actions, or bankruptcy), homeowners, and homeowners with non-exempt home equity - experience little to no consumption drop upon default. Overall, Figure 1.3 shows that if the impact of exemptions is concentrated among the subsets of defaulters more likely to benefit, this will reduce the value of exemption-generated default insurance.

\subsection{The Cost of Exemption-Generated Default Insur- ance}

This section estimates the cost of the default insurance generated by raising asset exemptions. Equation (1.2) shows how this cost, $\frac{e}{1-e} \frac{r^{\prime}(m)}{q^{\prime}(m)}-1$, enters the welfare gains formula. In this section, I use difference-in-differences regressions to estimate the causal effect of exemptions

\footnotetext{
${ }^{24}$ The PSID asks households to report debt from "credit card charges, student loans, medical or legal bills, or on loans from relatives." This measure should be treated with caution, however, as households are known to significantly underreport unsecured debt (Brown et al., 2011).

${ }^{25}$ This is not necessarily the case, since the exemption level could affect the equilibrium number and tactics of debt collectors in the state, and therefore also benefit defaulters without non-exempt assets.
} 
on interest rates $\left(r^{\prime}(m)\right)$ and recovery rates on defaulted debt $\left(q^{\prime}(m)\right)$.

\subsubsection{Data: Credit Union Call Reports}

I use state-level data on average interest rates and defaulted debt recovery rates aggregated from Credit Union Call Reports. Each quarter, all credit unions in the United States must submit a Call Report with financial information such as balance sheets and income statements. These Call Reports are publicly available from the website of the National Credit Union Administration. Credit Union Call Reports were first used to study interest rates and recovery rates in Fedaseyeu (2015), which examined how regulations on debt collectors, such as licensing requirements or criminal penalties, affect credit markets.

One advantage of using credit union data, as argued in Fedaseyeu (2015), is that credit unions are typically local lenders, so their lending practices will reflect state laws. ${ }^{26} \mathrm{~A}$ drawback, however, is that the lending practices of credit unions differ from those of larger banks. Credit union interest rates are slightly lower, with commercial bank credit card interest rates averaging 14.7\% between 1994 and 2004, while credit union interest rates average $12.3 \%$. The recovery rates for all commercial banks and credit unions are similar, with average recovery rates of $19.3 \%$ and $17.2 \%$, respectively. ${ }^{27}$ The recovery rates also exhibit similar patterns over time, as shown in Figure 1.1. Between 1991 and 2004, credit unions issued $7-10 \%$ as much revolving credit as commercial banks. ${ }^{28}$

I use credit union data for the years 1994-2004. I limit the sample to this period for two reasons. First, two shocks, a major bankruptcy reform and a severe recession, may cause the

\footnotetext{
${ }^{26}$ I drop the two major national credit unions, Navy Federal Credit Union and the Pentagon Federal Credit Union, from the sample.

${ }^{27}$ Source: Author's calculations from aggregating commercial and Credit Union Call Reports and taking the mean annual recovery rate between 1994 and 2004. These numbers differ slightly from those reported in Table 1.5, which averages of the state-level recovery rates.

${ }^{28}$ Source: Board of Governors of the Federal Reserve System, G.19 series - Consumer Credit. Revolving credit is mostly credit card loans but other types, such as prearranged overdraft plans, are also included.
} 
impact of exemptions in the late 2000s to differ from the typical impact of exemptions. The transition to the new bankruptcy system introduced a large, temporary spike in bankruptcies during late 2005. The housing collapse erased a substantial amount of home equity, which would alter the effect of the largest exemption, the homestead exemption. ${ }^{29}$ The second concern with the later period is that spatial heterogeneity in credit markets and defaults caused by the bankruptcy reform and recession make estimates from this period noisy and potentially biased. ${ }^{30}$ While understanding the impact of the reform and recession on credit markets is important, it is not the focus of this analysis.

I use 4th-quarter Call Reports to construct annual recovery rates on charged-off non-real estate loans. A charge-off occurs when a creditor marks a debt as unlikely to be collected, typically after 120-180 days of delinquency for consumer debts. ${ }^{31}$ Recoveries reflect the amount collected after a debt has been charged-off, and can consist of post-charge-off payments by debtors or revenues from selling the charged-off debt (Furletti, 2003). Therefore, recoveries capture the amount that creditors ultimately collect on debt that is severely delinquent, including collections in and out of bankruptcy. Credit unions report total charge-offs and recoveries and real-estate charge-offs and recoveries separately. Taking the difference, I construct non-real estate charge-offs and recoveries for each credit union. ${ }^{32}$ I then aggregate non-real estate charge-offs and recoveries to the state-level and measure the recovery rate in

\footnotetext{
${ }^{29}$ In 2010, 55-65\% of homeowners were completely protected by exemptions (Dobbie and Song, 2015).

${ }^{30}$ For example, in Pattison (2016), I provide evidence that trends in bankruptcy filings after 2005 were correlated with changes in exemption levels, which would bias difference-in-differences estimates from the post-2005 period.

${ }^{31}$ Bank (FFIEC) regulatory accounting requirements state that revolving credit must be charged-off after 180 days of delinquency and installment loans after 120 days - Uniform Retail Credit Classification and Account Management Policy, 65 Fed. Reg. 36903 (June 12, 2000). When loans are charged-off, issuers reverse the fees and finance charges on the loan in a process called "purification" (Furletti, 2003). Therefore, the charged-off amounts will reflect the unpaid principal (see NCUA 5300 CALL REPORT INSTRUCTIONS - June 2005).

${ }^{32}$ These charge-offs are primarily unsecured consumer loans (e.g. credit cards) and vehicle loans. In Appendix 1.A.2, I estimate a lower bound on the markup of exemptions that takes into account the potential influence and impact on auto loans and show that adjusting for the impact of auto loans does not alter the policy implications.
} 
state $j$ as aggregate recoveries divided by aggregate charge-offs.

Credit Union Call Reports also include data on credit card interest rates. Each credit union reports the most common interest rate offered for credit cards and the total number of credit card loans. I aggregate these interest rates to the state level, weighting each credit union's interest rate by the number of outstanding credit card loans. The summary statistics of the main variables are presented in Table 1.5. The primary outcomes in the analysis are shown in the first two rows. The mean interest rate on credit card debt is $12.3 \%$ and the average recovery rate on charged-off non-real estate debt is $17.73 \%$. I combine the interest rates and recovery rates with data on exemption levels.

The credit union interest rates and recovery rates are the empirical counterparts to $r(m)$ and $q(m)$ in the model of Section 1.3. The data, however, differ slightly from the ideal empirical objects in two ways. First, the ideal empirical object would be the interest rate and recovery rate for a specific borrower, holding all characteristics observable to the lender constant. The actual data, however, is the most commonly charged interest rate and the average recovery rate for borrowers. Second, the ideal data would contain the full schedule of interest rates charged to borrowers with different characteristics, since the effect of exemptions could differ across credit market segments. With only the most common interest rate and the average recovery rate available, heterogeneity across borrowers is not captured.

I sum the homestead and property exemptions available to an unmarried bankruptcy filer under the age of 65 for each state and year, following the procedure discussed in Section 1.4. Although some states allow doubling of exemptions for a married debtor, my specification uses the log of the exemption level and so the coefficient would not be affected by doubling. Between 1994 and 2004, there were 65 changes among 31 states, and the average (credit union membership-weighted) change is $\$ 8,985$ or 0.14 log points. Table 1.4 shows the distribution and timing of changes in the exemption level. 


\subsubsection{Empirical Strategy: The Effect of Exemptions on $r(m)$ and $q(m)$}

I use the state-level data to estimate the effect of exemptions on interest rates and recovery rates. For state $s$ at time $t$, the regressions are of the following form:

$$
y_{s t}=\alpha+\eta \ln \left(E_{s t}\right)+X_{s t} \beta+\delta_{s}+\tau_{t}+u_{s t} .
$$

where $\ln \left(E_{s t}\right)$ is the $\log$ of the exemption level. I use the log of a state's exemption level because it allows the effect of exemptions to diminish as the exemption level rises. A diminishing effect is likely, since as exemptions rise, more debtors will be fully protected. For example, an increase in Virginia's $\$ 5,000$ homestead exemption would affect everyone with more than $\$ 5,000$ in home equity, while an increase in Minnesota's $\$ 390,000$ homestead exemption would affect only those with more than $\$ 390,000$ in equity.

The outcome variable $y_{s t}$ is either the interest rate or the recovery rate in state $s$ during year $t$. The coefficient $\eta$ captures the effect of a one log point increase in a state's exemption level. The state controls, $X_{s t}$, contain the 25 th percentile of the log income distribution, the $\log$ of median income, the log of the home price index from the Federal Housing Finance Agency, and the state unemployment rate. I also include state fixed effects $\left(\delta_{s}\right)$ and year fixed effects $\left(\tau_{t}\right)$ in all specifications. The error term, $u_{s t}$, represents the unobserved state-year shocks that affect interest or recovery rates.

Unlike the previous section, I argue that estimates from these difference-in-differences regressions reflect the causal effect of exemptions. The identifying assumption is the parallel trends assumption: in the absence of an exemption increase, interest rates and recovery rates in states that increase exemptions and control states would have been parallel. I support this assumption in two ways. First, I argue that the changes in exemptions arise 
out of a political process that does not depend on states' lending conditions. Several states and the federal bankruptcy exemptions are adjusted at predetermined intervals, and many states intermittently to adjust for inflation. Other important debtor protection laws, namely wage garnishment restrictions and statutes of limitations on debt, do not change over this period. Additionally, Severino, Brown, and Coates (2015) examines a number of potential predictors of exemption changes, including house prices, state GDP, medical expenditures, the unemployment rate, the political climate, bankruptcy filings, and income growth. Only medical expenditure is found to be statistically significant.

Second, using an event study specification, I support the parallel trends assumption by testing whether trends in treatment and control states were parallel prior to an exemption increase. Since states have multiple exemption increases, a standard event study specification is not appropriate. Instead, I use a multiple event study framework, similar to those in Dube, Lester, and Reich (2010) and Sandler and Sandler (2014), that allows for overlapping events within a state. I estimate the following regression for state $s$ in year $t:^{33}$

$$
y_{s t}=\alpha+\sum_{k=-6}^{5}\left(\eta_{k} \Delta \ln \left(E_{s, t-k}\right)\right)+\eta_{6} \ln \left(E_{s, t-6}\right)+X_{s t} \beta+\delta_{s}+\tau_{t}+u_{s t} .
$$

The one-period difference operator, $\Delta$, produces coefficients $\eta_{k}$ that represent the cumulative effect of a one log-point increase in the exemption level $k$ years later. For example, if the exemption increased by $0.5 \mathrm{log}$ points in a state during $2000, \eta_{3}$ captures the effect of that increase on state bankruptcies in $2003\left(\Delta \ln \left(E_{s, t-3}\right)=0.5\right.$ when $\left.t=2003\right)$, while $\eta_{-3}$ captures the difference in bankruptcies in that state in 1997. The estimates provide evidence about the identification assumption by testing whether the trends were parallel prior to an exemption increase. If interest rates $y_{s t}$ in the treatment and control states are similar prior

\footnotetext{
${ }^{33}$ To produce a balanced panel in this regression, I use exemption data from 1989-2010 even though $y_{s t}$ is only used from 1995-2004.
} 
to an exemption increase, then the coefficients $\eta_{-6}, \ldots, \eta_{-1}$ will be zero. The coefficients $\eta_{0}$ through $\eta_{5}$ capture the cumulative effect of an exemption increase in the first six years after the increase. Since $\eta_{6}$ does not use the difference operator, it captures the average effect of the exemption increase in and after year $t+6$.

\subsubsection{Results}

Table 1.6 reports the main results. Columns 1-3 show the effect of changes in exemptions on the interest rate. The estimate in column 1 indicates that a $10 \%$ increase in the exemption level raises credit card interest rates by 0.038 percentage points, or 3.8 basis points, and is statistically significant at the 1\%-level. Columns 2 and 3 add state-level economic controls and region-year fixed effects for the four Census regions. The estimated effect remains largely unchanged. The magnitude of the preferred specification in column 2 indicates that a $10 \%$ increase in the exemption level raises interest rates by 4 basis points. This interest rate effect is in the lower end of the range of estimates found in papers using cross-sectional variation in exemptions (for example, Gropp, Scholz, and White (1997)). ${ }^{34}$ Columns 4-6 repeat the regressions, but with the recovery rate as the outcome. The results across all specifications are similar and the magnitude in column 5 indicates that a $10 \%$ increase in the exemption level reduces the recovery rate on charged-off debt by 42 basis points, significant at the $1 \%$-level.

Using the estimates from columns 2 and 4 in Table 1.6, a $10 \%$ increase in the exemption level increases interest rates by 4 basis points and reduces the recovery rate on charged-off

\footnotetext{
${ }^{34}$ Direct comparison of the estimates is difficult because of the variety of specifications used across papers. The method I use is to compare each paper's predicted increase in interest rates caused by increasing the exemption level from $\$ 5,000$ to $\$ 50,000$, which is effect reported in Gropp, Scholz, and White (1997). Using this method, my estimates predict an increase of 92 basis points, while others find estimates in the range of 23-230 basis points for auto loans and small business loans (Gropp, Scholz, and White, 1997, Berkowitz and White, 2004, Berger, Cerqueiro, and Penas, 2011). The other paper using panel variation, Severino, Brown, and Coates (2015), finds an effect that is similar in magnitude to my estimate.
} 
debt by 42 basis points. Setting the probability of default equal to the mean credit card charge-off rate from Table $1.5(1-e=2.2 \%)$, and substituting the estimates for $r^{\prime}(m)$ and $q^{\prime}(m)$ gives

$$
-\frac{e}{1-e} \frac{r^{\prime}(m)}{q^{\prime}(m)}-1=3.23 .
$$

That is, in order to repay $\$ 1$ less in default, expected interest payments increase by $\$ 4.23$, so the markup markup of the default insurance generated by asset exemptions is $323 \%$.

Figure 1.5 plots the $\eta_{t}$ estimates and $95 \%$ confidence intervals from the event study specification in equation (2.3). For both interest rates and recovery rates, the coefficients $\eta_{t-6}, \ldots, \eta_{t-1}$ are small and insignificant, consistent with the parallel trends assumption. In the period $t$, when exemptions increase, interest rates begin to rise. At the same time, the recovery rate on charged-off loans falls sharply in period $t$, and remains low over the next six years.

\subsubsection{Explaining the Markup: The Role of Default}

The interest rate markup exceeds the actuarially fair rate by $323 \%$. Such a large markup raises the concern that changes in exemptions affect lenders' profits. This would be problematic, since a critical assumption in the derivation of the welfare gain formula is that lenders' profits are unaffected by exemptions, which eliminates any welfare impact on the lenders. An alternative explanation for the markup is that moral hazard and adverse selection change the probability of default, which would generate markup without affecting lender profits. This subsection shows that the observed markup can be fully explained by changes in the probability of default and, therefore, is consistent with the assumption that lenders' profits are not affected by exemption increases.

I show that the magnitude of the markup is consistent with a model of competitively priced loans. If lenders are competitive and risk-neutral, then the returns from lending 
satisfy the zero-profit condition

$$
(1-e(m)) q(m)+e(m)(1+r(m))=1+\tilde{r}
$$

where $e$ is the probability of repayment, $q$ is the recovery rate in default, $r$ is the interest rate, and $\tilde{r}$ is the market rate of return. Differentiating this expression with respect to $m$,

$$
e^{\prime}(m)(1+r(m)-q(m))+(1-e(m)) q^{\prime}(m)+e(m) r^{\prime}(m)=0 .
$$

If rates are competitive, the increase in interest rates will exactly offset lenders' losses due to the increase in the probability of default $\left(e^{\prime}(m)(1+r(m)-q(m))\right)$ and the loss in recovery in default $\left((1-e(m)) q^{\prime}(m)\right)$.

To test whether the observed interest rate change is consistent with this model of lending, columns 1-3 of Table 1.7 reports difference-in-differences estimates from equation 1.4 with the credit card default (charge-off) rate as the outcome. The estimates are positive and significant, indicating that higher exemptions increase the probability of default. The point estimates in column 2 implies that a $10 \%$ increase in asset exemptions raises the credit card charge-off rate by 0.035 percentage points, a $1.6 \%$ increase. Using estimates of $q^{\prime}(m)=$ $-0.042, e^{\prime}(m)=-0.0035$ and the sample means for $e, r$, and $q$, equation (1.7) implies that that the profit-neutral interest rate increase justified by the change in default and recovery rates is 4.3 basis points. This is similar in magnitude to the actual observed increase of 4 basis points. Thus, the observed changes in default and recovery rates are large enough to explain the increase in interest rates.

Columns 4-6 test whether the resulting change in lender profits is statistically different from zero. I construct the empirical analog to equation (1.6) for each state $s$ and year $t$ as $\left(1-e_{s t}\right) q_{s t}+e_{s t}\left(1+r_{s t}\right)$. I multiply this measure by $\$ 1,000$, so that it gives the expected 
return from a $\$ 1,000$ loan. The average return in the sample is $\$ 1,098$. The estimates in columns 4-6 indicate that exemptions have little effect on this measure of lender returns, consistent with the model of competitive lending. The estimate in column 6 implies that a $10 \%$ increase in exemptions reduces lender profits on a $\$ 1,000$ by a statistically insignificant $\$ 0.08$. Together, the results in Table 1.7 show that the increase in the probability of default can fully account for the observed markup in interest rates and, therefore, is consistent with the assumption that changes in exemptions do not affect lender profits.

\subsection{Calculating the Welfare Impact}

In this section, I use the estimates from the two empirical sections to compute the marginal welfare gain from equation (1.2), which I repeat here:

$$
\frac{d W(m)}{d m}=\left\{\left(\frac{u^{\prime}\left(c_{l}\right)}{u^{\prime}\left(c_{h}\right)}-1\right)-\left(-\frac{e}{1-e} \frac{r^{\prime}(m)}{q^{\prime}(m)}-1\right)\right\} T
$$

where $T=-(1-e) q^{\prime}(m) d>0$. I first calculate the welfare gain using the point estimates from Sections 1.4 and 1.5, then investigate the sensitivity of the result to variation within the $95 \%$ confidence interval of these estimates.

\subsubsection{Computing the Welfare Gain}

Since I estimate the effect of changes in the log of the exemption level, the policy parameter

is $m=\log ($ exemption $)$. I use the approximation $\frac{u^{\prime}\left(c_{l}\right)}{u^{\prime}\left(c_{h}\right)}-1 \approx \gamma \frac{\Delta c}{c_{h}}(m)$. To calculate the 
welfare formula, I assume that

$$
\begin{aligned}
\frac{\Delta c}{c_{h}}\left(m_{j}\right) & =-\alpha_{j} \quad \text { for } j=L, M, H \\
r^{\prime}(m) & =\beta \\
q^{\prime}(m) & =\gamma .
\end{aligned}
$$

I use the estimates $\hat{\alpha}_{L}=-0.055, \hat{\alpha}_{M}=-0.032, \hat{\alpha}_{H}=-0.016, \hat{\beta}=0.004$ and $\hat{\gamma}=0.042$. I set the share of borrowers in repayment to one minus the mean credit card charge-off rate so that $\hat{e}=0.978$, and set the level of unsecured debt $d=3,391$, the mean level of unsecured debt held in the PSID sample of defaulters. Since the level of debt enters only through $T$, choosing a higher level of debt will linearly increase the magnitude of the welfare gain. There is uncertainty about the appropriate value for the coefficient of relative risk aversion, $\gamma$, so I report the welfare gains for $\gamma=1, \ldots, 5$.

The results from this welfare calculation are reported in Table 1.8. In low-exemption states, a $10 \%$ increase in the exemption level reduces welfare by $\$ 0.94-1.00$, depending on the coefficient of relative risk aversion. ${ }^{35}$ If consumers are more risk-averse, smoothing consumption becomes more valuable, but the high costs of transferring resources using exemptions still dominates. Among mid- and high-exemption states, the smaller drop in consumption upon default decreases the benefits of insurance. In these states, a 10\% increase in consumption reduces welfare by $\$ 0.97-1.02$. These results indicate that states would increase welfare by reducing exemption levels. ${ }^{36}$

\footnotetext{
${ }^{35}$ Since welfare is normalized by $u^{\prime}\left(c_{h}\right)$, this is $\$ 0.94-1.00$ evaluated at the marginal utility of those in repayment.

${ }^{36}$ The policy implication differs from the calibration of Dávila (2016), who finds that the optimal exemption level is around $\$ 100,000$ and, consequently, that most states would benefit from increasing exemptions. In Appendix 1.A.3, I discuss the source of the differences between our results.
} 


\subsubsection{Sensitivity of the Welfare Gain}

The policy implication of the welfare gain calculation is that states would benefit from reducing exemptions. I now investigate the sensitivity of this result to variation in the parameters of the welfare gain formula. Whether higher exemptions raise or lower welfare is determined by the sign of

$$
\left[\left(\frac{u^{\prime}\left(c_{l}\right)}{u^{\prime}\left(c_{h}\right)}-1\right)-\left(-\frac{e}{1-e} \frac{r^{\prime}(m)}{q^{\prime}(m)}-1\right)\right],
$$

which gives the welfare impact of an additional dollar of default insurance that generated by exemptions. Using the estimates of this paper, this expression equals -3.07 , which implies that one additional dollar of exemption insurance is equivalent to a $\$ 3.07$ welfare loss.

Table 1.9 shows that the policy implication is not sensitive to reasonable variation in the estimates of the components. The table reports the assigned values based on the estimates, the $95 \%$ confidence intervals of those estimates, and the set of values that would reverse the policy implication. Specifically, the values that would reverse the policy implication and generate a welfare gain are those that cause the expression in (1.8) to become positive, holding the other parameters fixed at their assigned value. The coefficient of relative risk aversion would have to be above 58 for additional exemption insurance to generate a welfare gain. For the four estimated parameters, the range of values that would generate a welfare gain from increasing exemptions all lie outside of the $95 \%$ confidence intervals. Thus, each parameter can be individually varied within its $95 \%$ confidence interval without altering the sign of the welfare impact of exemptions. 


\subsection{Conclusion}

In this paper, I estimate the welfare impact of changing the default insurance provided by asset exemptions. The welfare impact depends on 1) the drop in consumption upon default and 2) the costs of transferring money to those in default using exemptions. I estimate these values in a two-part empirical analysis. In the first part, I show that the drop in consumption upon default among borrowers with little exemption protection is $5.5 \%$. Scaled by a coefficient of relative risk aversion of 3, this estimate implies that borrowers are willing to pay a markup of up to $16.5 \%$ over the actuarially fair rate in order to increase consumption in default. In the second part, I use panel variation in state asset exemption laws to estimate the effect of exemptions on interest rates (the "insurance premium") and recovery rates on defaulted debt (the "insurance payout"). These estimates imply that the additional insurance provided by raising exemptions is marked up 320\%. This high markup makes exemptions an expensive method of providing default insurance, and implies that welfare would be improved if states reduced exemption levels.

This analysis investigates the main tradeoff in raising exemptions, but there are a few potential externalities that are not accounted for in this analysis. First, my model allows exemptions to affect lending only through the interest rate and the recovery rate on defaulted debt. Exemptions may also affect the set of loan contracts offered or loan denial rates, and this could make increasing asset exemptions even more costly. Second, my analysis assumes that consumers make financial decisions optimally. There is a growing literature that argues behavioral biases are important in understanding household financial decisions (see Zinman (2014a) and Zinman (2014b) for an overview). If consumers do not make decisions optimally, the analysis in this paper could either overstate or understate the welfare gains of exemptions, depending on the specific behavioral biases of borrowers.

Third, this analysis considers the welfare effect of exemption policy in isolation. In re- 
ality, debtor protections exist alongside many other forms of social and private insurance programs. There is evidence that some of these programs interact, as consumers view health insurance, unemployment insurance, and default or bankruptcy as substitutes (Gross and Notowidigdo, 2011, Hsu, Matsa, and Melzer, 2016, Mahoney, 2015). Changes in exemption policy may reduce or exacerbate externalities in other social insurance programs, and this paper ignores these effects. The interaction of debtor protections and social insurance programs is important, since debtor protections also affects consumers' ability to self-insure through credit markets. Additional responses of lenders, behavioral biases in borrowing, and externalities on other forms of insurance are three important avenues for future research on the welfare impact of debtor protection laws. 
Table 1.1: Consumption Sample (PSID)

\begin{tabular}{lcc}
\hline & Non-Defaulters & Defaulters \\
\hline$\Delta$ log consumption & .00061 & -.036 \\
$\Delta$ log food needs & -.0023 & -.0042 \\
Food consumption $(1990 \$)$ & 4,800 & 4,321 \\
Age & 46 & 38 \\
Female & .24 & .38 \\
Years of education & 13 & 12 \\
White & .7 & .48 \\
Number of children & .86 & 1.3 \\
Married & .62 & .43 \\
Unsecured debt $(1990 \$)$ & 2,407 & 3,391 \\
Mortgage debt $(1990 \$)$ & 24,590 & 13,645 \\
Observations & 20,252 & 1,120 \\
\hline
\end{tabular}

This table shows descriptive statistics for the 1992-1996 PSID data set. It displays means for a sample of individuals who never reported defaulting (non-defaulters), and the analysis sample, which consists of the observations of defaulters during the period of default. 
Table 1.2: The Consumption Drop Upon Default

\begin{tabular}{|c|c|c|c|}
\hline & \multicolumn{3}{|c|}{ Default sample } \\
\hline & $\begin{array}{c}\text { Baseline } \\
(1)\end{array}$ & $\begin{array}{c}\text { Controls } \\
(2) \\
\end{array}$ & $\begin{array}{c}\text { State Controls } \\
(3) \\
\end{array}$ \\
\hline Low-exemption states $\left(\alpha_{L}\right)$ & $\begin{array}{c}-0.056^{* * *} \\
(0.016)\end{array}$ & $\begin{array}{c}-0.055^{* * * *} \\
(0.016)\end{array}$ & $\begin{array}{c}-0.055^{* * *} \\
(0.017)\end{array}$ \\
\hline Mid-exemption states $\left(\alpha_{M}\right)$ & $\begin{array}{l}-0.028 \\
(0.023)\end{array}$ & $\begin{array}{l}-0.032 \\
(0.022)\end{array}$ & $\begin{array}{l}-0.032 \\
(0.024)\end{array}$ \\
\hline High-exemption states $\left(\alpha_{H}\right)$ & $\begin{array}{l}-0.019 \\
(0.020)\end{array}$ & $\begin{array}{l}-0.017 \\
(0.020)\end{array}$ & $\begin{array}{l}-0.016 \\
(0.020)\end{array}$ \\
\hline Log(median income) & & & $\begin{array}{c}0.018 \\
(0.083)\end{array}$ \\
\hline Unemp. rate & & & $\begin{array}{c}0.000 \\
(0.012)\end{array}$ \\
\hline Observations & 1,123 & 1,123 & 1,123 \\
\hline Year FE & $\mathrm{X}$ & $\mathrm{X}$ & $\mathrm{X}$ \\
\hline Demographic controls & & $\mathrm{X}$ & $\mathrm{X}$ \\
\hline
\end{tabular}

This table reports regression results from the regression in equation (1.3) estimated on the sample of default instances. Demographic controls consist of age, sex, years of education, an indicator for white, marital status, number of children, and the change in the log of the food needs of the family, which is a function of family size and age computed by the PSID. Standard errors are clustered by state. 


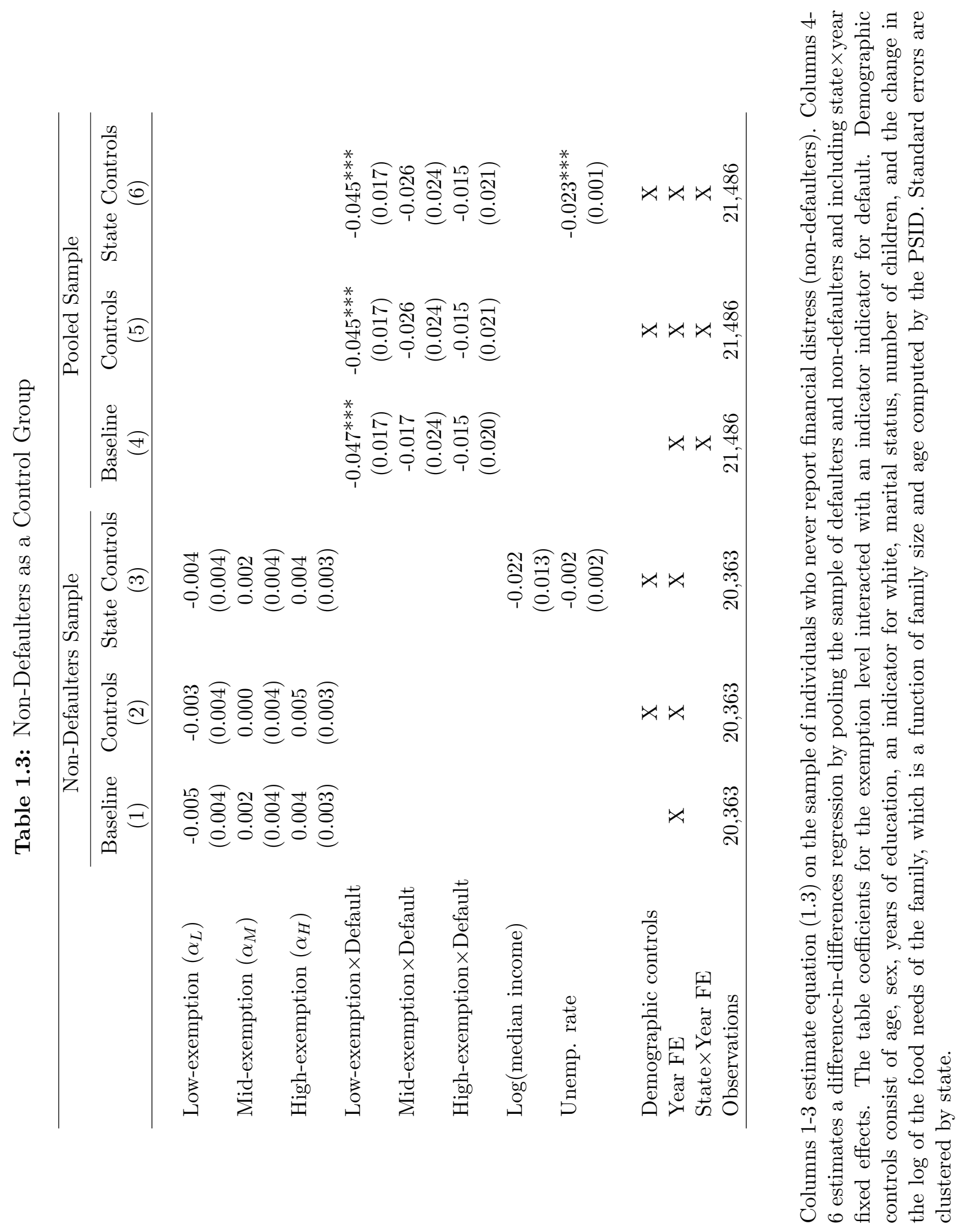


Table 1.4: Leads and Lags of the Consumption Change

\begin{tabular}{|c|c|c|c|c|c|c|}
\hline \multirow[b]{2}{*}{ Period relative to default } & \multicolumn{3}{|c|}{ Full sample of defaulters } & \multicolumn{3}{|c|}{ Defaulters with a lead and lag } \\
\hline & $\begin{array}{c}\mathrm{t}-2 \text { to } \mathrm{t}-1 \\
(1)\end{array}$ & $\begin{array}{c}\mathrm{t}-1 \text { to } \mathrm{t} \\
(2)\end{array}$ & $\begin{array}{c}\mathrm{t} \text { to } \mathrm{t}+1 \\
(3)\end{array}$ & $\begin{array}{c}\mathrm{t}-2 \text { to } \mathrm{t}-1 \\
(4)\end{array}$ & $\begin{array}{c}\mathrm{t}-1 \text { to } \mathrm{t} \\
(5)\end{array}$ & $\begin{array}{c}\mathrm{t} \text { to } \mathrm{t}+1 \\
(6)\end{array}$ \\
\hline Change in consumption & $\begin{array}{l}-0.008 \\
(0.010)\end{array}$ & $\begin{array}{c}-0.036^{* * *} \\
(0.011)\end{array}$ & $\begin{array}{l}-0.004 \\
(0.013)\end{array}$ & $\begin{array}{l}-0.003 \\
(0.010)\end{array}$ & $\begin{array}{c}-0.032^{* *} \\
(0.014)\end{array}$ & $\begin{array}{l}-0.006 \\
(0.012)\end{array}$ \\
\hline Observations & 975 & 1,123 & 1,071 & 931 & 931 & 931 \\
\hline
\end{tabular}

This table reports regression results from estimating equation (1.3) on leads and lags of the log change in consumption. Columns 1-3 estimate the equation on the full sample of defaulters. Columns 4-6 estimate the equation on the subsample of defaulters for which a lead and lag of the consumption change is available. All specifications include year fixed effects and demographic controls for age, sex, years of education, an indicator for white, marital status, number of children, and the change in the log of the food needs of the family. Additionally, state-year level controls for the log of median income and the unemployment rate are included. Standard errors are clustered by state. 
Table 1.5: Cost Sample (Credit Union Call Reports)

\begin{tabular}{lccccc}
\hline \hline \multicolumn{1}{c}{ Variable } & Mean & Std. Dev. & Min. & Max. & N \\
\hline Interest rate & 12.30 & 0.93 & 9.56 & 14.49 & 550 \\
Recovery rate, non-real estate debt & 17.73 & 6.44 & 6.21 & 48.56 & 550 \\
Charge-off rate, credit cards & 2.16 & 0.516 & 0.88 & 5.82 & 350 \\
Charge-off rate, non-real estate debt & 0.91 & 0.24 & 0.25 & 1.91 & 550 \\
Exemption level (1990\$) & 29,424 & 41,029 & 3,458 & 347,069 & 473 \\
\hline
\end{tabular}

This table shows descriptive statistics of data from 1994-2004 Credit Union Call Reports, aggregated to the state-year level. Observations are weighted by the credit union membership in that stateyear. The sample size is smaller for credit card charge-offs because that data is only available after 1997. The exemption statistics exclude the 7 states with unlimited exemptions. 
Table 1.6: Credit Union Interest Rates and Recovery Rates

\begin{tabular}{|c|c|c|c|c|c|c|}
\hline & \multicolumn{3}{|c|}{ Credit card interest rates } & \multicolumn{3}{|c|}{ Recovery rates on non-real estate debt } \\
\hline & $(1)$ & $(2)$ & $(3)$ & $(4)$ & $(5)$ & $(6)$ \\
\hline $\log ($ exemption $)$ & $\begin{array}{c}0.381^{* * *} \\
(0.130)\end{array}$ & $\begin{array}{c}0.400^{* * *} \\
(0.129)\end{array}$ & $\begin{array}{c}0.306^{*} \\
(0.160)\end{array}$ & $\begin{array}{c}-3.235^{*} \\
(1.850)\end{array}$ & $\begin{array}{c}-4.182^{* * *} \\
(1.175)\end{array}$ & $\begin{array}{c}-4.607^{* * *} \\
(1.351)\end{array}$ \\
\hline $\log ($ median income $)$ & & $\begin{array}{l}-0.457 \\
(0.513)\end{array}$ & $\begin{array}{l}-0.229 \\
(0.539)\end{array}$ & & $\begin{array}{c}0.727 \\
(4.733)\end{array}$ & $\begin{array}{c}1.949 \\
(4.697)\end{array}$ \\
\hline Unemp. rate & & $\begin{array}{c}-0.0152 \\
(0.0453)\end{array}$ & $\begin{array}{l}0.00453 \\
(0.0535)\end{array}$ & & $\begin{array}{c}-1.746^{* * *} \\
(0.581)\end{array}$ & $\begin{array}{c}-1.206^{* *} \\
(0.578)\end{array}$ \\
\hline $\log ($ house price index $)$ & & $\begin{array}{l}-0.197 \\
(0.279)\end{array}$ & $\begin{array}{r}-0.0778 \\
(0.395)\end{array}$ & & $\begin{array}{c}11.95^{* * *} \\
(2.750)\end{array}$ & $\begin{array}{c}10.11^{* * *} \\
(2.312)\end{array}$ \\
\hline Observations & 550 & 550 & 550 & 550 & 550 & 550 \\
\hline State and year FE & $\mathrm{X}$ & $\mathrm{X}$ & $\mathrm{X}$ & $\mathrm{X}$ & $\mathrm{X}$ & $\mathrm{X}$ \\
\hline Region-year FE & & & $\mathrm{X}$ & & & $\mathrm{X}$ \\
\hline
\end{tabular}

This table reports regression results from estimating equation (1.4). Observations are weighted by credit union membership. Standard errors clustered at the state-level are in parentheses. 
Table 1.7: Investigating Default and Loan Profitability

\begin{tabular}{|c|c|c|c|c|c|c|}
\hline & \multicolumn{3}{|c|}{ Credit card charge-off rate } & \multicolumn{3}{|c|}{ Return on $\$ 1000$ loan } \\
\hline & (1) & $(2)$ & $(3)$ & $(4)$ & $(5)$ & $(6)$ \\
\hline $\log ($ exemption $)$ & $\begin{array}{c}0.184 \\
(0.211)\end{array}$ & $\begin{array}{c}0.345^{* * *} \\
(0.0838)\end{array}$ & $\begin{array}{c}0.389 * * * \\
(0.0965)\end{array}$ & $\begin{array}{c}2.022 \\
(2.096)\end{array}$ & $\begin{array}{c}0.247 \\
(1.248)\end{array}$ & $\begin{array}{c}-0.819 \\
(1.431)\end{array}$ \\
\hline Log(median income) & & $\begin{array}{l}-0.590 \\
(0.379)\end{array}$ & $\begin{array}{c}-0.669^{*} \\
(0.382)\end{array}$ & & $\begin{array}{l}-4.877 \\
(6.796)\end{array}$ & $\begin{array}{l}-3.312 \\
(8.020)\end{array}$ \\
\hline Unemp. rate & & $\begin{array}{c}0.103^{* * *} \\
(0.0351)\end{array}$ & $\begin{array}{c}0.0988^{* * *} \\
(0.0324)\end{array}$ & & $\begin{array}{c}-0.261 \\
(0.650)\end{array}$ & $\begin{array}{c}-0.180 \\
(0.722)\end{array}$ \\
\hline Log(house price index $)$ & & $\begin{array}{c}-1.930^{* * *} \\
(0.217)\end{array}$ & $\begin{array}{c}-2.068^{* * *} \\
(0.263)\end{array}$ & & $\begin{array}{c}23.93^{* * *} \\
(2.871)\end{array}$ & $\begin{array}{c}26.26^{* * *} \\
(6.203)\end{array}$ \\
\hline Observations & 350 & 350 & 350 & 350 & 350 & 350 \\
\hline State and year FE & $\mathrm{X}$ & $\mathrm{X}$ & $\mathrm{X}$ & $\mathrm{X}$ & $\mathrm{X}$ & $\mathrm{X}$ \\
\hline Region-year FE & & & $\mathrm{X}$ & & & $\mathrm{X}$ \\
\hline Mean of dep. var. & 2.16 & 2.16 & 2.16 & $\$ 1,098$ & $\$ 1,098$ & $\$ 1,098$ \\
\hline
\end{tabular}

This table reports regression results from estimating equation (1.4) with credit card charge-offs and lender profits as outcome variables. The measure of loan profitability is $e(1+r)+(1-e) q$, where $e$ is the share of credit card debt that is not charged-off, $r$ is the credit card interest rate, and $q$ is the recovery rate conditional on charge-off. Observations are weighted by credit union membership. Standard errors clustered at the state-level are in parentheses. 
Table 1.8: Calculation of the Marginal Welfare Gain of Increasing Exemptions

\begin{tabular}{cccc}
\hline Consumption drop $\frac{\Delta c}{c_{h}}(m)$ & $\begin{array}{c}\text { Low-exemption } \\
\text { Mid-exemption }\end{array}$ & $\begin{array}{c}\text { High-exemption } \\
-0.055\end{array}$ & -0.032 \\
\hline Risk aversion $\gamma$ & & & -0.016 \\
1 & -1.00 & -1.01 & -1.02 \\
2 & -0.99 & -1.00 & -1.01 \\
3 & -0.97 & -0.99 & -1.01 \\
4 & -0.95 & -0.98 & -1.00 \\
5 & -0.94 & -0.97 & -1.00 \\
\hline
\end{tabular}

Each cell reports the marginal welfare gains of increasing exemptions by $10 \%$ ( $\mathrm{dW} / \mathrm{db} \times 10 \%)$ calculated from equation (1.2). The parameters are set to $d=3,391, r^{\prime}(m)=0.4 / 100$, $q^{\prime}(m)=-4.2 / 100$, and $e=0.978$. 
Table 1.9: Sensitivity of the Welfare Impact

\begin{tabular}{llcccl}
\hline \multicolumn{1}{c}{ Parameter } & & Assigned Value & Lower 95\% CI & Upper 95\% CI & $\begin{array}{l}\text { Values Needed for } \\
\text { Positive Impact }\end{array}$ \\
\hline Risk aversion & $\gamma$ & 3 & - & - & $>58.7$ \\
Consumption drop & $\frac{\Delta c}{c}$ & 0.055 & 0.024 & 0.086 & $>1.08$ \\
Interest rate change & $\mathrm{r}^{\prime}(\mathrm{m})$ & 0.400 & 0.147 & 0.653 & $<0.11$ \\
Recovery rate change & $\mathrm{q}^{\prime}(\mathrm{m})$ & -4.18 & -6.48 & -1.88 & $<-15.26$ \\
Probability of default & $(1-\mathrm{e})$ & 0.022 & 0.011 & 0.032 & $>0.075$ \\
\hline
\end{tabular}




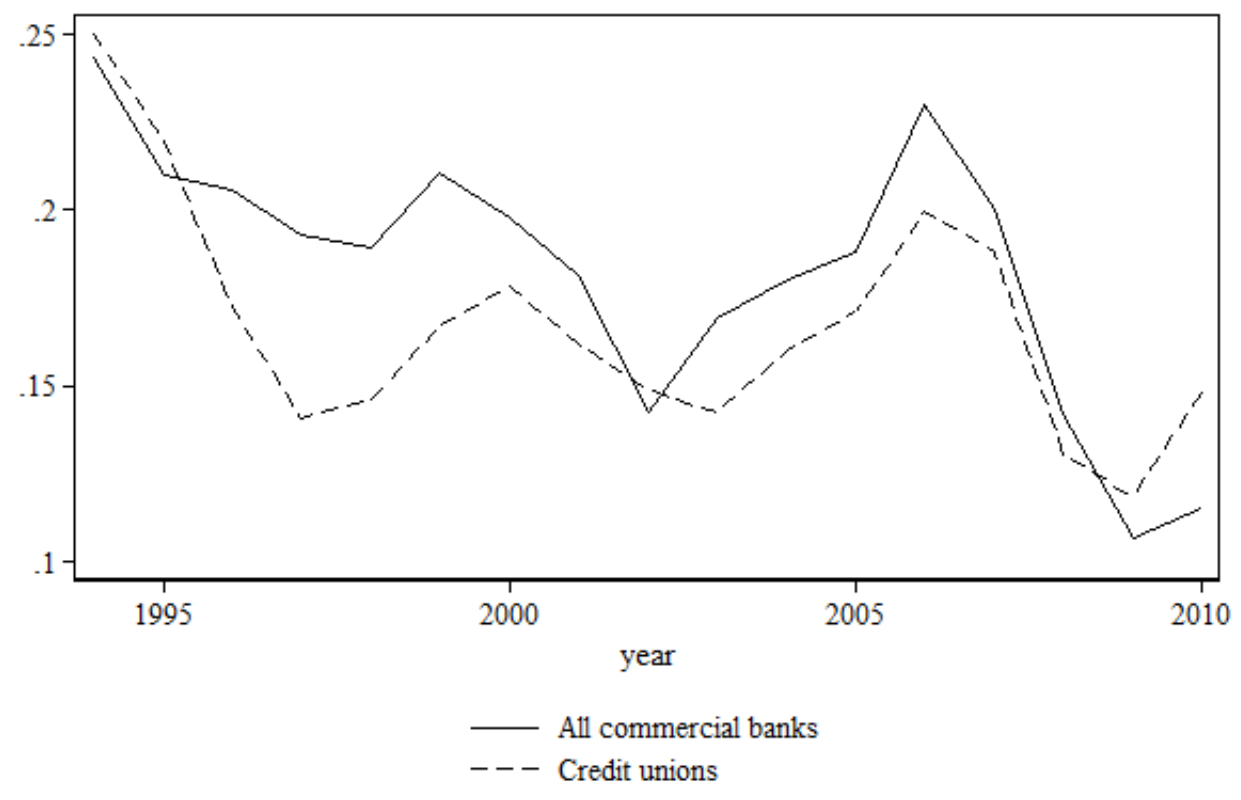

Figure 1.1: Comparison of Recovery Rates on Charged-Off Loans Source: Aggregated credit union and commercial bank Call Reports. 


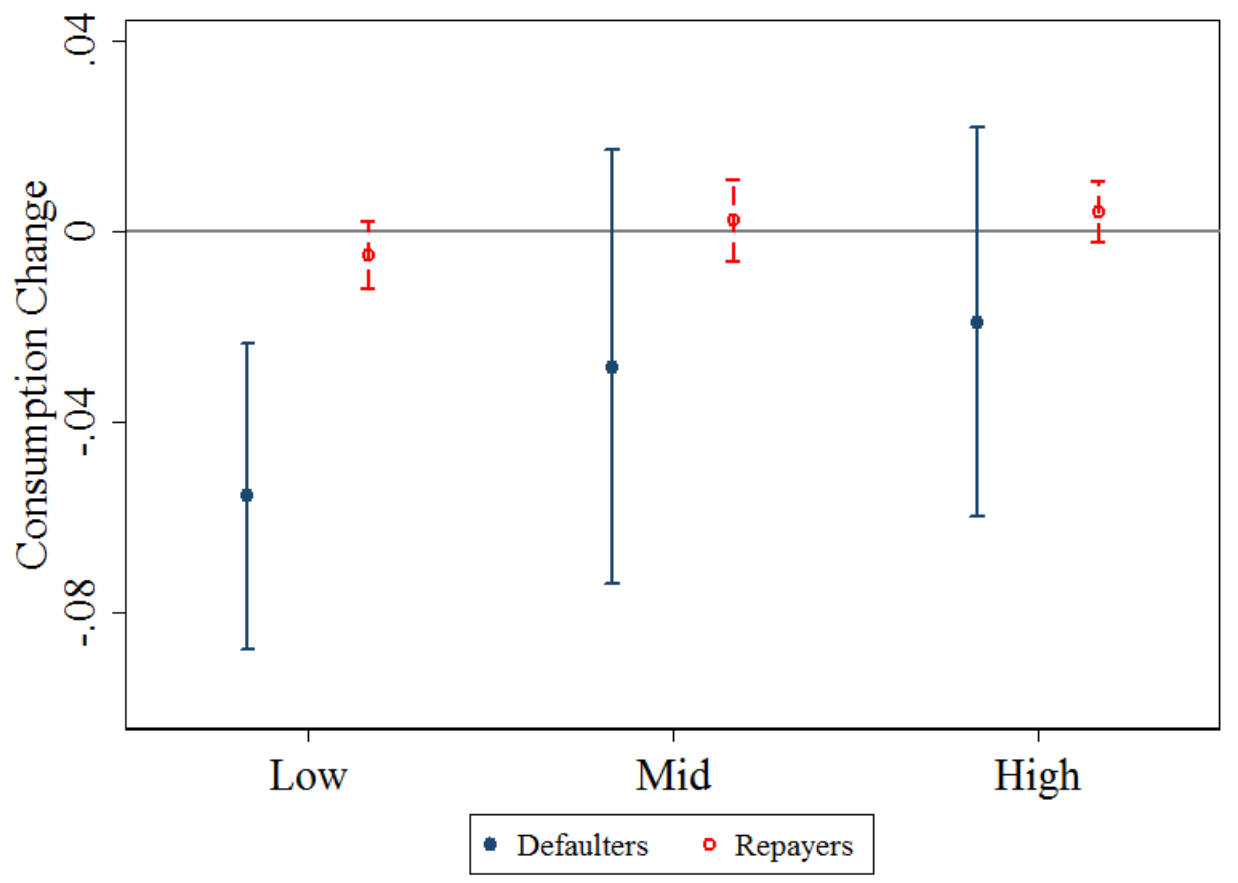

\section{Figure 1.2: Change in Consumption by Exemption Tercile}

This figure presents the mean consumption drop upon default and $95 \%$ confidence intervals for defaulters living in low-, mid-, and high-exemption states. It also presents the average consumption change for non-defaulters living in those states. The estimated coefficients and $95 \%$ confidence intervals are from the regression in specification (1.3). The "Repayer" results present the estimated coefficients from the same regression estimated on the sample of individuals who never report financial distress (non-defaulters). Both regressions include only year fixed effects and an indicator for whether the respondent lives in a low-, mid-, or high- exemption state. Low-exemption states have total exemptions less than $\$ 12,700$, mid-exemption states range from $\$ 12,700-45,200$, and high exemption states have total exemptions above $\$ 45,200$ (including the unlimited exemption states). 


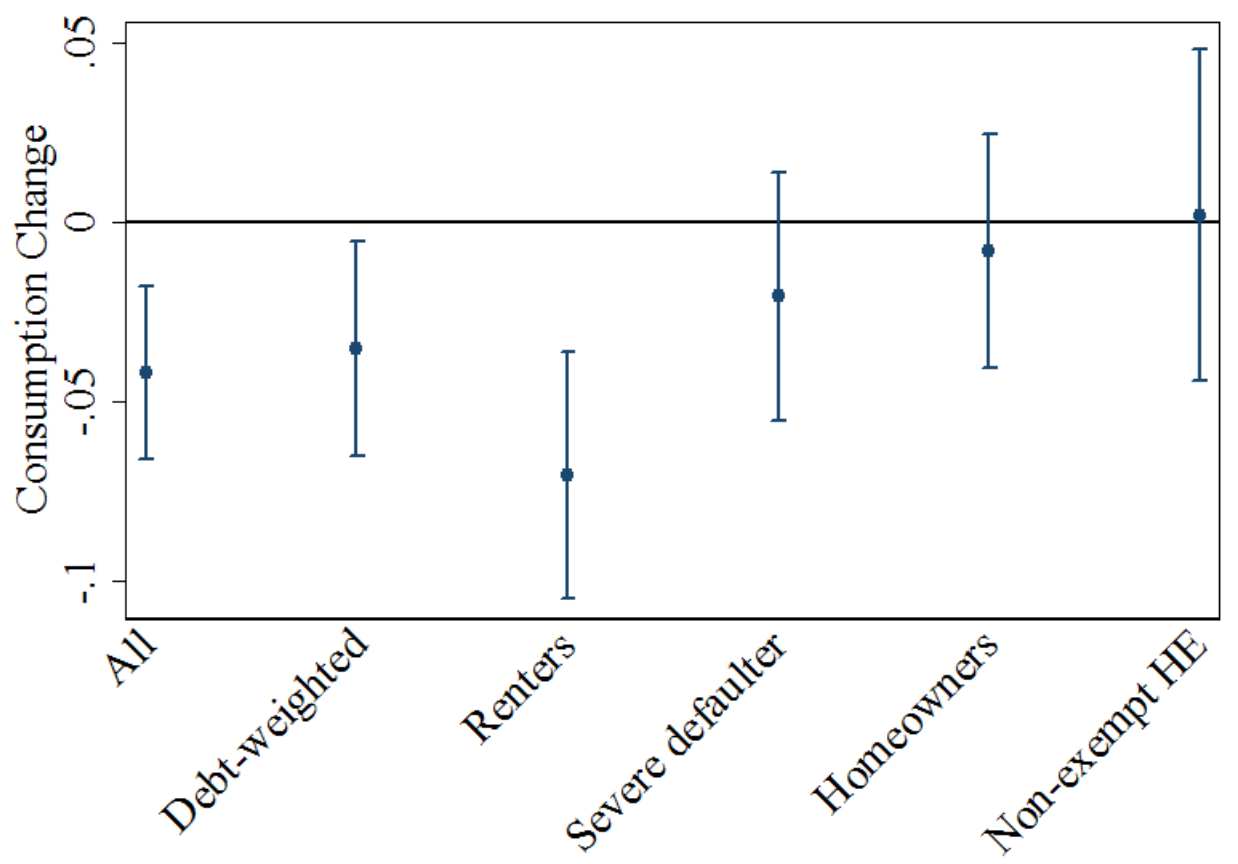

\section{Figure 1.3: Heterogeneity in the Consumption Change upon Default}

This figure presents the mean and $95 \%$ confidence intervals of the change in consumption upon default for subsamples of defaulters. Observations, with the exception of Debt-weighted, are weighted by the PSID family weights for the core sample. Debt-weighted averages are weighted by the amount of unsecured debt. Severe defaulters are those who report a more serious type of financial distress (debt collection actions, judicial actions, or bankruptcy). Non-exempt home equity is the subsample of homeowners that are not fully protected by exemptions. The means in this figure are shown in Table 1.A.1. 


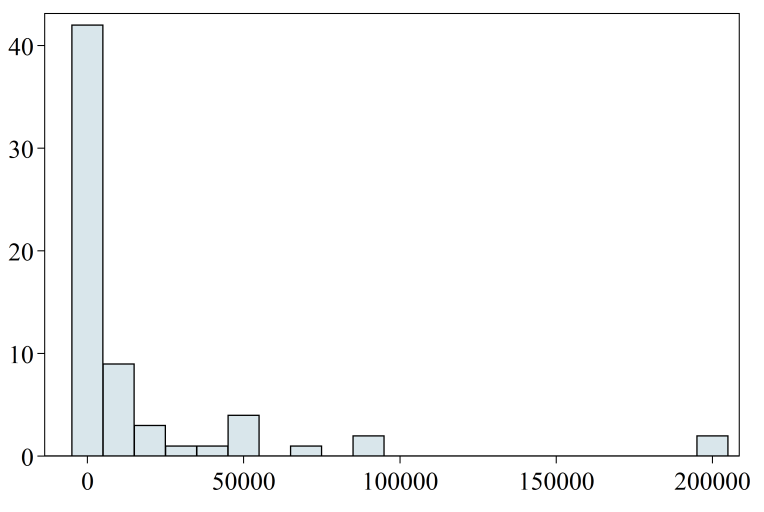

(a) Size of Exemption Changes

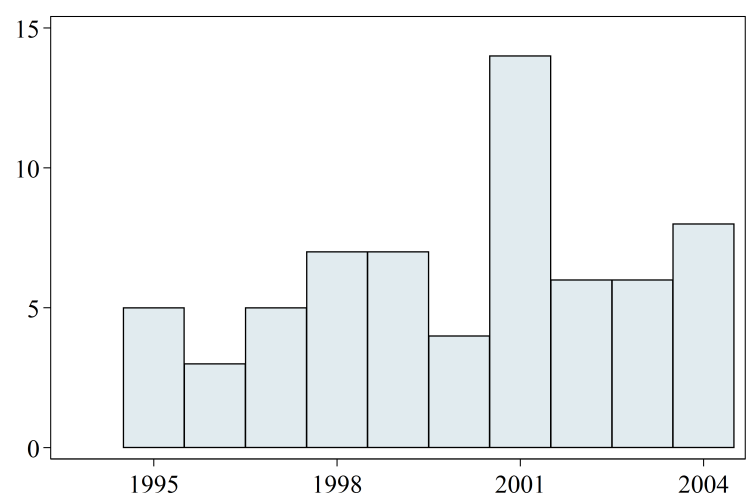

(b) Number of Exemption Changes

Figure 1.4: Distributions of the size and number of changes in homestead exemptions from 1994-2004. 


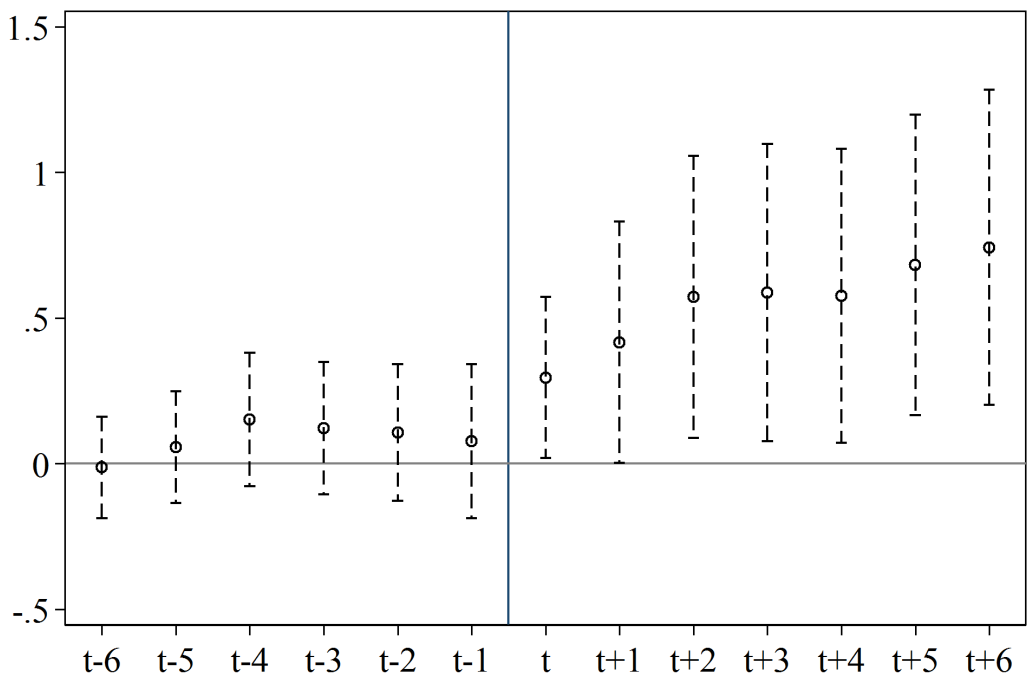

(a) Credit Card Interest Rates

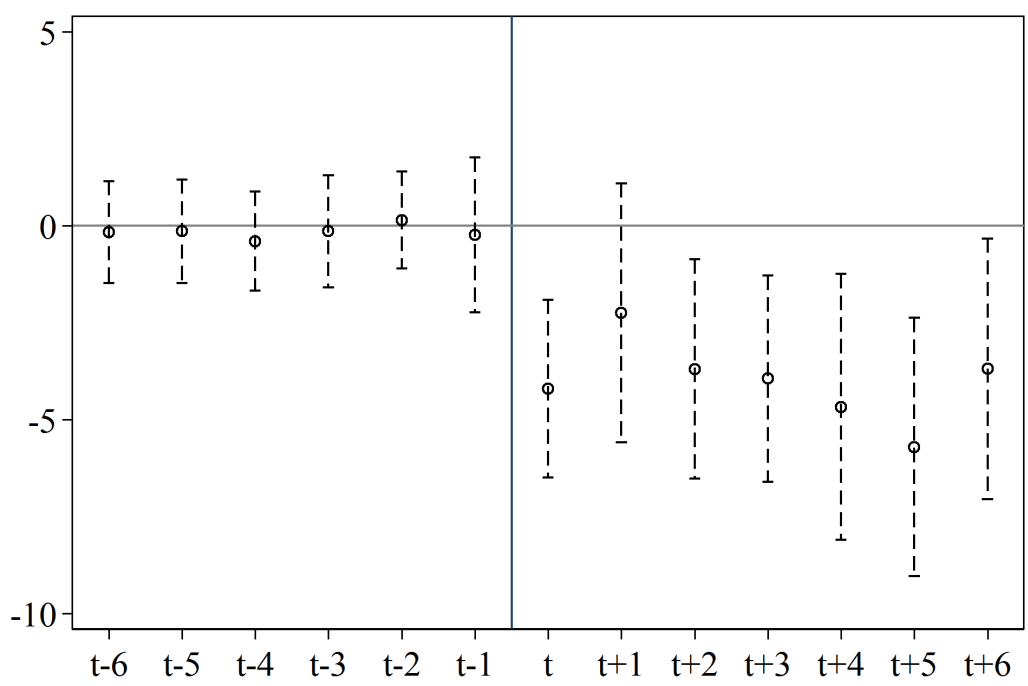

(b) Recovery Rates on Charged Off Loans

Figure 1.5: Annual Effects of Exemption Increases in Year $\mathbf{t}$ The cumulative effect of a one percent increase in asset exemptions in period t, estimated from a distributed lag model with 6 leads and lags using annual data. The sample period is 1995-2004, with exemption data used from 1989-2010 to allow for 6 leads and lags for each observation. The dotted lines show $95 \%$ confidence intervals for standard errors clustered at the state level. 


\section{Appendix}

\section{A Appendices}

\section{A.1 Dynamic Model}

In this appendix, I apply the general model of social insurance in Chetty (2006) to the case of asset exemptions. The key assumptions and arguments are taken directly from Chetty (2006) and adapted to the asset exemption setting. One difference in this model is that in the welfare gain formula, marginal utility is weighted by the amount of debt held in each state. This is because exemptions affect the interest rate and recovery rate on debt, so their impact will be proportional to the amount of debt held.

Consider a discrete time dynamic model where an agent lives for $T+1$ periods $t \in$ $\{0, \ldots, T\}$. Let $\omega_{t}$ be the state variable that contains all the information up to time $t$ necessary to determine the borrower's debt and behavior. Let $F_{t}\left(\omega_{t}\right)$ denote the unconditional distribution function of $\omega_{t}$ given information available at $t=0$. I assume $F_{t}$ is a smooth function with support $\Omega$. The borrower chooses consumption $c\left(t, \omega_{t}\right)$, debt $d\left(t, \omega_{t}\right)$ and a general vector of other choices $x\left(t, \omega_{t}\right)$. Utility is time-separable and the flow utility in period $t$ is $u\left(c\left(t, \omega_{t}\right), x\left(t, \omega_{t}\right)\right)$. Let $c=\left\{c\left(t, \omega_{t}\right)\right\}_{t \in\{0, \ldots, T\}, \omega_{t} \in \Omega}, d=\left\{d\left(t, \omega_{t}\right)\right\}_{t \in\{0, \ldots, T\}, \omega_{t} \in \Omega}$, and $x=\left\{x\left(t, \omega_{t}\right)\right\}_{t \in\{0, \ldots, T\}, \omega_{t} \in \Omega}$ denote the full plan of state-contingent consumption, debt, and other choices for the agent. 
Let $\gamma\left(t, \omega_{t}, c, x, d\right)$ denote the borrower's repayment status at time $t$ in state $\omega_{t} . \gamma=1$ when the borrower repays his debts for that period $(1+r(m)) d\left(t-1, \omega_{t-1}\right)$, and $\gamma=0$ when he defaults and pays $q(m) d\left(t-1, \omega_{t-1}\right)$ instead. Here, $r(m)$ is the interest rate and $q(m)$ is the recovery rate on defaulted debt, both of which are functions of the exemption level $m$. To reduce notation, I often suppress $(c, x, d)$ in $\gamma\left(t, \omega_{t}, c, x, d\right)$.

For each period $t$, the borrower faces the budget constraint

$f\left(x\left(t, \omega_{t}\right)\right)-c\left(t, \omega_{t}\right)+d\left(t, \omega_{t}\right)-\gamma\left(t, \omega_{t}\right)\left[(1+r) d\left(t-1, \omega_{t-1}\right)\right]-\left[1-\gamma\left(t, \omega_{t}\right)\right] q d\left(t-1, \omega_{t-1}\right)=0$.

The function $f\left(x\left(t, \omega_{t}\right)\right)$ captures the influence of choices other than consumption and borrowing on the budget constraint. For example, labor income and investment income can enter through $f\left(x\left(t, \omega_{t}\right)\right)$. The terminal condition is that the individual cannot borrow in the final period:

$$
d\left(T, \omega_{T}\right) \leq 0 \quad \forall \omega_{T}
$$

There are $\mathrm{N}$ additional constraints in each state $\omega_{t}$ at time $t$

$$
g_{i \omega t}(c, x, d ; r, q) \geq \bar{k}_{i \omega t} \quad i=1, \ldots, N .
$$

Let $\lambda_{\omega, t}$ be the multiplier on the budget constraint in state $\omega_{t}$ at time $t, \lambda_{w_{T}, T}$ be the multipliers on the terminal conditions, and $\lambda_{g_{i}, \omega, t}$ be the multipliers on the additional constraints. 
The borrower chooses a plan $(c, d, x)$ to

$$
\begin{aligned}
& \max \sum_{t=0}^{T} \int_{\omega_{t}} u\left(c\left(t, \omega_{t}\right), x\left(t, \omega_{t}\right)\right) d F\left(\omega_{t}\right)+\int_{\omega_{t}} \lambda_{\omega_{T}, T}\left(-d\left(T, \omega_{T}\right)\right) d F_{T}\left(\omega_{T}\right) \\
&+\sum_{t=0}^{T} \int_{\omega_{t}} \lambda_{\omega, t}\left\{f\left(x\left(t, \omega_{t}\right)\right)-c\left(t, \omega_{t}\right)+d\left(t, \omega_{t}\right)-\gamma\left(t, \omega_{t}\right)\left[(1+r) r d\left(t-1, \omega_{t-1}\right)\right]\right. \\
&\left.-\left(1-\gamma\left(t, \omega_{t}\right)\right)\left[q d\left(t-1, \omega_{t-1}\right)\right]\right\} d F_{t}\left(\omega_{t}\right)+\sum_{i=1}^{N} \sum_{t=0}^{T} \int_{\omega_{t}} \lambda_{g_{i}, \omega, t}\left\{g_{i \omega t}(c, x, d ; r, q)-\bar{k}_{i \omega t}\right\} d F_{t}\left(\omega_{t}\right) .
\end{aligned}
$$

Let $V(r(m), q(m))$ be the value of the maximum for a given $(r(m), q(m))$, where $m$ is the $\log$ of the asset exemption level. The planner solves

$$
\max _{m} V(r(m), q(m))
$$

taking into account the endogenous responses of the borrowers through $(c, d, x)$. Instead of the balanced budget requirement that typically constrains the government provision of social insurance, they are constrained by how creditors respond to changes in exemption levels through $r(m)$ and $q(m)$.

The following assumptions, taken directly from Chetty (2006), ensure that the borrower's problem has a unique global maximum and the Envelope Theorem applies.

Assumption 1. Total lifetime utility $\sum_{t=0}^{T} \int_{\omega_{t}} u\left(c\left(t, \omega_{t}\right), x\left(t, \omega_{t}\right)\right) d F\left(\omega_{t}\right)$ is smooth, increasing, and strictly quasiconcave in $(c, x)$.

Assumption 2. The set of choices $\{c, d, x\}$ that satisfy all the constraints is convex.

Assumption 3. At the borrower's optimum, the binding set of constraints does not change in response to a small perturbation in $m$.

The following assumption guarantees that the value of reducing $q(m)$ and increasing $r(m)$ can be determined from the marginal utilities of consumption in the two states. 
Assumption 4. The feasible set of choices can be defined using a set of constraints such that:

$$
\begin{aligned}
& \text { i) } \frac{\partial g_{i \omega t}}{\partial r}=\gamma\left(t, \omega_{t}\right) d\left(t-1, \omega_{t-1}\right) \frac{\partial g_{i \omega t}}{\partial c\left(t, \omega_{t}\right)} \\
& \text { ii) } \frac{\partial g_{i \omega t}}{\partial q}=\left[1-\gamma\left(t, \omega_{t}\right)\right] d\left(t-1, \omega_{t-1}\right) \frac{\partial g_{i \omega t}}{\partial c\left(t, \omega_{t}\right)} \\
& \text { iii) } \frac{\partial g_{i \omega t}}{\partial c\left(s, \omega_{s}\right)}=0 \quad \text { if } t \neq s
\end{aligned}
$$

This assumption is satisfied, for example, if there is a borrowing constraint when in default:

$$
g_{1 \omega t}=\left(1-\gamma\left(t, \omega_{t}\right)\right)\left(f\left(x\left(t, \omega_{t}\right)\right)-c\left(t, \omega_{t}\right)-q d\left(t-1, \omega_{t-1}\right)\right) \geq 0
$$

Let $R$ be the expected amount of time in repayment

$$
R=\sum_{t=0}^{T} \int_{\omega_{t}}\left(\gamma\left(t, \omega_{t}\right)\right) d F_{t}\left(\omega_{t}\right)
$$

and $E\left\{u^{\prime}\left(c_{h}\right) d\right\}$ and $E\left\{u^{\prime}\left(c_{l}\right) d\right\}$ be the expectation of the debt-weighted marginal utility in the repayment and default states:

$$
\begin{aligned}
E\left\{u^{\prime}\left(c_{h}\right) d\right\} & =\frac{\sum_{t=0}^{T} \int_{\omega_{t}} \gamma\left(t, \omega_{t}\right) u^{\prime}\left(c\left(t, \omega_{t}\right)\right) d\left(t-1, \omega_{t-1}\right) d F_{t}\left(\omega_{t}\right)}{\sum_{t=0}^{T} \int_{\omega_{t}} \gamma\left(t, \omega_{t}\right) d F_{t}\left(\omega_{t}\right)} \\
E\left\{u^{\prime}\left(c_{l}\right) d\right\} & =\frac{\sum_{t=0}^{T} \int_{\omega_{t}}\left(1-\gamma\left(t, \omega_{t}\right)\right) u^{\prime}\left(c\left(t, \omega_{t}\right)\right) d\left(t-1, \omega_{t-1}\right) d F_{t}\left(\omega_{t}\right)}{\sum_{t=0}^{T} \int_{\omega_{t}}\left(1-\gamma\left(t, \omega_{t}\right)\right) d F_{t}\left(\omega_{t}\right)} .
\end{aligned}
$$

Proposition 1. The marginal value of increasing the exemption level is

$$
\frac{d V}{d m}=-r^{\prime}(m) R E\left\{u^{\prime}\left(c_{h}\right) d\right\}-q^{\prime}(m)(T+1-R) E\left\{u^{\prime}\left(c_{l}\right) d\right\}
$$

Proof: Assumptions 1-3 guarantee that the Envelope Theorem can be applied to $V(m)$. 
Without loss in generality, assume that all $N$ of the constraints bind. Using the envelope conditions associated with individual optimization and differentiating $V(r(m), q(m))$ with respect to $m$ gives

$$
\begin{aligned}
\frac{d V}{d m}=-r^{\prime}( & m) \sum_{t=0}^{T} \int_{\omega_{t}}\left[\lambda_{w t} \gamma\left(t, \omega_{t}\right) d\left(t-1, \omega_{t-1}\right)-\sum_{i=1}^{N} \lambda_{g_{i}, \omega, t} \frac{\partial g_{i \omega t}}{\partial r}\right] d F_{t}\left(\omega_{t}\right) \\
- & q^{\prime}(m) \sum_{t=0}^{T} \int_{\omega_{t}}\left[\lambda_{w t}\left[1-\gamma\left(t, \omega_{t}\right)\right] d\left(t-1, \omega_{t-1}\right)-\sum_{i=1}^{N} \lambda_{g_{i}, \omega, t} \frac{\partial g_{i \omega t}}{\partial q}\right] d F_{t}\left(\omega_{t}\right)
\end{aligned}
$$

The third part of Assumption 4 implies that, at the borrower's optimal consumption choice,

$$
\frac{\partial u\left(c\left(t, \omega_{t}\right), x\left(t, \omega_{t}\right)\right)}{\partial c\left(t, \omega_{t}\right)}=\lambda_{\omega, t}-\sum_{i=1}^{N} \lambda_{g_{i}, \omega_{t}, t} \frac{\partial g_{i \omega t}}{c\left(t, \omega_{t}\right)} \quad \forall t, \omega_{t} .
$$

Also, the first two parts of Assumption 4 imply that $\forall t, \omega_{t}$,

$$
\begin{aligned}
& \sum_{i=1}^{N} \lambda_{g_{i}, \omega, t} \frac{\partial g_{i \omega t}}{\partial r}=\sum_{i=1}^{N} \lambda_{g_{i}, \omega, t} \gamma\left(t, \omega_{t}\right) d\left(t-1, \omega_{t-1}\right) \frac{\partial g_{i \omega t}}{\partial c\left(t, \omega_{t}\right)} \text { and } \\
& \sum_{i=1}^{N} \lambda_{g_{i}, \omega, t} \frac{\partial g_{i \omega t}}{\partial q}=\sum_{i=1}^{N} \lambda_{g_{i}, \omega, t}\left[1-\gamma\left(t, \omega_{t}\right)\right] d\left(t-1, \omega_{t-1}\right) \frac{\partial g_{i \omega t}}{\partial c\left(t, \omega_{t}\right)}
\end{aligned}
$$

Substituting these conditions into equation (1.9) gives

$$
\begin{aligned}
\frac{d V}{d m}=-r^{\prime}(m) \sum_{t=0}^{T} \int_{\omega_{t}} \gamma\left(t, \omega_{t}\right) & d\left(t-1, \omega_{t-1}\right) u^{\prime}\left(c\left(t, \omega_{t}\right)\right) d F_{t}\left(\omega_{t}\right) \\
& -q^{\prime}(m) \sum_{t=0}^{T} \int_{\omega_{t}}\left[1-\gamma\left(t, \omega_{t}\right)\right] d\left(t-1, \omega_{t-1}\right) u^{\prime}\left(c\left(t, \omega_{t}\right)\right) d F_{t}\left(\omega_{t}\right)
\end{aligned}
$$


and using the definitions of $R, E\left\{u^{\prime}\left(c_{h}\right) d\right\}$, and $E\left\{u^{\prime}\left(c_{l}\right) d\right\}$ gives

$$
\frac{d V}{d m}=-r^{\prime}(m) R E\left\{u^{\prime}\left(c_{h}\right) d\right\}-q^{\prime}(m)(T+1-R) E\left\{u^{\prime}\left(c_{l}\right) d\right\}
$$

Normalizing $\frac{d V(m)}{d m}$ by the welfare gain from a marginal reduction in interest rates $E\left\{u^{\prime}\left(c_{h}\right) d\right\}$ gives an equation similar to equation (1.2):

$$
\frac{d V(m)}{d m} / E\left\{u^{\prime}\left(c_{h}\right) d\right\}=\left[\frac{E\left\{u^{\prime}\left(c_{l}\right) d\right\}-E\left\{u^{\prime}\left(c_{h}\right) d\right\}}{E\left\{u^{\prime}\left(c_{h}\right) d\right\}}-\left(-\frac{R}{T+1-R} \frac{r^{\prime}(m)}{q^{\prime}(m)}-1\right)\right]\left(-(T+1-R) q^{\prime}(m)\right)
$$

This general equation is very similar to the welfare gain formula for the two-period model

$$
\frac{d W(m)}{d m}=\left\{\frac{u^{\prime}\left(c_{l}\right)-u^{\prime}\left(c_{h}\right)}{u^{\prime}\left(c_{h}\right)}-\left(-\frac{e}{1-e} \frac{r^{\prime}(m)}{q^{\prime}(m)}-1\right)\right\}\left\{-(1-e) q^{\prime}(m) d\right\}
$$

The main difference is that the dynamic model allows exemptions to impact people in various states of the world where they hold different levels of debt. Since the impact of changes in the interest rate and recovery rate is proportional to the level of debt, the dynamic welfare gain formula weights the marginal utility in each state by the level of debt held.

\section{A.2 Multiple Loan Types and Implications for Welfare Gain}

One concern in the analysis is that while I use the credit card interest rate, the recovery rate is computed for all non-real estate loans. This appendix shows that this feature of the data does not affect the policy implication of this paper. Non-real estate loans at credit unions consist almost entirely of unsecured consumer loans (22\%) and auto loans (69\%). ${ }^{37}$ Rough estimates based on the share of credit card debt and non-real estate debt that is charged-off

\footnotetext{
${ }^{37}$ The remaining $9 \%$ includes all other types of loans, such as partially secured personal loans and member business loans. These figures are for 2002 from NCUA (2002) which compiles totals from the quarterly Credit Union Call Reports.
} 
imply that $56 \%$ of charged-off non-real estate debt is comprised of unsecured loans, and $44 \%$ is comprised of auto loans. ${ }^{38}$

First, I extend the model in the paper to allow for two different types of loans that exemptions may affect differently. When a debtor defaults on an auto loan, the vehicle serving as collateral is repossessed, and exemptions only influence the recovery of the remaining portion of the loan that is not recovered from the sale of the collateral. Let $d_{A}$ be the unsecured portion of the auto debt (principal less the value of the collateral) and $d_{U}$ be unsecured credit (e.g. credit card debt). Debtors again make repayment effort choices, but choose effort for auto loan repayment $e_{A}$ and unsecured debt repayment $e_{U}$ separately, with effort cost given by $f\left(e_{A}, e_{U}\right)$. To represent the gains from a vehicle, I allow utility in period 0 to depend directly on $d_{A}$. Borrowers maximize expected utility

$$
\begin{aligned}
V(m) & =\max _{e_{A}, e_{U}, d_{A}, d_{U}} u\left(c_{0}, d_{A}\right)+e_{A} e_{U} u(c(1,1))+e_{A}\left(1-e_{U}\right) u(c(1,0)) \\
& +\left(1-e_{A}\right) e_{U} u(c(0,1))+\left(1-e_{A}\right)\left(1-e_{U}\right) u(c(0,0))-f\left(e_{A}, e_{U}\right)
\end{aligned}
$$

where

$$
\begin{aligned}
& c_{0}=y_{0}+d_{U}, \\
& c(1,1)=y_{1,1}-\left(1+r_{A}(m)\right) d_{A}-\left(1+r_{U}(m)\right) d_{U} \\
& c(1,0)=y_{1,0}-\left(1+r_{A}(m)\right) d_{A}-q_{U}(m) d_{U} \\
& c(0,1)=y_{0,1}-q_{A}(m) d_{A}-\left(1+r_{U}(m)\right) d_{U} \\
& c(0,0)=y_{0,0}-q_{A}(m) d_{A}-q_{U}(m) d_{U} .
\end{aligned}
$$

With this indirect utility functions, the welfare impact of raising exemptions is

\footnotetext{
${ }^{38}$ These numbers are obtained by multiplying the shares of unsecured $(22 \%)$ and auto $(78 \%)$ loans by their respective charge-off rates of $2.18 \%$ and $0.56 \%$. I treat the $9 \%$ of loans classified as "Other" as auto loans.
} 


$$
\begin{aligned}
\frac{d V(m)}{d m}=- & e_{A} e_{U} u^{\prime}(c(1,1))\left(r_{A}^{\prime} d_{A}+r_{U}^{\prime} d_{U}\right)-e_{A}\left(1-e_{U}\right) u^{\prime}(c(1,0))\left(r_{A}^{\prime} d_{A}+q_{U}^{\prime} d_{U}\right) \\
& -\left(1-e_{A}\right) e_{U} u^{\prime}(c(0,1))\left(q_{A}^{\prime} d_{A}+r_{U}^{\prime} d_{U}\right)-\left(1-e_{A}\right)\left(1-e_{U}\right) u^{\prime}(c(0,0))\left(q_{A}^{\prime} d_{A}+q_{U}^{\prime} d_{U}\right) \\
=- & e_{A} e_{U} u^{\prime}(c(1,1))\left(r_{A}^{\prime} d_{A}+r_{U}^{\prime} d_{U}\right)-\left(1-e_{A} e_{U}\right)\left(\frac{e_{A}\left(1-e_{U}\right)}{1-e_{A} e_{U}} u^{\prime}(c(1,0))\left(r_{A}^{\prime} d_{A}+q_{U}^{\prime} d_{U}\right)\right. \\
& \left.\quad-\frac{\left(1-e_{A}\right) e_{U}}{1-e_{A} e_{U}} u^{\prime}(c(0,1))\left(q_{A}^{\prime} d_{A}+r_{U}^{\prime} d_{U}\right)-\frac{\left(1-e_{A}\right)\left(1-e_{U}\right)}{1-e_{A} e_{U}} u^{\prime}(c(0,0))\left(q_{A}^{\prime} d_{A}+q_{U}^{\prime} d_{U}\right)\right) \\
\leq- & \left.e_{A} e_{U} u^{\prime}(c(1,1))\left(r_{A}^{\prime} d_{A}+r_{U}^{\prime} d_{U}\right)-\left(1-e_{A} e_{U}\right) \bar{u}^{\prime}(c)\right)\left(q_{A}^{\prime} d_{A}+q_{U}^{\prime} d_{U}\right),
\end{aligned}
$$

where $\bar{u}^{\prime}(c)$ is the expected marginal utility in the states where borrowers default. Dividing both sides of the inequality by $u^{\prime}(c(1,1))$ gives an expression similar to the welfare gains formula

$$
\frac{d V(m) / d m}{u^{\prime}(c(1,1))} \leq\left[\left(\frac{\bar{u}^{\prime}(c)}{u^{\prime}(c(1,1))}-1\right)-\left(-\frac{\bar{e}}{1-\bar{e}} \frac{r_{A}^{\prime} d_{A}+r_{U}^{\prime} d_{U}}{q_{A}^{\prime} d_{A}+q_{U}^{\prime} d_{U}}-1\right)\right] \bar{T}
$$

where $\bar{e}=e_{A} e_{U}$ and $\bar{T}=(1-\bar{e})\left[q_{A}^{\prime} d_{A}+q_{U}^{\prime} d_{U}\right]$. This expression gives an upper bound for the welfare impact of raising exemptions when exemptions affect auto loans and credit cards differently and borrowers can default on these loans independently.

First, I argue that $q_{A}^{\prime} \approx q_{U}^{\prime}$. The accounting guidelines that determine how loans are charged-off makes it likely that the recovery rate for auto loans and unsecured credit card debt is similar. Instead of charging off the entire loan balance, loans with collateral, e.g. auto loans, may be written down to the value of the collateral, less the cost to sell. ${ }^{39}$ Thus, the portion of the collateralized loan that is charged-off is unlikely to be secured by collateral, and so will be subject to the same laws and collection efforts used for unsecured credit card debt. If recoveries for charged-off auto loans and charged-off credit card debt are similar, then nothing is lost by using the recovery rate for non-real estate debt instead of the recovery

\footnotetext{
${ }^{39}$ For details on charge-off guidelines, see (https://www.fdic.gov/regulations/laws/rules/5000-1000.html, Guidance on Charge-offs).
} 
rate for credit card debt and the main analysis in the paper correctly analyzes the welfare impact of exemptions on credit card borrowers.

However, if exemptions also affect interest rates for auto loan borrowers, this may alter the welfare analysis. Since $q_{A}^{\prime} \approx q_{U}^{\prime}$, I replace $q_{A}^{\prime}$ and $q_{U}^{\prime}$ with $q^{\prime}$ in the above formula to give

$$
\frac{d V(m) / d m}{u^{\prime}(c(1,1))} \leq\left[\left(\frac{\bar{u}^{\prime}(c)}{u^{\prime}(c(1,1))}-1\right)-\left(-\frac{\bar{e}}{1-\bar{e}} \frac{r_{A}^{\prime} \frac{d_{A}}{d}+r_{U}^{\prime} \frac{d_{U}}{d}}{q^{\prime}}-1\right)\right](1-\bar{e}) q^{\prime} d
$$

where $d=d_{A}+d_{U}$. This upper bound on the welfare impact looks similar to the welfare gains formula in equation (1.2), but $r^{\prime}(m)$ is replaced by the debt-weighted average interest rate increases for auto loans and credit cards. The expected marginal utility in the states where borrowers default $\bar{u}^{\prime}(c)$ is actually what is estimated in Section 1.4, since I estimate the drop in consumption among borrowers who default on any loan.

To compute this bound, I estimate the specification from equation (1.4) with credit card, new auto loan, and used auto loan interest rates as the outcome. The estimates are reported in Table 1.A.2. Columns 1 and 2 show the earlier results for credit card interest rates. Columns 3-6 show that, for new and used auto loans, a $10 \%$ increase in exemptions cause a 1.7-2.1 basis point increase in interest rates, which is half the size of the increase for credit cards.

Using these estimates to compute actual markup for the bound in equation 1.10,

$$
\left(-\frac{\bar{e}}{1-\bar{e}} \frac{r_{A}^{\prime} \frac{d_{A}}{d}+r_{U}^{\prime} \frac{d_{U}}{d}}{q^{\prime}}-1\right)=161 \%
$$

where $(1-\bar{e})$ is set to the credit card charge-off rate of $2.18 \%$ and $\frac{d_{A}}{d}=78 \%$, which is the share of non-real estate debt made of auto loans. I chose the credit card charge-off rate as the default probability because most borrowers default on credit card debt first, so the credit card charge-off rate likely reflects the share of borrowers who default on any debt. Even if I 
set $(1-\bar{e})$ as the sum of the credit card charge-off rate $(2.18 \%)$ and the auto loan charge-off rate $(0.56 \%)$, the markup is still $91 \%$. Since the markup $(161 \%)$ is substantially above the maximum willingness to pay of $16.5 \%$, the upper bound on the welfare effect of raising asset exemptions in equation (1.10) is negative. In reality, since auto loan charge-offs are rare, the actual markup for auto loans will likely be well above this lower bound.

\section{A.3 Comparison with Calibration of Dávila (2016)}

The policy implications of my results differ from those of Dávila (2016). The calibration in Dávila (2016) generates an optimal exemption level of $\$ 100,000$, which implies that most states should raise exemptions to improve welfare. My estimates, however, imply that exemptions are too high and even low-exemption states would benefit from reducing exemptions. The key difference is that, although exemptions in my model affect more people, my estimates of the benefits of raising exemptions are much smaller. First, I find that consumption drops by only 2-5.5\% upon default, relative to a 10\% consumption drop assumed in Dávila (2016). This smaller consumption drop makes insurance less valuable. Second, my estimates imply that raising exemptions has a relatively small effect on the consumption of debtors in default. Dávila (2016) uses the intuitive assumption that a $\$ 1$ increase in asset exemptions will raise consumption of bankruptcy filers with non-exempt assets by $\$ 1$. In contrast, a rough calculation using my estimates implies that a $\$ 1$ increase in exemptions reduces the average amount debtors in default pay by 0.5 cents. ${ }^{40}$ So, although my model allows exemptions to affect a broad set of defaulters, the average effect on an individual defaulter is so small that the total benefit of raising exemptions is lower.

A small effect of exemptions on repayment is consistent with what is known about the

\footnotetext{
${ }^{40}$ This estimate is obtained by evaluating the estimated effect that a $1 \%$ increase in exemptions leads to a 0.046 percentage point decrease in the recovery rate at the mean exemption level of $\$ 29,446$ and the mean unsecured debt level of $\$ 3,391$. Using these values, the raising exemptions by $\$ 1$ reduces the recovery rate by $\frac{0.046}{29,446} * 3,391=0.005$.
} 
assets of defaulters. Even Chapter 7 bankruptcy filers with non-exempt assets may not be affected by changes in exemptions. This is because the large majority of variation in exemptions is from the homestead exemption, while Chapter 7 bankruptcy filers rarely have non-exempt home equity. Only 4-6\% of Chapter 7 cases have any non-exempt assets. Moreover, in a sample of cases with non-exempt assets, only $11 \%$ of them had any non-exempt equity in real estate of any kind, which can include equity in other types of real property as well as home equity (Jiménez, 2009). This mismatch between the type of assets exempted and the assets of debtors, as well as frictions in the debt settlement process could explain why the impact of a $\$ 1$ increase in exemptions translates into a much smaller reduction in the amount paid on charged-off debt. 
Table 1.A.1: Heterogeneity in the Consumption Drop

\begin{tabular}{lcc}
\hline Consumption Drop: & Average & $\mathrm{N}$ \\
\hline Defaulters & -.042 & 1,109 \\
Defaulters (debt-weighted) & -.035 & 666 \\
Renters & -.07 & 623 \\
Severe Defaulters & -.021 & 551 \\
Homeowners & -.0079 & 486 \\
Non-exempt home equity & .0019 & 236 \\
Reports unsecured debt & -.044 & 658 \\
\hline
\end{tabular}

This table reports the mean or median drop in consumption for subsamples of defaulters. Observations, with the exception of Defaulters (debt-weighted), are weighted by the PSID family weights for the core sample. Debt-weighted averages are weighted by the amount of unsecured debt. Severe defaulters are those who report a more serious type of financial distress (debt collection actions, judicial actions, or bankruptcy). Non-exempt home equity is the subsample of homeowners that are not fully protected by exemptions. Reports unsecured debt is equal to one if the household reports positive unsecured debt. 
Table 1.A.2: Impact of Exemptions on Credit Card and Auto Loan Interest Rates

\begin{tabular}{lcccccc}
\hline & \multicolumn{2}{c}{ Credit cards } & \multicolumn{2}{c}{ New auto loans } & \multicolumn{2}{c}{$\begin{array}{c}\text { Used auto loans } \\
(1)\end{array}$} \\
& & $(2)$ & $(3)$ & $(4)$ & $(5)$ & $(6)$ \\
\hline \multirow{2}{*}{$\log ($ exemption) } & $0.381^{* * *}$ & $0.400^{* * *}$ & $0.166^{*}$ & $0.191^{* *}$ & $0.186^{* *}$ & $0.205^{* * *}$ \\
& $(0.130)$ & $(0.129)$ & $(0.0920)$ & $(0.0934)$ & $(0.0845)$ & $(0.0755)$ \\
Log(median income) & & -0.457 & & 0.0513 & & -0.0736 \\
& & $(0.513)$ & & $(0.330)$ & $(0.308)$ \\
Unemp. rate & & -0.0152 & & $-0.0706^{* *}$ & & $-0.0973^{* * *}$ \\
& & $(0.0453)$ & & $(0.0276)$ & & $(0.0297)$ \\
Log(house price index) & & -0.197 & & -0.282 & & -0.193 \\
& & $(0.279)$ & & $(0.190)$ & & $(0.201)$ \\
Observations & 550 & 550 & 550 & 550 & 550 & 550 \\
State and year FE & $\mathrm{X}$ & $\mathrm{X}$ & $\mathrm{X}$ & $\mathrm{X}$ & $\mathrm{X}$ & $\mathrm{X}$ \\
\hline
\end{tabular}

Observations are weighted by credit union membership. Standard errors clustered at the state-level are in parentheses. 


\section{Chapter 2}

New Evidence on Asset Exemptions and Consumer

\section{Bankruptcies}




\section{$2.1 \quad$ Introduction}

In 2014, consumers filed over 850,000 bankruptcies for relief from over $\$ 128$ billion in debt. ${ }^{1}$ Depending on where these debtors lived, the bankruptcy system varied in its generosity. Each state sets a homestead exemption that determines the amount of home equity a bankruptcy filer can retain, ranging from $\$ 5,000$ to an unlimited amount. The effect of these exemption differences on equilibrium bankruptcy rates is uncertain. Generous homestead exemptions make bankruptcy more attractive to debtors, increasing filings. But creditors may compensate for additional losses by raising interest rates and reducing access to credit. If borrowers respond by holding less debt, there will be less of a need for debt relief and bankruptcy filings may fall.

In addition to ambiguous theoretical predictions, a body of literature examining the impact of exemptions finds conflicting empirical results. Within structural models of borrowing and default, Athreya (2006), Pavan (2008), and Mankart (2014) find that generous exemptions cause bankruptcies to rise, while Li and Sarte (2006) and Mitman (2015) find that the reduction in credit supply causes bankruptcies to fall. In reduced-form analysis using statelevel variation in exemptions, several papers find that higher exemptions increase bankruptcies (White, 1987, Hynes, 1998, Lehnert and Maki, 2002, Edmiston, 2006), while others find that bankruptcies were unaffected or fall (Buckley and Brinig, 1998, Weiss, Bhandari, and Robins, 2000, Lefgren and McIntyre, 2009). The research is summarized in Dawsey, Hynes, and Ausubel (2013) as having "failed to establish a clear link between property exemptions and the bankruptcy filing rate."

This paper uses more recent and more detailed data on bankruptcies and a stronger empirical strategy to provide clear evidence that higher exemptions increase bankruptcy filings. My empirical strategy differs from the earlier papers in four ways. First, most

\footnotetext{
${ }^{1} 2014$ BAPCPA report tables 1A and 1D (AOUSC, 2014).
} 
earlier work has relied on cross-sectional variation in exemption laws. ${ }^{2}$ In contrast, I exploit over 100 changes in states' exemption levels between 1991 and 2014 to identify the effect of exemptions from variation within a state, allowing me to control for time-invariant state characteristics that could confound cross-sectional results. Second, I estimate the effect using both state-level bankruptcy filings and a sample of contiguous county-pairs. The countypairs form a better comparison group by isolating variation in exemptions within neighboring counties. Third, I estimate event study regressions that can detect pre-existing trends in bankruptcies, as well as differences between the short-run and long-run impact of raising exemptions. Finally, I separately estimate the effect after 2005 to determine whether the Bankruptcy Abuse Prevention and Consumer Protection Act of 2005 (BAPCPA), a major reform of the bankruptcy system, changed the impact of exemptions. In the post-BAPCPA period, I also estimate short-run effect of increasing exemptions using monthly data on bankruptcy filings.

I investigate the effect of exemptions on the bankruptcy filing rate during the preBAPCPA period of 1991-2005 and the post-BAPCPA period of 2006-2014. In the preBAPCPA sample, difference-in-differences estimates show that a $10 \%$ increase in the homestead exemption level raises the bankruptcy filing rate by 2.5-6 bankruptcies per 100,000 individuals (a 0.7-1.8\% increase over the mean). Evaluated at the median exemption increase of $0.4 \log$ points, this translates into a 3-7\% increase in bankruptcy filings. The countypair regressions, which isolate variation in exemptions within contiguous county-pairs that straddle a state border, produce similar estimates. In the post-BAPCPA sample, however, difference-in-differences estimates show little effect of exemptions on bankruptcy filing rates. The estimates from the post-BAPCPA period are smaller in magnitude and statistically

\footnotetext{
${ }^{2}$ There are a few papers that use panel variation in exemptions, but the results in these studies remain inconsistent. Hynes (1998) provides moderate evidence that exemptions increase bankruptcy filings. Lehnert and Maki (2002) also find that exemptions rise, but measure a state's exemption quartile and therefore only identify the effect of changes in exemptions that happen to pass a quartile threshold. Buckley and Brinig (1998) find insignificant or negative effects of exemption increases on bankruptcy filings.
} 
insignificant.

Next, I estimate an event study model to examine changes in bankruptcy filing rates in the years around an exemption increase. This exercise provides an explanation for the difference between the pre- and post-BAPCPA estimates. For the pre-BAPCPA sample, the results show that bankruptcy rates are stable and then rise sharply when exemptions increase. Bankruptcy rates then remain high for at least six years, indicating that the shortrun and long-run effects of an exemption increase are similar. In the post-BAPCPA period, however, the event study estimates show that bankruptcies are declining in the years before an exemption increase. This decline is present even in the county-pair sample. If states that increase exemptions tend to have pre-existing falling bankruptcy rates, then difference-indifferences estimates in the post-BAPCPA period will be biased downward.

These declines prior to exemption increases could reflect either anticipation effects or spurious pre-trends. To help distinguish between the two interpretations, I use monthly data on bankruptcies between 2007 and 2013. Consistent with pre-trends, there is no decline in bankruptcies before an exemption increase once state-specific linear or quadratic trends are included. In the presence of pre-trends, estimates from a shorter window around exemption increases will be less biased. Using two measures of the short-run impact, I find that the effect size is similar to the pre-BAPCPA effect, suggesting that BAPCPA did not alter how bankruptcy filings respond to exemption increases.

The rest of the paper is structured as follows. Section 2.2 reviews the relevant bankruptcy law and discusses previous research on exemptions and bankruptcy filings. Section 2.3 discusses the data and variation in exemptions. Section 2.4 describes the empirical strategy. Section 2.5 reports results for the pre-and post-BAPCPA periods and compares these results to the earlier literature. Section 2.6 concludes. 


\subsection{Bankruptcy Law and Related Work}

\subsubsection{Exemptions in Bankruptcy}

In the United States, $70 \%$ of consumer bankruptcies are filed under Chapter 7 . Under this chapter, exemptions for personal and real property determine the assets that a debtor may keep. Chapter 7 debtors receive an immediate discharge of most unsecured debt, but non-exempt assets are sold and the proceeds are given to creditors. While federal asset exemptions exist, most states have opted out of the federal law to set their own. As of 2014, 46 states have either opted out or offer more lenient state exemptions alongside the federal ones. This generates substantial variation in exemption levels across states.

States sometimes exempt specific items (e.g., wedding rings, burial plots), quantities (e.g., 1 vehicle, 2 swine), or values (e.g., jewelry to $\$ 500$ ). The variety of the exempted items makes it difficult to objectively quantify all of the personal property exemptions (discussed in detail in Hynes (1998)). Instead, I focus only on the homestead exemption, which protects home equity and varies from $\$ 5,000$ in Virginia to an unlimited amount in seven states. Almost all homestead exemptions are for a specific dollar amount of home equity, making them easier to quantify. ${ }^{3}$ Another reason to focus on homestead exemptions is that they are the largest exemption. In 2005 , homestead exemptions averaged $\$ 54,500$, while property exemptions averaged $\$ 6,623 .^{4}$

Exemptions also apply outside of Chapter 7. They apply indirectly in Chapter 13, the other type of consumer bankruptcy. A Chapter 13 debtor keeps all of his assets and instead uses his income to repay a portion of his debt over a three- to five-year repayment plan. If the debtor successfully completes the plan, most of his remaining unsecured debt is then

\footnotetext{
${ }^{3}$ Some states also restrict the lot size. The most common restrictions are that the property must be less than than 0.5-1 acre if in a town and 80-160 acres if outside of a town.

${ }^{4}$ These averages use the coding of property exemptions from Traczynski (2011) and exclude the seven states with unlimited homestead exemptions.
} 
discharged. Exemptions determine the minimum amount that the debtor must repay through the "best interest of creditors" test, which requires that creditors in Chapter 13 receive at least as much as they would from asset sales in Chapter 7. Chapter 13 filers may be required to pay more than the minimum, however, since the terms of the repayment plan depend on court discretion and the filer's financial situation. In most states, asset exemptions also protect debtors outside of bankruptcy when they are sued in state court. In this paper, I do not estimate the effect of exemptions on non-bankruptcy default.

In October 2005, Congress enacted the Bankruptcy Abuse Prevention and Consumer Protection Act (BAPCPA), which encouraged repayment by making it more difficult to file Chapter 7. The main impact of BAPCPA on this research is that its provisions may have altered how bankruptcies respond to changes in exemptions. Here I provide an overview of the major changes of BAPCPA. ${ }^{5}$ First, BAPCPA restricted access to Chapter 7 among high-income borrowers. To be eligible for Chapter 7, the borrower must either earn less than the state median income adjusted for family size (the means test) or have a sufficiently low disposable income after allowed expenses (the repayment test). ${ }^{6}$ Second, BAPCPA increased the total cost of filing for bankruptcy; the out-of-pocket costs for a Chapter 7 increased to $\$ 1,309$, a fifty percent increase (Lupica, 2012).

Third, BAPCPA directly restricted the use of exemptions in some situations. It placed a cap on the use of homestead exemptions for those who recently moved or purchased a home, restricted the use of exemptions for debt arising from criminal or civil sanctions, and allowed the court to check for fraudulent conversions from non-exempt to exempt assets that occurred up to 10 years prior to the bankruptcy filing (Alper, 2007). These restrictions eliminate some forms of strategic response to exemption changes, e.g., moving to a state

\footnotetext{
${ }^{5}$ For a more detailed discussion of BAPCPA, see White (2009).

${ }^{6}$ The household's income minus allowed expenses must be low enough that it cannot repay either $25 \%$ of its unsecured debts or $\$ 10,000$. See 11 U.S. Code 707 - Dismissal of a case or conversion to a case under chapter 11 or 13 .
} 
with generous exemptions before filing. Because of BAPCPA, some debtors are no longer eligible to file Chapter 7, cannot afford to file, or can no longer engage in certain strategic responses. For these reasons, bankruptcies may respond differently to exemption changes in the post-BAPCPA period.

\subsubsection{Related Work}

Studies have consistently found that states with higher asset exemptions have lower loan volumes and higher interest rates. Gropp, Scholz, and White (1997) show that states with generous asset exemptions have higher interest rates, less credit available to low-asset households, and higher loan denial rates. Related research finds that generous exemptions lead to lower credit availability, higher interest rates, and stricter lending terms on small business loans, as well as higher interest rates on unsecured consumer loans (Berkowitz and White, 2004, Berger, Cerqueiro, and Penas, 2011, Severino, Brown, and Coates, 2015). ${ }^{7}$

There is no consensus, however, on how exemptions affect equilibrium bankruptcy filings. Using cross-sectional variation, some have found that higher exemptions increase filings (White, 1987, Agarwal, Liu, and Mielnicki, 2003, Dawsey and Ausubel, 2004, Edmiston, 2006), while others find no effect or a negative effect (Weiss, Bhandari, and Robins, 2000, Lefgren and McIntyre, 2009, Dawsey, Hynes, and Ausubel, 2013). A few papers have estimated the effect using panel variation and difference-in-differences regressions, with Hynes (1998) and Lehnert and Maki (2002) finding mostly positive effects of exemptions on bankruptcies, while Buckley and Brinig (1998) report insignificant or negative effects. Hynes (1998) highlights the sensitivity of the results to changes in the specification, particularly for crosssectional estimates.

Other studies combine data on households' assets with exemption levels. Fay, Hurst, and

\footnotetext{
${ }^{7}$ For mortgages, the results are mixed, with Berkowitz and Hynes (1999) finding no effect and Lin and White (2001) finding that higher exemptions increase denial rates.
} 
White (2002) use data on exemptions, assets, and debt to construct a measure of the financial benefit of bankruptcy and show that those with a greater financial benefit are more likely to file, though the effect of non-exempt assets is insignificant when included separately. Miller (2011), using household data and cross-sectional variation in exemption levels, finds that high-asset households are more likely to file in high exemption states. While not explicitly studying bankruptcies, Dobbie and Goldsmith-Pinkham (2015) examine the role of debtor protections during the Great Recession and find that homeowners whose equity was fully protected by exemptions were more likely to default on non-mortgage debt. These studies suggest that the effect of exemption is not uniform across households, but depends on a household's assets and debts.

There are also several macroeconomic and structural models that highlight the trade-offs between more generous exemption laws and reduced credit supply. Within the models of Li and Sarte (2006) and Mitman (2015), as exemptions increase, the reduced credit supply leads to a lower bankruptcy rate. Oppositely, Athreya (2006) and Pavan (2008) find that higher exemptions increase the bankruptcy rate. In Mankart (2014), raising exemptions leads to additional bankruptcies, but this is only significant when exemptions are low. Focusing on borrowers' debt portfolios, Hintermaier and Koeniger (2016) find that unsecured borrowers optimally choose to hold small amounts of home equity, so homestead exemptions have little effect. These models differ in both how default is modeled and the endogenous responses available to debtors (e.g., labor supply, debt portfolio), which may account for some of the differences in the equilibrium effects of exemptions.

Another strand of work studies the impact of BAPCPA on debtors and credit markets. BAPCPA led to increases in subprime mortgage foreclosures and more default outside of bankruptcy (Li, White, and Zhu, 2011, Albanesi and Nosal, 2015). A few papers exploit the restrictions placed on the use of exemptions as a source of geographic variation in the impact of BAPCPA, finding that BAPCPA led to more home foreclosures, greater credit availability, 
and fewer Chapter 7 bankruptcies (Morgan, Iverson, and Botsch, 2012, Boustanifar, 2015, Cornwell and $\mathrm{Xu}, 2014)$.

This paper adds to the literature by providing clear evidence that higher exemptions lead to more bankruptcies. Using panel variation in exemptions, I control for time-invariant state factors that could bias previous estimates. Additionally, I use contiguous cross-border county-pair and event study specifications to address two other potential sources of bias: unobserved time-varying spatial heterogeneity and state-specific bankruptcy trends. The results can complement structural research by comparing the quantitative predictions of the models to the estimates in this paper. Finally, this paper provides the first estimates of the effect of increasing exemptions on bankruptcies after BAPCPA.

\subsection{Data and Variation in Exemption Levels}

\subsubsection{Data}

The analysis requires data on exemption levels and bankruptcy filings. I collect homestead exemption levels from state statutes and various editions of Elias, Renauer, and Leonard (1996-2013), a popular consumer bankruptcy guide. There is often a one- to three-year lag between when a state changes its homestead exemption and when it is reported in Elias, Renauer, and Leonard (1996-2013). ${ }^{8}$ I establish the correct timing of exemption changes by reviewing state statutes. The exemption data cover 1986-2014. My measure of a state's homestead exemption is the maximum amount available to an unmarried bankruptcy filer under the age of 65 living in the state. ${ }^{9}$ For states that allow individuals to choose between

\footnotetext{
${ }^{8}$ I thank Rich Hynes, Anup Malani, and Eric Posner for their data on exemptions from state statutes prior to 1996.

${ }^{9}$ New York has within-state variation in asset exemption levels beginning in 2011, which I use in the county-level analysis. For the state-level analysis, I use the exemption level of $\$ 75,000$ for the years 2011 2014.
} 
the state and federal exemption, I use whichever is higher. I code states with unlimited homestead exemptions as $\$ 550,000$, the maximum finite exemption level in a state during the period 1991-2014. ${ }^{10}$ Since I estimate the effect of changes in the log of exemption levels, I drop the two states, Delaware and Maryland, that have no homestead exemption during the period.

I focus on nonbusiness Chapter 7 bankruptcy filings, where exemptions apply directly, and report results for Chapter 13 in the appendix. I rely on counts of consumer bankruptcies published by the Administrative Office of the United States Courts to construct two samples of bankruptcy filings. The first sample consists of annual counts of all nonbusiness Chapter 7 bankruptcies filed within each state. The advantage of this sample is that it covers a long period, 1991-2014, and produces estimates of the average effect on state bankruptcy rates.

The second sample consists of contiguous county-pairs that straddle a state border. I use annual county-level bankruptcy filings available from 1999-2013 to construct this sample. ${ }^{11}$ As discussed in more detail in the empirical strategy, the advantage of the county-pair sample is that neighboring counties may form a better control group than randomly chosen states or counties. A particular county will be in the sample multiple times if it shares a border with multiple counties in a neighboring state. The final county-pair sample contains 1,099 unique counties that form 1,126 matched county-pairs.

Since BAPCPA dramatically changed the bankruptcy system, I split the samples into the pre-BAPCPA period (up to 2005) and the post-BAPCPA period (after 2005). Table 2.1 shows descriptive statistics for the sample of state bankruptcy filings. Prior to BAPCPA, there were 3.3 Chapter 7 filings per thousand individuals, and after BAPCPA there were 2.4. The average exemption level (excluding states with unlimited exemptions) is $\$ 44,680$

\footnotetext{
${ }^{10}$ The only unlimited exemption state to change their exemption level during this period was Minnesota, which reduced the exemption from unlimited to $\$ 200,000$.

${ }^{11}$ The county-level counts of nonbusiness Chapter 7 bankruptcies are based on the filer's county of residence. For joint filings, the bankruptcy is marked as the county of residence for the first debtor listed.
} 
$(2010 \$)$ during the pre-BAPCPA period and almost $\$ 70,000$ in the post-BAPCPA period, so the real value of exemptions increased. Table 2.2 shows the same statistics for the countypair sample and, for comparison, statistics for all counties. ${ }^{12}$ Bankruptcies and population in the county-pairs are similar to those for all counties, though the county-pairs over-represent higher exemption states (of those with finite exemptions) and under-represent unlimited exemption states.

\subsubsection{Variation in exemption levels}

There is substantial variation in homestead exemption levels across states. Many studies treat this variation in the exemption levels as exogenous because of the legislative origin of the laws. The laws emerged during the mid-19th century in response to idiosyncratic factors that are unlikely to be related to modern credit markets (Goodman, 1993). While states have since adjusted their exemption levels in response to inflation and changes in household assets, the current exemption levels remain highly correlated with these early levels (Hynes, Malani, and Posner, 2004). Still, there remain concerns that asset exemptions are correlated with other state characteristics affecting bankruptcy filings. For example, Grant and Koeniger (2009) provide evidence that states use exemptions and redistributive taxation as substitute policies.

To overcome the potential endogeneity of the laws, I exploit changes in exemptions within a state over time. Between 1991 and 2014, states changed their exemptions 105 times (53 pre-BAPCPA, 52 post-BAPCPA), with a median change of $\$ 10,000$ (2010\$) or 0.4 log points. Figure 2.1 shows the distributions of the size and frequency of exemption changes during the sample period. Only two states, Minnesota in 1993 and South Carolina in 1996, decreased exemptions. The federal homestead exemption increased to account for inflation in 1994

\footnotetext{
${ }^{12}$ The all counties sample excludes counties in Delaware, Maryland, or Washington D.C.
} 
and every three years since 1998, causing a higher than average number of changes for those years. Panel (a) of Figure 2.2 shows the geographic distribution of exemption changes. Only eleven states (seven of which have unlimited exemptions) did not change their exemption levels. Panel (b) shows the 999 county-pairs that experience at least one exemption change between 1999 and 2014.

\subsection{Empirical Strategy}

The effect of increasing exemptions on bankruptcy rates could be either positive or negative. While the direct effect of increasing the homestead exemption is to make bankruptcy more attractive for debtors with non-exempt home equity, the equilibrium response of credit markets or debt portfolios could offset this direct effect. This paper uses changes in homestead exemptions within states to estimate the effect of increasing exemptions on equilibrium bankruptcy rates.

First, I estimate standard difference-in-differences regressions that include state and year fixed effects. For state $s$ at time $t$, the regressions take the following form:

$$
b_{s t}=\alpha+\eta \ln \left(E_{s t}\right)+\delta_{s}+\tau_{t}+u_{s t},
$$

where $b_{s t}$ is the number of nonbusiness Chapter 7 bankruptcies per thousand individuals, $\ln \left(E_{s t}\right)$ is the $\log$ of the homestead exemption, and $u_{s t}$ is the error term. I use the log of exemptions rather than the exemption value because fewer borrowers are affected by increases as the exemption level rises. For example, a marginal increase of the $\$ 500,000$ homestead exemption in Massachusetts will affect few borrowers, while a marginal increase in Virginia's $\$ 5,000$ exemption will affect many. ${ }^{13}$ The coefficient $\eta$ captures the effect of exemptions

\footnotetext{
${ }^{13}$ Another advantage of using the log of exemptions is that some states allow married couples to double the exemptions, and the coefficients on $\ln \left(E_{s t}\right)$ will not change if exemptions are doubled in all years.
} 
on the equilibrium bankruptcy rate. If $\eta>0$, it implies that borrowers respond to higher exemptions by filing more bankruptcies, and this dominates any offsetting responses of credit markets or debt portfolios.

I include state fixed effects $\left(\delta_{s}\right)$ and year fixed effects $\left(\tau_{t}\right)$ in all specifications. As additional controls for spatial heterogeneity, in some specifications I add division-year fixed effects for the nine Census divisions, state-specific linear time trends, or controls for state economic conditions. The economic controls consist of the log of state median income, the 25th percentile of the state log income distribution, the log of the Federal Housing Finance Agency (FHFA) home price index, and the state unemployment rate. ${ }^{14}$

One concern is that economic conditions vary geographically, possibly in unobservable ways, and these differences might be correlated with changes in exemptions. The second set of regressions uses the sample of contiguous county-pairs, which form a better comparison group in the presence of unobserved spatial heterogeneity. When a state increases its exemption level, the state-level difference-in-differences regression in equation (2.1) treats all other states as equally suitable comparisons. The county-pair specification, following the strategy used in Dube, Lester, and Reich (2010) to study the minimum wage, relies only on neighboring counties to form the comparison group. As long as neighboring counties are more similar on unobservable characteristics than two randomly chosen states, the county-pairs will better control for unobserved spatial heterogeneity.

The county-pair specification isolates variation in exemptions between these cross border county-pairs by including pair-specific year fixed effects $\left(\tau_{p t}\right)$ :

$$
b_{c p t}=\alpha+\eta \ln \left(E_{c t}\right)+X_{c t} \beta+\delta_{c}+\tau_{p t}+u_{c p t},
$$

\footnotetext{
${ }^{14}$ The median income is from the Census Bureau, the 25th percentile of the log income distribution is from the Current Population Survey, the home price index is from the Federal Housing Finance Agency, and the unemployment rate is from the Bureau of Labor Statistics.
} 
where $b_{c p t}$ is the bankruptcy filing rate (per thousand) in county $c$ of county-pair $p$ in year $t$. The county controls $X_{c t}$ include the county unemployment rate and the log of county median income. ${ }^{15}$ All specifications include county fixed effects $\left(\delta_{c s}\right)$ and year $\left(\tau_{t}\right)$ fixed effects.

OLS standard errors in both the state and county specifications are potentially subject to bias from serial correlation in bankruptcies. Standard errors in county-level regressions may be biased downward since errors are likely correlated within a state and the exemption level is the same for all counties within a state-year. Additionally, since the county-pair sample can include a single county multiple times, there will be a mechanical correlation in the errors. For these reasons, I cluster standard errors at the state-level in all regressions. Since bankruptcy rates of larger states and counties are generated from more individuallevel decisions to file bankruptcy and changes in these areas affect more people, I weight each observation by population. I report unweighted results in the appendix. ${ }^{16}$

The identifying assumption in these difference-in-differences regressions is the parallel trends assumption: in the absence of an exemption increase, bankruptcy rates in the treatment states and counties (those that change exemptions) would have been parallel to those in the control states and counties. To support this assumption, I estimate differences in bankruptcy rates between treatment and control states or counties in the years before an exemption increase using an event study specification. This specification also allows the effect of exemptions to vary over time, providing evidence about short-run and long-run differences.

Since states have multiple exemption increases during the sample period and the lagged impact of these increases may overlap, a standard event study specification is not appropriate. I use a multiple event study specification, following Dube, Lester, and Reich (2010) and

\footnotetext{
${ }^{15}$ The unemployment rate is from the Bureau of Labor Statistics Local Area Unemployment Statistics, median income is from the Census Small Area Income and Poverty Estimates.

${ }^{16}$ State observations are weighted by the contemporaneous population in the state. County-level observations are weighted by the average population in that county during the sample period.
} 
Sandler and Sandler (2014), that allows events to overlap. For state $s$ in year $t$, I estimate a regression that includes six leads and lags for each exemption increase:

$$
b_{s t}=\alpha+\sum_{k=-6}^{5}\left(\eta_{k} \Delta \ln \left(E_{s, t-k}\right)\right)+\eta_{6} \ln \left(E_{s, t-6}\right)+X_{s t} \beta+\delta_{s}+\tau_{t}+u_{s t} .
$$

I estimate a similar specification for the county-pair sample, which also includes pair-specific year fixed effects. For county $c$ in pair $p$ at time $t$, the regression takes the form:

$$
b_{c p t}=\alpha+\sum_{k=-6}^{5}\left(\eta_{k} \Delta \ln \left(E_{c, t-k}\right)\right)+\eta_{6} \ln \left(E_{c, t-6}\right)+X_{c t} \beta+\delta_{c}+\tau_{p t}+u_{c p t} .
$$

In these regressions, $\Delta$ is a one-year difference operator. Using the difference operator produces coefficients $\eta_{k}$ that capture the cumulative effect of a log point increase in the exemption level on bankruptcy rates $k$ years later. For example, if the exemption increased in a state during 2000, $\eta_{3}$ captures the effect of that increase on bankruptcies in 2003, while $\eta_{-3}$ captures the pre-existing difference in bankruptcies in 1997. If changes in exemptions are exogenous to the bankruptcy rate, treatment and controls states should have similar bankruptcy rates prior to an exemption increase and the lead coefficients $\eta_{-6}, \ldots, \eta_{-1}$ will be zero. The lag terms $\eta_{0}, \ldots, \eta_{5}$ capture the impact on bankruptcy rates during the six years after an exemption increase. Since $\eta_{6}$ does not use the difference operator, it captures the average effect on bankruptcy rates after the first six years. The economic controls $X_{s t}$ and $X_{c t}$ are the same controls from the difference-in-differences regressions. For the preBAPCPA sample, I use changes in exemptions between 1985-2011 so that each state has a full set of leads and lags. In order to maintain a full set of leads and lags, the post-BAPCPA sample is limited to 2006-2011 and includes just three years of leads and lags. ${ }^{17}$

\footnotetext{
17 The latest exemption data are for 2014. Estimating the effect in year t-3 requires that the sample stop in 2011, so that each observation has three years of future exemption changes.
} 


\subsection{Results}

\subsubsection{Main Results}

This section reports the estimates of the effect of exemptions before and after BAPCPA. The pre-BAPCPA estimates, reported in Table 2.3, are positive in all specifications and range between 0.25 and 0.56 . These magnitudes imply that a $10 \%$ increase in asset exemptions raises the bankruptcy rate by $0.025-0.056$ bankruptcies per thousand individuals. With a mean bankruptcy rate of 3.3, these estimates imply that a median-sized exemption change of $0.4 \log$ points increases bankruptcy rates by $3-7 \%$.

Columns 1-4 report estimates from the state sample, varying the controls for economic conditions and spatial heterogeneity. ${ }^{18}$ Column 1, which includes only state and year fixed effects as controls, produces a positive but insignificant estimate of the effect of exemptions. ${ }^{19}$ To control for time-varying spatial heterogeneity, column 2 allows separate year fixed effects for the nine Census divisions. The estimated effect of exemptions increases to 0.56 and is significant at the $1 \%$ level. In column 3 , state economic controls replace the division-year fixed effects and the estimate remains significant. The similarity of the estimates in columns 2 and 3 suggests that the division-year fixed effects may simply be controlling for differences in economic conditions. When state trends are included in column 4, the effect decreases in magnitude, but remains significant.

Columns 5-7 report results from the sample of county-pairs. To gauge the importance of time-varying spatial heterogeneity, I estimate three specifications on the county-pair sample. Column 5 includes only county fixed effects, controls for county economic conditions, and

\footnotetext{
${ }^{18}$ Results for Chapter 13 bankruptcies, reported in Appendix Table 2.A.1, are small and insignificant. Unweighted results, reported in Appendix Table 2.A.2, are positive and significant, though slightly smaller than the population-weighted estimates.

${ }^{19}$ Appendix Table 2.A.3 shows that the imprecision in column 1 is mostly caused by differences in house price growth, as the effect in column 1 becomes significant at the $10 \%$ level when only the house price index is added as a control. Additionally, the estimate from the specification in column 1 becomes significant when the housing "boom" period of 2000-2005 is dropped.
} 
year fixed effects. Column 6 adds division-year fixed effects so that estimates are based only on variation within a Census division. Finally, column 7 estimates the county-pair regression in equation (2.2), which includes pair-specific year fixed effects so that the estimates are based on variation within county-pairs. The similarity of the estimates in the three specifications, as well as their similarity to the state-level estimates in columns 2-3, suggests that even coarse controls, such as state economic conditions, adequately correct for time-varying spatial heterogeneity. Overall, Table 2.3 shows that an increase in exemptions raises the bankruptcy filing rate.

In contrast, the estimates from the post-BAPCPA period, reported in Table 2.4, suggest that exemptions have little effect on bankruptcies. Compared to the pre-BAPCPA estimates, the post-BAPCPA estimates are smaller in magnitude, sometimes negative, and not statistically different from zero. Only the estimate in column 4, which includes state-specific linear time trends, is similar in magnitude to the corresponding pre-BAPCPA estimate.

The event study results offer an explanation for the difference between pre- and postBAPCPA estimates. Figure 2.3 presents the coefficients on the lead and lag terms for the state and county event study specifications in equations (2.3) and (2.4), along with $95 \%$ confidence intervals. ${ }^{20}$ The estimates capture differences in bankruptcy rates between treatment states (those that increase exemptions) and control states during a 6-year window around an exemption increase in year t. I report the full set of coefficients and standard errors in Appendix Table 2.A.4.

Panel (a) of Figure 2.3 presents the pre-BAPCPA estimates for the coefficients on the leads and lags from the state-level specification. Consistent with the identification strategy, the small and statistically insignificant lead terms reflect similar pre-trends in the treatment and control states. The same pattern holds in panel (b), which shows estimates from the

\footnotetext{
${ }^{20}$ I present the corresponding figure for unweighted regressions in Appendix Figure 2.A.1. The long-run effect in the pre-BAPCPA period is somewhat sensitive to weighting. The unweighted county results are similar to the weighted results, but with larger standard errors.
} 
county-pair specification. Both the state and county-pair results show an immediate increase in bankruptcies during year t, the exact year of the exemption increase. The higher bankruptcy rates persist for at least six years, suggesting that contemporaneous and long-run effects are similar.

In contrast, the post-BAPCPA estimates of panels (c) and (d) show a statistically significant decline in bankruptcies prior to an exemption increase, which could explain the small estimates in the difference-in-differences regressions. If, after BAPCPA, bankruptcy rates are falling in the states that increase exemptions, the estimated effect of exemptions will be biased downward. There is, however, another interpretation for this decline: anticipation effects. In the next section, I examine monthly changes in bankruptcies and demonstrate that the data are consistent with pre-trends, but not anticipation effects.

\subsubsection{Impact of Exemptions After BAPCPA: Monthly Data}

This section uses monthly bankruptcy filings to investigate the decline in bankruptcies prior to an exemption change that is evident in the post-BAPCPA event study regressions. If caused by anticipation effects, the decline would be largest in the months before exemptions increase, since it is easier to delay a bankruptcy for a shorter period. Moreover, uncertainty about house prices makes it difficult to predict home equity far in advance. Finally, an obvious source of possible anticipation effects is the delay between when an exemption increase is passed and when it goes into effect. This delay is commonly less than 90 days.

To examine bankruptcy rates in the months before an exemption increase, I estimate an event study specification using monthly bankruptcy data from 2007 to 2013 and information on the month that exemption increases took effect. ${ }^{21}$ For state $s$ in month $t$, the event study

\footnotetext{
${ }^{21}$ The monthly bankruptcy data are from the F2 Tables available from the Administrative Office of the State Courts. The earliest available data are for 2007. I determine the month that the exemption changes go into effect from state legislative records.
} 
specification includes 12 months of leads and lags and takes the following form:

$$
b_{s t}=\alpha+\sum_{k=-12}^{11}\left(\eta_{k} \Delta \ln \left(E_{s, t-k}\right)\right)+\eta_{12} \ln \left(E_{s, t-12}\right)+X_{s t} \beta+\delta_{s}+\tau_{t}+u_{s t},
$$

where the dependent variable $b_{s t}$ is the monthly bankruptcy filing rate in state $s$ in month $t$, multiplied by 12 so that the coefficients can be compared to the annual estimates. $\Delta$ is a one-month difference operator. The coefficients $\eta_{k}$ for $k=-12, \ldots, 11$ capture the effect of an exemption change on bankruptcy rates $k$ months after the change. Since there is no difference operator on $\ln \left(E_{s, t-12}\right)$, the coefficient $\eta_{12}$ captures the average effect after the first year. The controls $X_{s t}$ consist of the monthly state unemployment rate, the log of the quarterly FHFA seasonally-adjusted house price index, the annual log of state median income, and the 25 th percentile of the log income distribution. I also include state $\left(\delta_{s}\right)$ and time fixed effects $\left(\tau_{t}\right)$. In some specifications, I add state-specific linear and quadratic time trends.

The full set of coefficients on the leads and lags, along with $95 \%$ confidence intervals, are shown in Figure 2.4. All three specifications in the figure show an increase in bankruptcies during month $t$, the exact month that exemptions increase. As with the annual estimates of the last section, the lead terms in panel (a) are negative, reflecting lower bankruptcy rates in the year prior to an exemption increase.

The pattern of bankruptcy rates is more consistent with pre-trends than anticipation effects. Although panel (a) shows that bankruptcy rates decline before an exemption increase, the decline is not concentrated in the few months before the exemption increase. Moreover, panels (b) and (c) show that, once controls for state-specific trends are included, there is no decline in bankruptcies in the year before an exemption increase.

Short-run estimates of the effect in the months around an exemption increase will be less biased by underlying trends. The first rows of Table 2.5 offer two measures of the short- 
run effect: a one-month difference $\left(\eta_{0}-\eta_{-1}\right)$ and a two-year difference $\left(\eta_{11}-\eta_{-12}\right)$. The one-month difference, which compares bankruptcy rates one month before an exemption increase to the first month after, is $0.39-0.41$ and significant at the $1 \%$ level in all three specifications. The two-year difference compares the bankruptcy rate twelve months before an exemption increase to the bankruptcy rate twelve months after the increase. The twoyear differences are similar to the one-month differences, range from 0.36 to 0.68 , and remain statistically significant. The similarity of the one-month and two-year estimates provides further evidence against anticipation effects. Finally, the coefficient $\eta_{12}$ captures the average effect on bankruptcy rates after the first year. This estimate is more susceptible to bias from pre-existing trends and, as expected, is sensitive to the inclusion of linear or quadratic state trends in columns 2 and 3.

Overall, the results using monthly data are consistent with underlying state-specific trends biasing difference-in-differences estimates downward during the post-BAPCPA period. Short-run estimates, which are less influenced by state trends, show an effect of 0.36-0.68. These effect sizes are very similar to the pre-BAPCPA estimates, suggesting that BAPCPA did not alter how bankruptcy filings respond to exemption increases.

\subsubsection{Comparison with Cross-Sectional Estimates}

This paper provides evidence that higher exemptions raise bankruptcy rates. To compare my estimates with the earlier findings in the literature, particularly those using cross-sectional variation, Table 2.6 shows the sensitivity of the pre-BAPCPA state-level results to the source of variation. Columns 1 and 2 of Table 2.6 compare the difference-in-differences (DD) estimate to a pooled cross-sectional estimate by running regressions with and without state fixed effects. Rather than assigning unlimited exemptions an arbitrary value, I include an unlimited exemption indicator and set the log of exemptions equal to zero for unlimited 


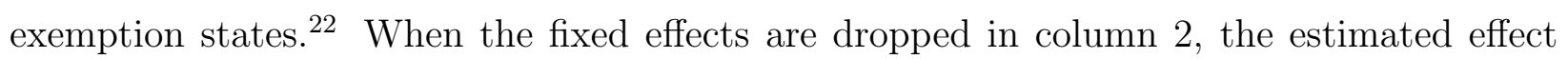
becomes negative, smaller in magnitude, and insignificant.

One possible explanation for the difference between DD and cross-sectional estimates is that short-run and long-run effects of exemptions differ, since cross-sectional results reflect the long-run effect. The pre-BAPCPA event study results, however, show that the contemporaneous and lagged effects are similar through the first six years. Another possible explanation is that the difference is due to heterogeneity between low and high exemption states. The DD regressions identify the effect in states that change exemptions, which tend to be those with lower exemption levels; I only observe one change involving an unlimited exemption state. Columns 3 and 4 show that the DD and cross-sectional estimates are different even in a sample of only low exemption states. Restricting the sample to states with 2005 exemptions less than $\$ 60,000$, the difference between DD and cross-sectional estimates remains.

The sharp effects found in the DD analysis become small and insignificant when state fixed-effects are removed. The sensitivity of the results do not seem to be explained by two plausible sources of heterogeneity in the effect of exemptions: short-run vs. long-run and low vs. high exemption states. This suggests state fixed effects may capture important, time-invariant state characteristics that are correlated with asset exemption levels and affect the bankruptcy filing rate.

\subsection{Discussion and Conclusion}

Using changes in exemptions within states as a source of exogenous variation, this paper provides causal evidence that raising homestead exemptions increases bankruptcy filings. I

\footnotetext{
${ }^{22}$ In the regressions with state fixed effects, the coefficient on the unlimited indicator is identified entirely from the one change in a state's unlimited exemption status: Minnesota in 1993.
} 
estimate the effect of exemptions before and after the 2005 Bankruptcy Abuse Prevention and Consumer Protection Act (BAPCPA). In the pre-BAPCPA period, a 10\% increase in the exemption level causes a $0.7-1.8 \%$ increase in a state's bankruptcy filing rate. These estimates imply that a median-sized exemption increase of $0.4 \log$ points raises bankruptcy rates by $3-7 \%$. Event study analysis shows that the increase in bankruptcies persists for at least six years, so it is not temporary. In the post-BAPCPA period, the states that increase exemptions tend to have falling bankruptcy rates, which biases difference-in-differences estimates downward. Using short-run estimates from monthly data, which are less susceptible to bias from underlying trends, I find that the post-BAPCPA effect is similar in magnitude to the pre-BAPCPA effect.

That exemptions increase bankruptcy rates has implications for exemption policy. First, if policymakers seek to reduce Chapter 7 bankruptcies, as they sought to with BAPCPA, lowering exemption levels would be an effective tool. Second, the behavioral response of borrowers makes exemption protection more costly, relative to a world where borrowers do not respond. Generous exemptions cause more people to file, resulting in greater losses to creditors and, potentially, larger changes in the supply and price of credit. Finally, these results help explain how borrowers make bankruptcy filing decisions. The positive effect of exemptions shows that at least some borrowers respond strategically to the financial benefit of bankruptcy. 
Table 2.1: Summary Statistics for the State Sample

\begin{tabular}{lcccc}
\hline & mean & s.d. & min. & max. \\
\hline Pre-BAPCPA Sample: 1991-2005 & & & & \\
Chapter 7s per 1,000 & 3.3 & 1.4 & .63 & 10 \\
Homestead exemption, 2010\$ & 44,680 & 65,473 & 5,583 & 577,173 \\
Share with unlimited exemption & .18 & .38 & 0 & 1 \\
Observations & 720 & & & \\
& & & & \\
Post-BAPCPA Sample: 2006-2014 & & & & \\
Chapter 7s per 1,000 & 2.4 & 1.3 & .37 & 8.1 \\
Homestead exemption, 2010\$ & 69,629 & 104,578 & 4,605 & 578,420 \\
Share with unlimited exemption & .19 & .39 & 0 & 1 \\
Observations & 432 & & & \\
\hline
\end{tabular}

Observations are weighted by population. The mean and standard deviation of the homestead exemption are for states without unlimited exemption levels. 
Table 2.2: Summary Statistics for the County-Pair Sample

\begin{tabular}{lccccc}
\hline & \multicolumn{2}{c}{ County-Pairs } & & \multicolumn{2}{c}{ All Counties } \\
\cline { 2 - 3 } & mean & s.d. & & mean & s.d. \\
\hline & & & & \\
Pre-BAPCPA Sample: 1999-2005 & & & & \\
Chapter 7s per 1,000 & 4 & 1.8 & & 3.8 & 1.8 \\
Homestead exemption, 2010\$ & 65,947 & 110,147 & 49,002 & 78,399 \\
Share with unlimited exemption & .08 & .27 & & .18 & .39 \\
& & & & \\
Post-BAPCPA Sample: 2006-2013 & & & & \\
Chapter 7s per 1,000 & 2.6 & 1.6 & & 2.5 & 1.5 \\
Homestead exemption, 2010\$ & 104,423 & 161,117 & 70,476 & 105,485 \\
Share with unlimited exemption & .081 & .27 & & .19 & .39 \\
& & & & \\
Population, 2000 & 80,199 & 210,678 & 88,428 & 293,560 \\
Number of counties & 1,099 & & & 3,100 & \\
Number of county-pairs & 1,126 & & & \\
Number of states & 46 & & & 48 & \\
\hline
\end{tabular}

Observations are weighted by population. The mean and standard deviation of the homestead exemption are for states without unlimited exemption levels. 


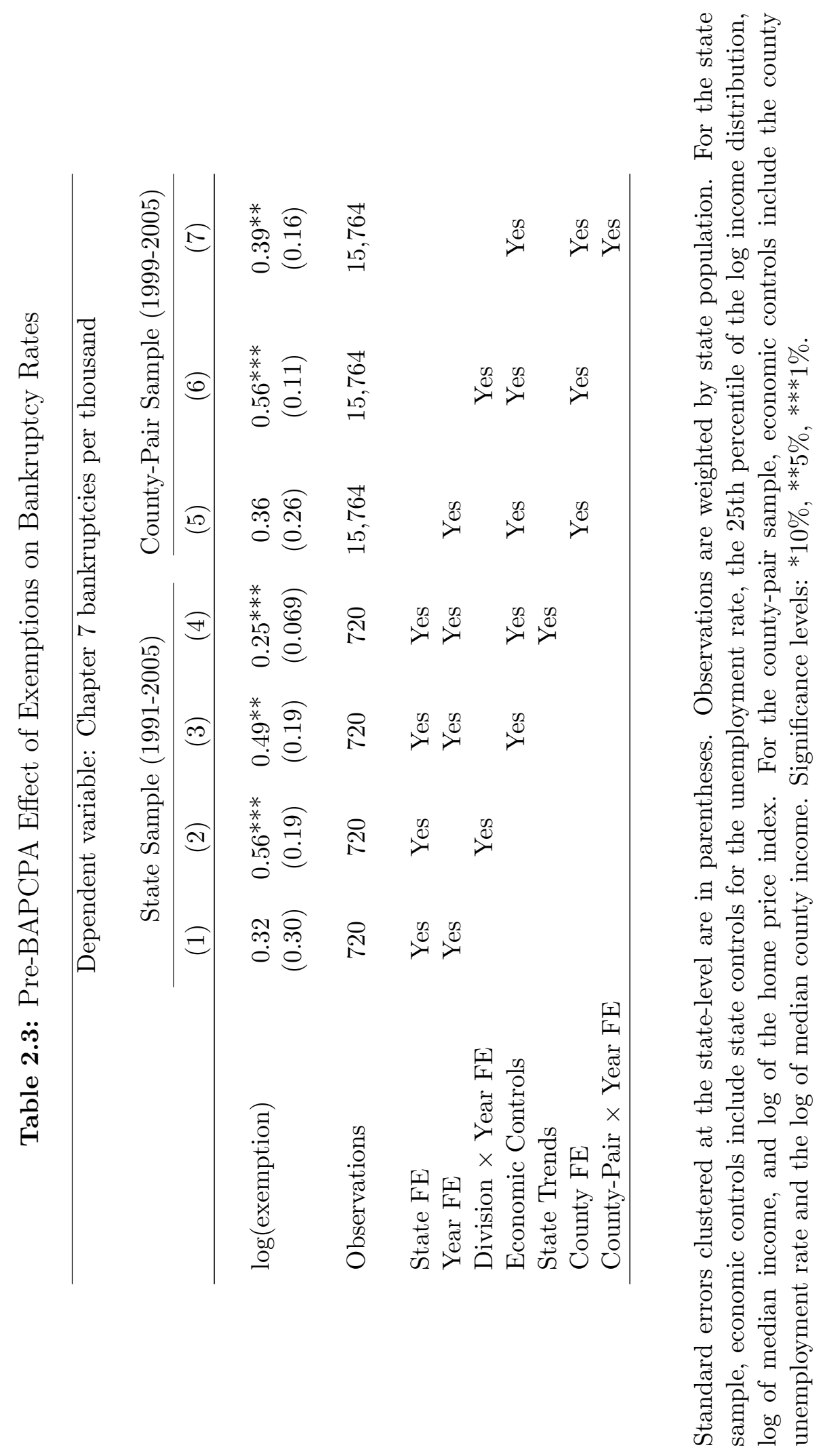




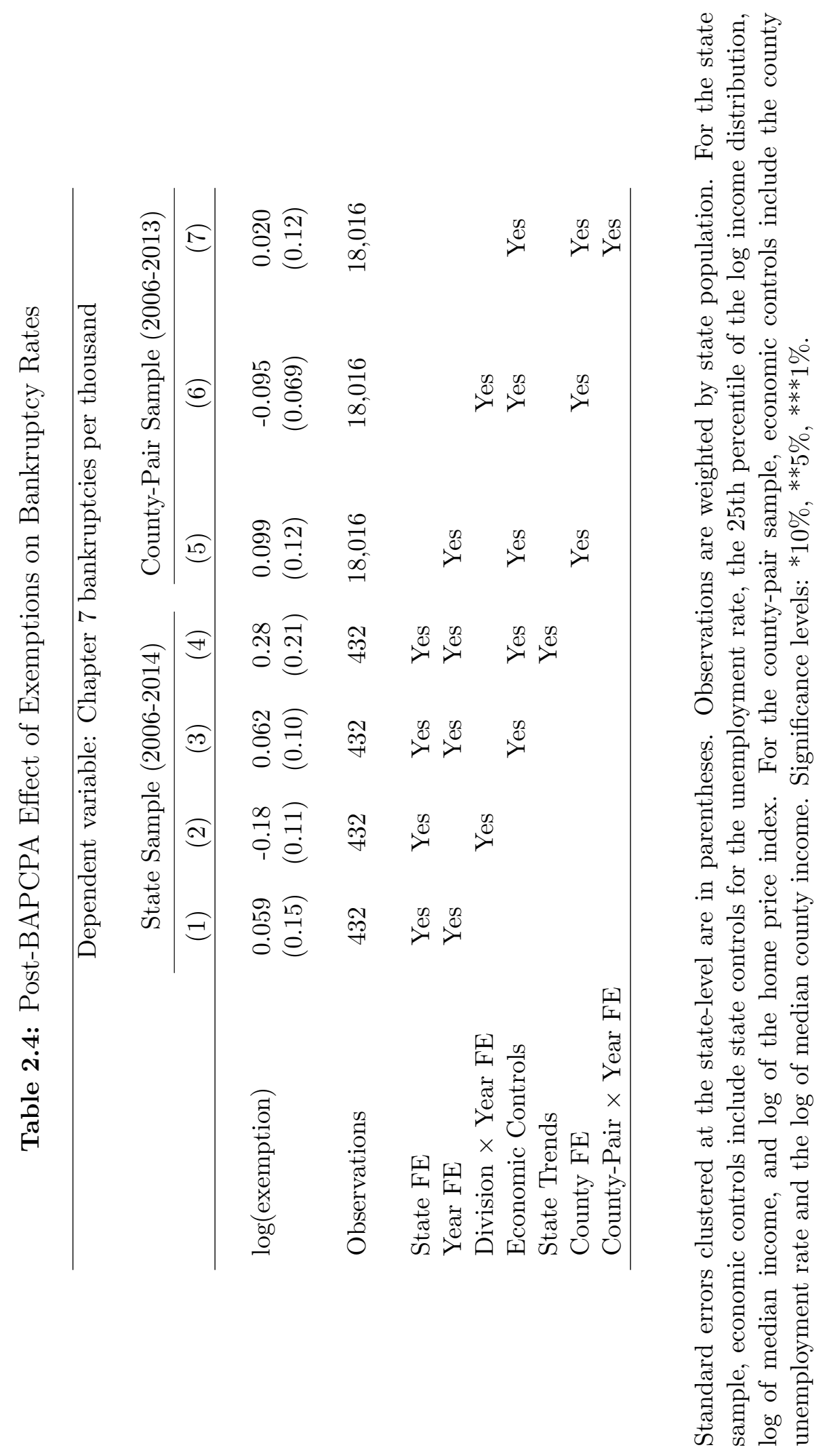


Table 2.5: Post-BAPCPA Estimates using Monthly Data

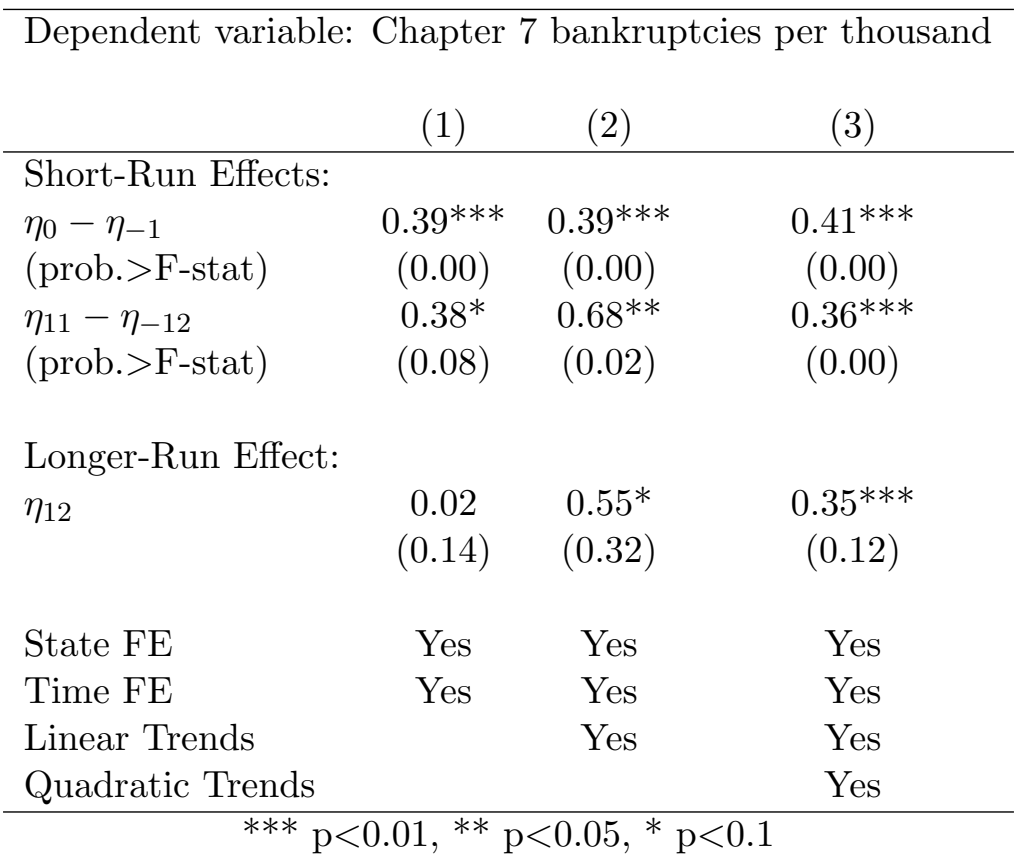

The sample size consists 4,032 annualized monthly state-level bankruptcy filing rates (per thousand) for 2007-2013. Standard errors are clustered at the state level. For the short-run estimates, probability values are reported for a test under the null hypothesis that the difference in coefficients is zero. Observations are weighted by population. All specifications include monthly state unemployment rate, the log of the FHFA quarterly seasonally adjusted house price index, state fixed effects, and time fixed effects. Significance levels: $* 10 \%, * * 5 \%, * * * 1 \%$. 
Table 2.6: Comparison with Cross-Sectional Estimates

\begin{tabular}{lcccc}
\hline & \multicolumn{3}{c}{ Dependent variable: Chapter 7 bankruptcies per thousand } \\
& & & \multicolumn{2}{c}{ Low Exemption States Only } \\
\cline { 4 - 5 } & DD & Cross-sectional & DD & Cross-sectional \\
& $(1)$ & $(2)$ & $(3)$ & $(4)$ \\
\hline \multirow{3}{*}{$\log ($ exemption $)$} & $0.49^{* *}$ & -0.037 & $0.73^{* *}$ & 0.033 \\
& $(0.20)$ & $(0.13)$ & $(0.31)$ & $(0.19)$ \\
unlimited & $6.33^{* *}$ & -1.03 & 4.25 & -0.33 \\
& $(2.39)$ & $(1.44)$ & $(2.70)$ & $(1.84)$ \\
State FE & $\mathrm{X}$ & & & \\
Observations & 720 & 720 & 540 & 540 \\
\hline
\end{tabular}

Standard errors clustered at the state-level are in parentheses. Observations are weighted by population. All specifications include year fixed effects and state controls for the unemployment rate, the 25 th percentile of the log income distribution, log of median income, and log of the home price index. The low exemption state sample in columns 3-4 drops all states with an exemption level above $\$ 60,000$ in 2005 . Significance levels: $* 10 \%, * * 5 \%, * * * 1 \%$. 


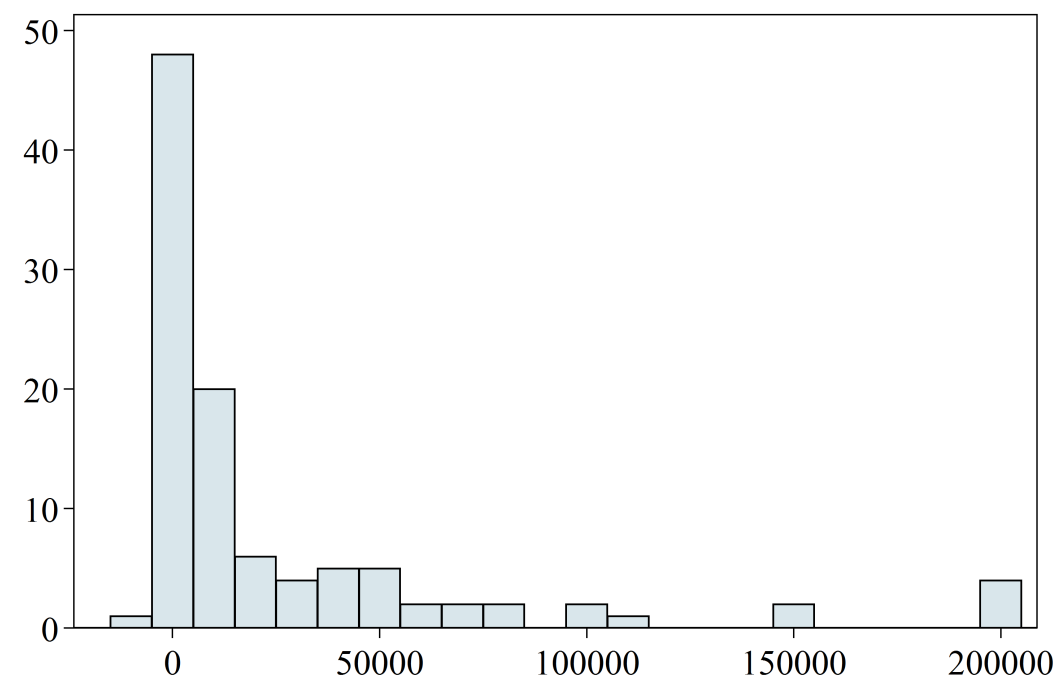

(a) Size of Exemption Changes

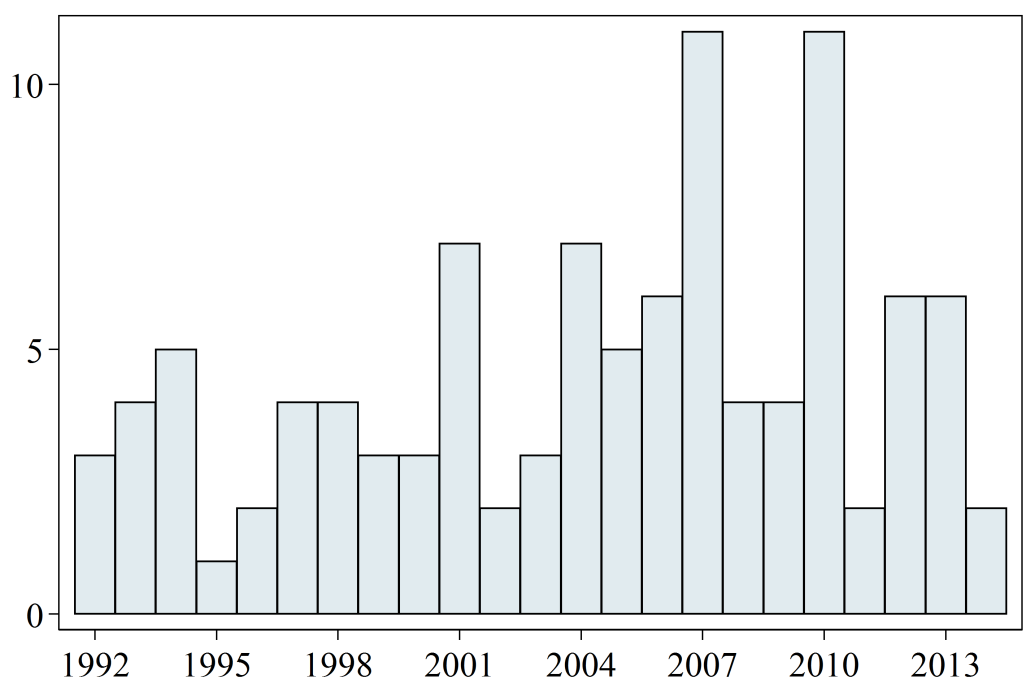

(b) Number of Exemption Changes Each Year

Figure 2.1: Distributions of the size and number of changes in homestead exemptions from 1991-2014. Panel (a) does not show the change in Minnesota in 1993, when the homestead exemption was reduced from unlimited to $\$ 200,000$. 


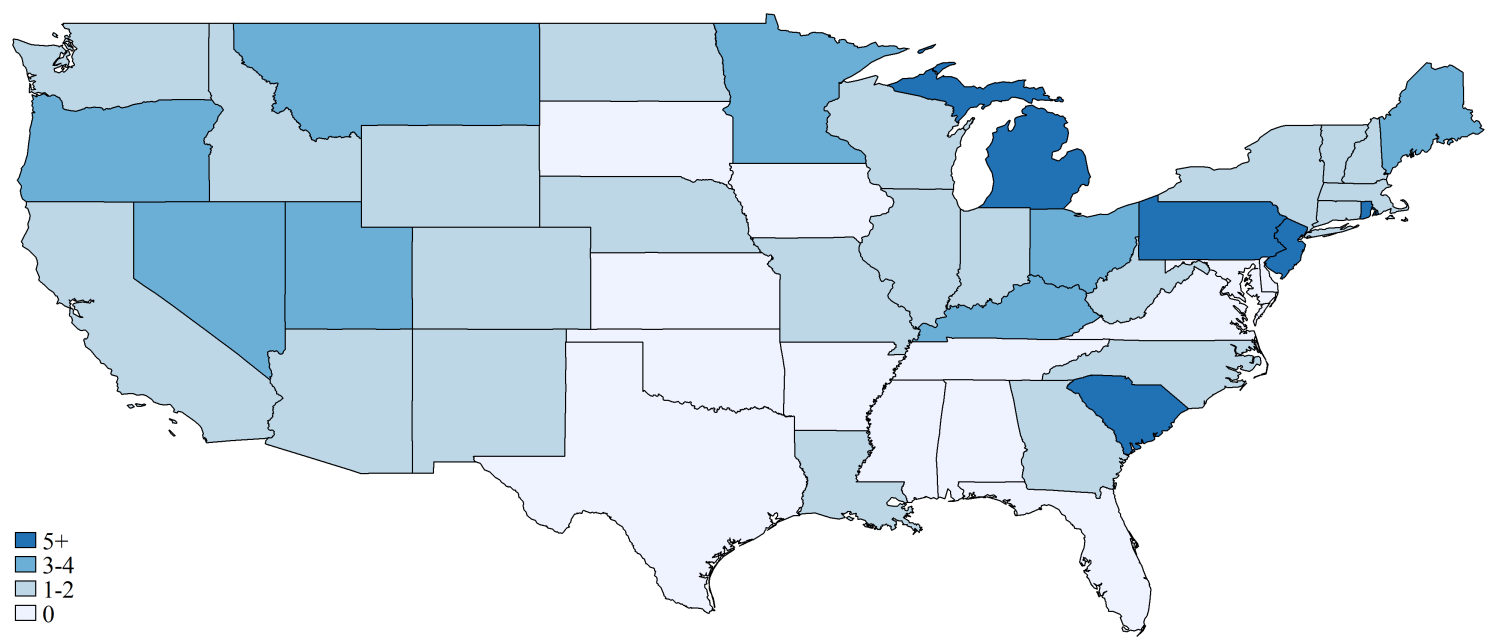

(a) Number of Exemption Changes by State (1991-2014)

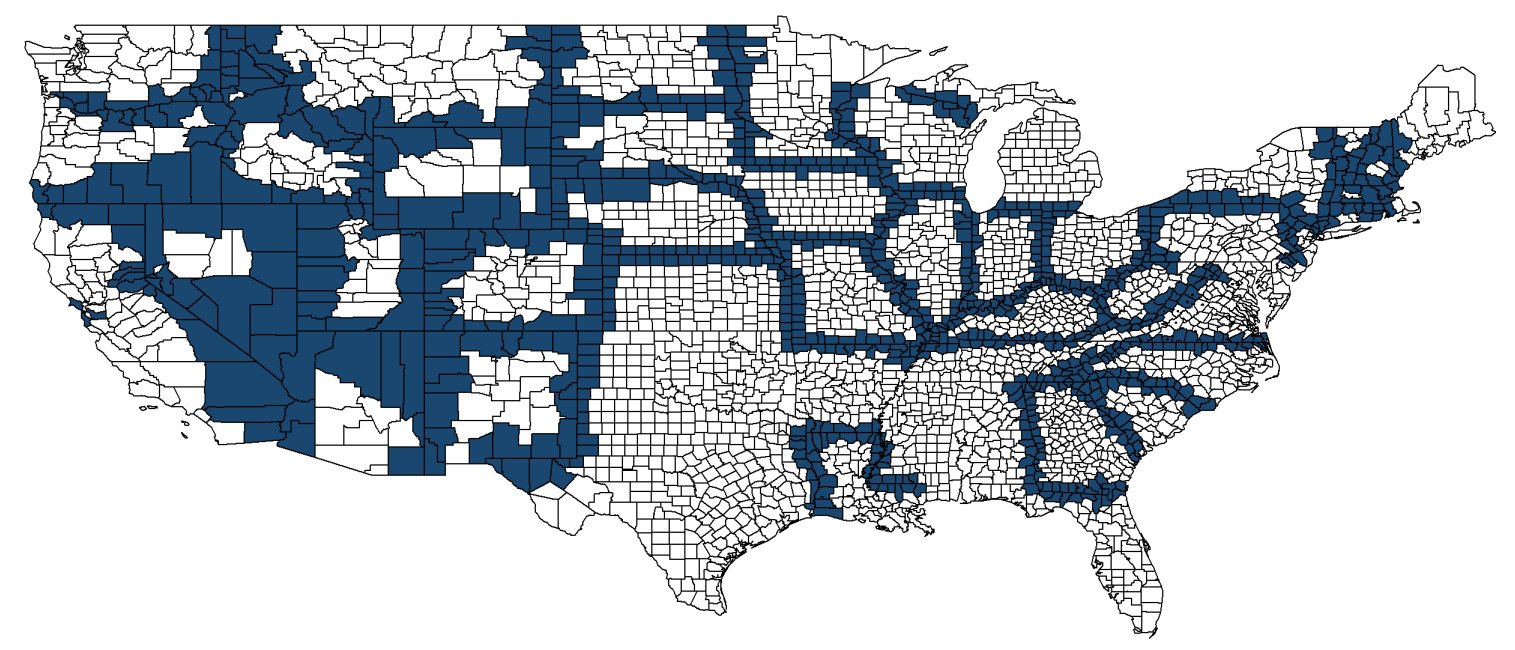

(b) Contiguous County-Pairs with an Exemption Change (1999-2013)

Figure 2.2: Maps of Exemption Changes 


\section{Pre-BAPCPA}

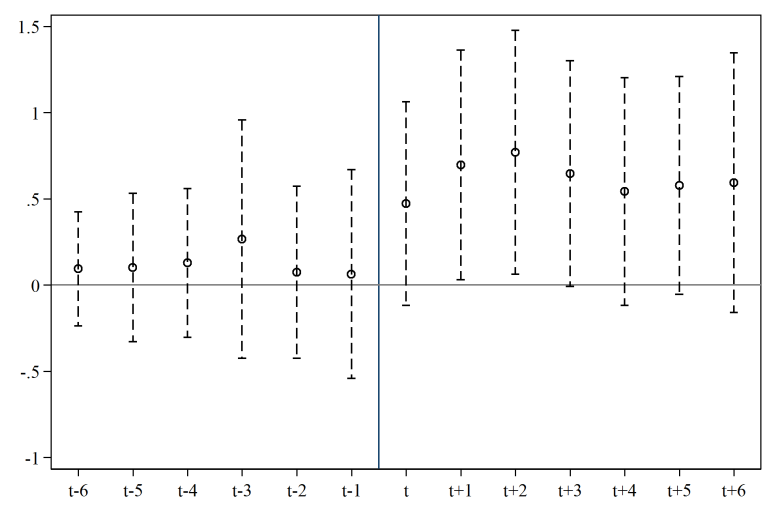

(a) States (1991-2005)

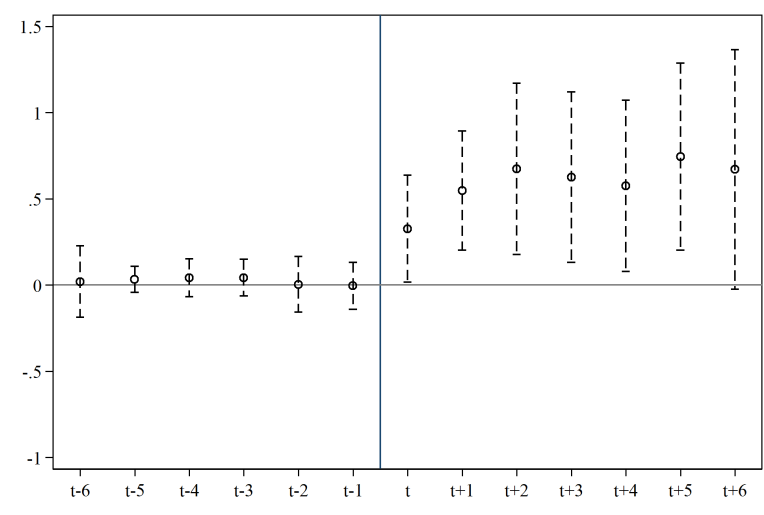

(b) County-Pair (1999-2005)

Post-BAPCPA

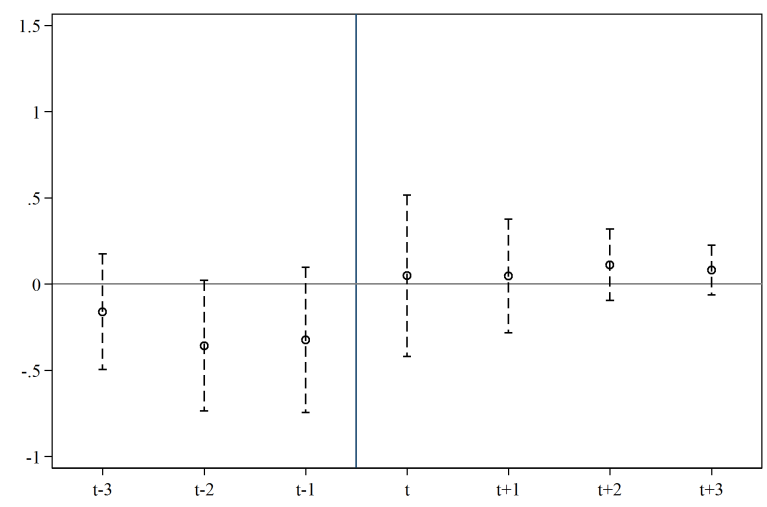

(c) States (2006-2011)

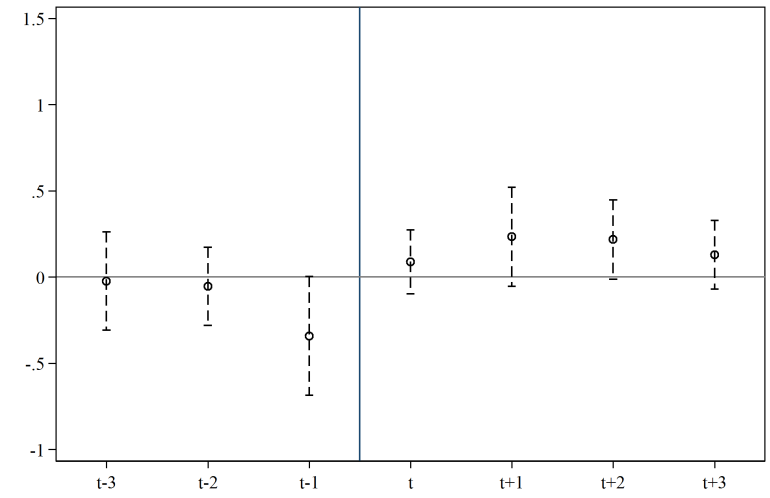

(d) County-Pair (2006-2011)

Figure 2.3:

Effects of an Exemption Increase in Year $\mathbf{t}$ The figure shows cumulative response of Chapter 7 bankruptcies per thousand to a one log point exemption increase in year t. 95\% confidence intervals for standard errors clustered at the state-level are shown. For the sample of states in panels (a) and (c), the regression includes state and year fixed effects and state economic controls for the unemployment rate, the 25th percentile of the log income distribution, $\log$ of median income, and the log of the home price index. For the countypairs in panels (b) and (d), the regression includes county fixed effects, pair-specific year fixed effects, and controls for the county unemployment rate and log of county median income. Observations are weighted by population. The full set of coefficients and standard errors from this and other specifications are reported in Appendix Table 2.A.4. 


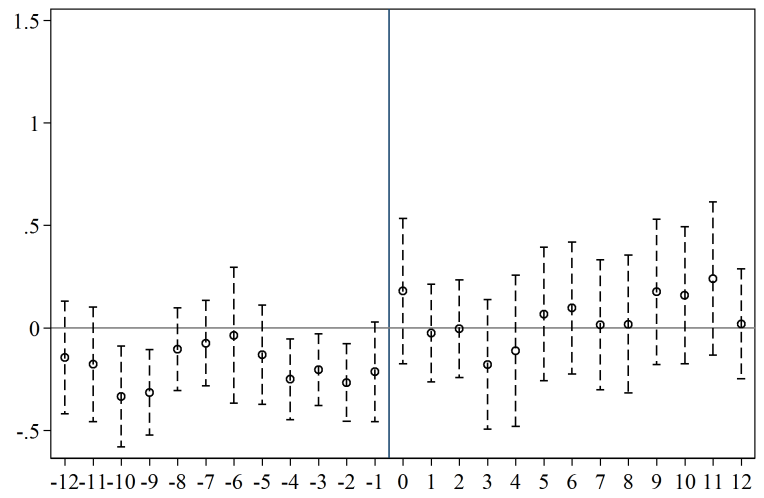

(a) Baseline

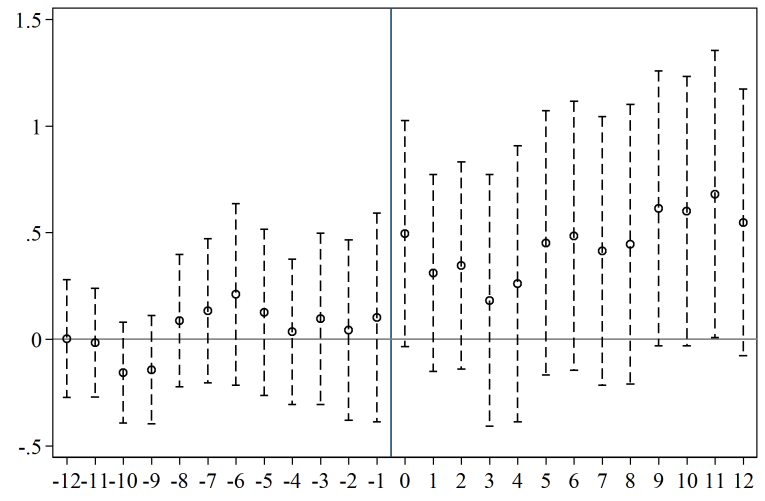

(b) Linear state trends

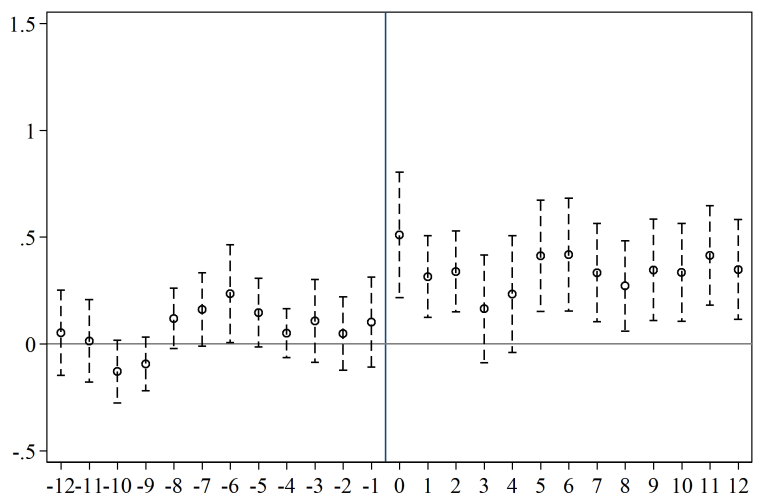

(c) Quadratic state trends

Figure 2.4:

Post-BAPCPA Effects of an Exemption Increases in Month 0 The sample consists of annualized monthly state-level bankruptcy rates (per thousand) from 2007-2013. The figure shows the cumulative response of Chapter 7 bankruptcies per thousand to an increase in asset exemptions in month 0 alongside $95 \%$ confidence intervals for standard errors clustered by state. All specifications include controls for the monthly state unemployment rate, the log of the FHFA quarterly seasonally adjusted house price index, the annual log of state median income and 25th percentile of the log income distribution, state fixed effects, and time fixed effects. Coefficients and standard errors are reported in Appendix Table 2.A.5. 


\title{
Appendix
}

\author{
2.A Appendix
}




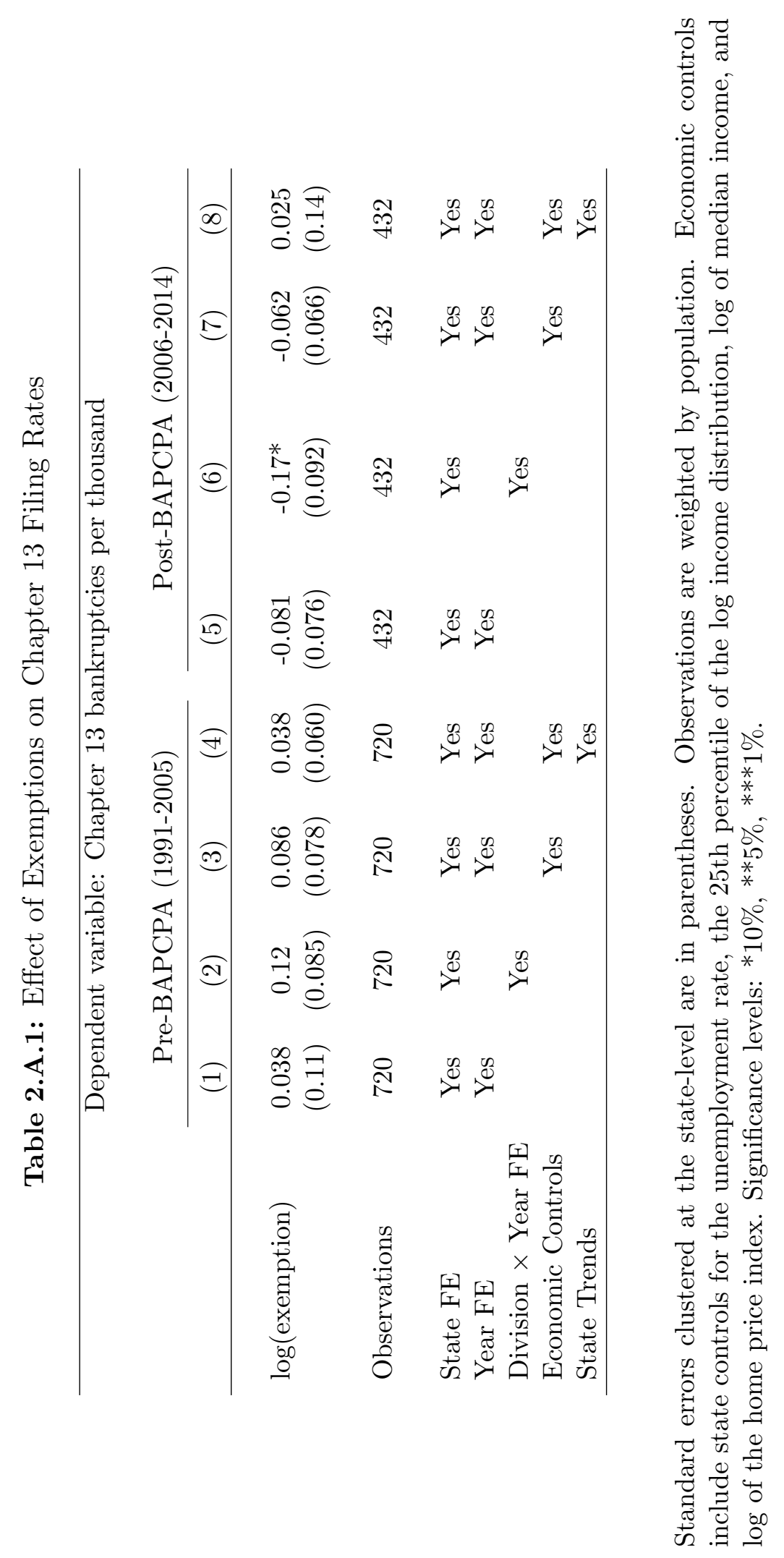




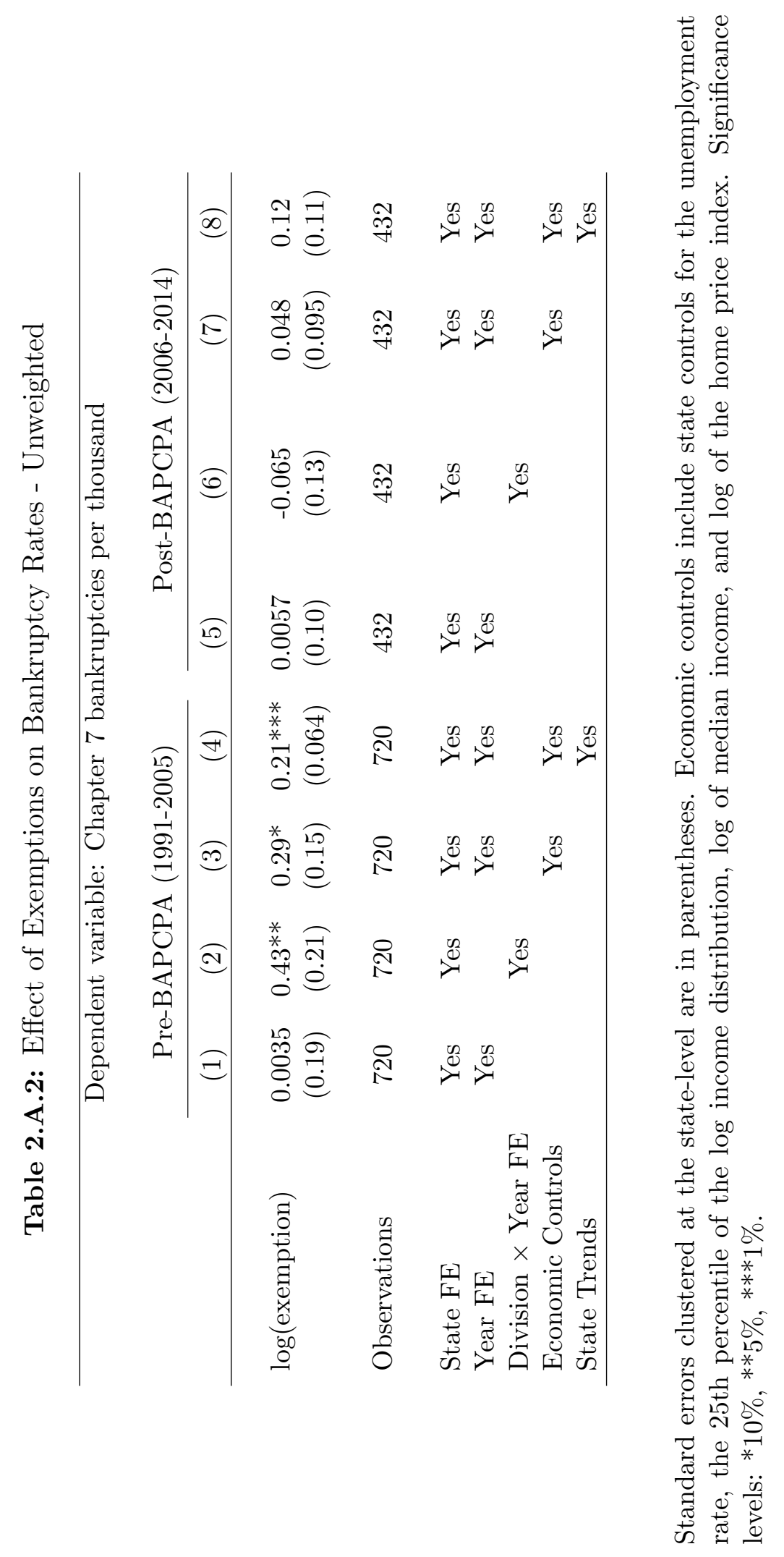




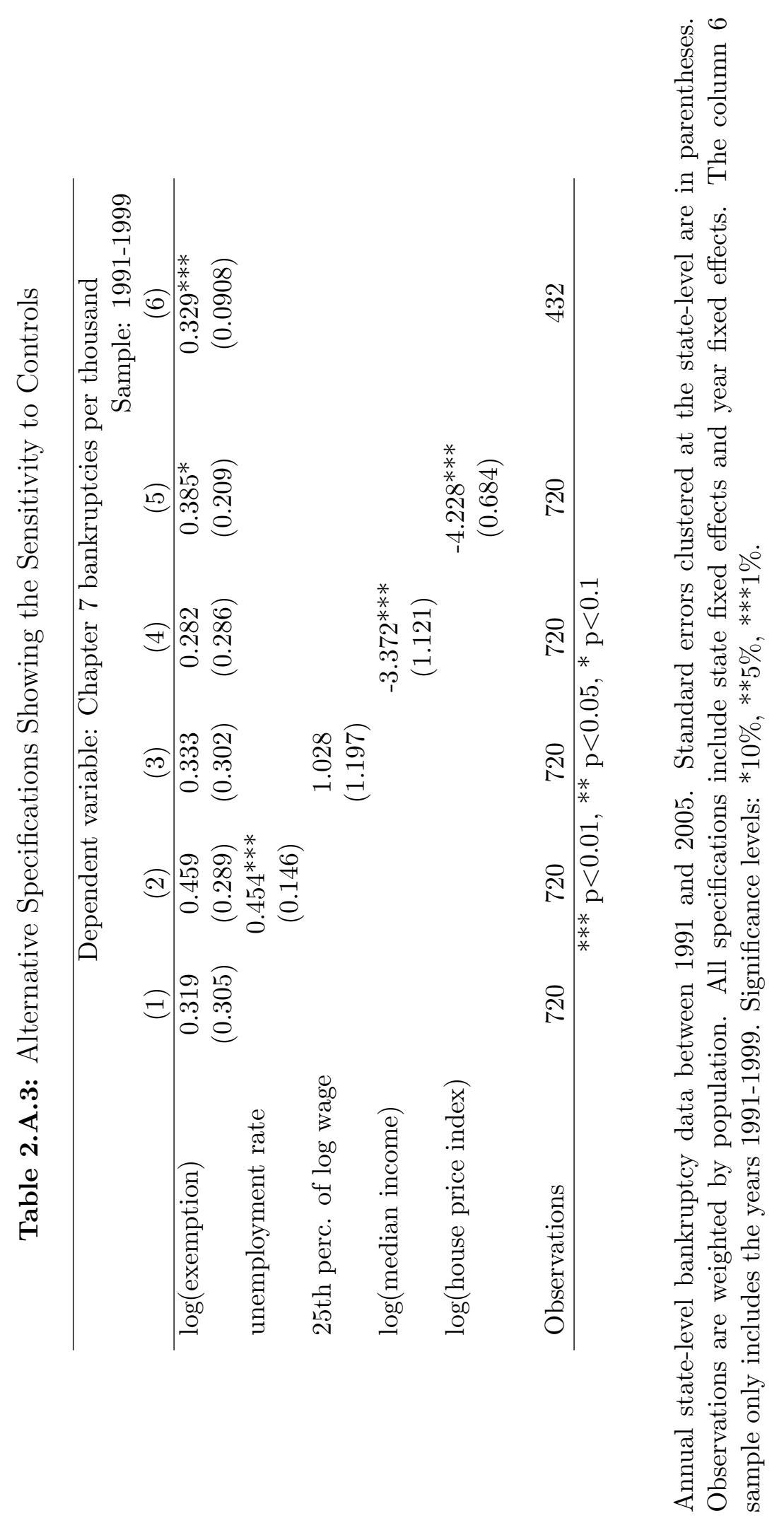


Table 2.A.4: Dynamic Response to Exemption Increases

\begin{tabular}{|c|c|c|c|c|}
\hline & \multicolumn{2}{|c|}{ Pre-BAPCPA } & \multicolumn{2}{|c|}{ Post-BAPCPA } \\
\hline & $\begin{array}{c}\text { States } \\
(1)\end{array}$ & $\begin{array}{c}\text { County-pairs } \\
(2)\end{array}$ & $\begin{array}{c}\text { States } \\
(3)\end{array}$ & $\begin{array}{c}\text { County-pairs } \\
\text { (4) }\end{array}$ \\
\hline$\Delta \ln \left(E_{s, t+6}\right)$ & 0.0939 & 0.0201 & & \\
\hline (6-year lead) & $(0.169)$ & $(0.107)$ & & \\
\hline$\Delta \ln \left(E_{s, t+5}\right)$ & 0.101 & 0.0335 & & \\
\hline & $(0.220)$ & $(0.0388)$ & & \\
\hline$\Delta \ln \left(E_{s, t+4}\right)$ & 0.128 & 0.0422 & & \\
\hline & $(0.220)$ & $(0.0566)$ & & \\
\hline$\Delta \ln \left(E_{s, t+3}\right)$ & 0.266 & 0.0430 & -0.161 & -0.0237 \\
\hline & $(0.352)$ & $(0.0543)$ & $(0.171)$ & $(0.147)$ \\
\hline$\Delta \ln \left(E_{s, t+2}\right)$ & 0.0739 & 0.00409 & $-0.358^{*}$ & -0.0541 \\
\hline & $(0.255)$ & $(0.0830)$ & $(0.193)$ & $(0.117)$ \\
\hline$\Delta \ln \left(E_{s, t+1}\right)$ & 0.0635 & -0.00463 & -0.325 & $-0.342^{*}$ \\
\hline & $(0.309)$ & $(0.0701)$ & $(0.215)$ & $(0.177)$ \\
\hline$\Delta \ln \left(E_{s, t}\right)$ & 0.472 & $0.326^{* *}$ & 0.0477 & 0.0873 \\
\hline (exemption increases) & $(0.301)$ & $(0.160)$ & $(0.239)$ & $(0.0953)$ \\
\hline$\Delta \ln \left(E_{s, t-1}\right)$ & $0.696^{* *}$ & $0.548^{* * *}$ & 0.0468 & 0.233 \\
\hline & $(0.340)$ & $(0.178)$ & $(0.168)$ & $(0.148)$ \\
\hline$\Delta \ln \left(E_{s, t-2}\right)$ & $0.769^{* *}$ & $0.673^{* *}$ & 0.112 & $0.218^{*}$ \\
\hline & $(0.361)$ & $(0.256)$ & $(0.106)$ & $(0.119)$ \\
\hline$\Delta \ln \left(E_{s, t-3}\right)$ & $0.646^{*}$ & $0.626^{* *}$ & 0.0806 & 0.129 \\
\hline & $(0.335)$ & $(0.255)$ & $(0.0736)$ & $(0.103)$ \\
\hline$\Delta \ln \left(E_{s, t-4}\right)$ & 0.542 & $0.576^{* *}$ & & \\
\hline & $(0.337)$ & $(0.256)$ & & \\
\hline$\Delta \ln \left(E_{s, t-5}\right)$ & $0.577^{*}$ & $0.744^{* *}$ & & \\
\hline & $(0.322)$ & $(0.279)$ & & \\
\hline $\ln \left(E \_s, t-6\right)$ & 0.593 & $0.671^{*}$ & & \\
\hline (6-year lag) & $(0.384)$ & $(0.358)$ & & \\
\hline Observations & 720 & 16,072 & 288 & 13,776 \\
\hline
\end{tabular}

The table reports coefficients on leads and lags from the event study models in equations (2.3) and (2.4). Observations are weighted by population. Standard errors clustered at the state-level are in parentheses. For the sample of states in columns 1 and 3, the regression includes state and year fixed effects and state economic controls for the unemployment rate, the 25th percentile of the log income distribution, log of median income, and the log of the home price index. For the county pairs in columns 2 and 4, the regression includes county fixed effects, pair-specific year fixed effects, and controls for the county unemployment rate and log of county median income. Significance levels: * $10 \%, * * 5 \%, * * * 1 \%$. 
Table 2.A.5: Monthly Dynamic Response to Exemption Increases

\begin{tabular}{|c|c|c|c|}
\hline & \multicolumn{3}{|c|}{ Dependent variable: Chapter 7 bankruptcies per thousand } \\
\hline & $\begin{array}{l}\text { Baseline } \\
\text { (1) }\end{array}$ & $\begin{array}{c}\text { Linear Trends } \\
(2)\end{array}$ & $\begin{array}{c}\text { Quadratic Trends } \\
(3)\end{array}$ \\
\hline$\Delta \ln \left(E_{s, t+12}\right)$ & -0.144 & 0.00248 & 0.0519 \\
\hline (12-month lead) & $(0.140)$ & $(0.141)$ & $(0.102)$ \\
\hline$\Delta \ln \left(E_{s, t+10}\right)$ & $\begin{array}{c}-0.335^{* *} \\
(0.125)\end{array}$ & $\begin{array}{l}-0.157 \\
(0.121)\end{array}$ & $\begin{array}{l}-0.129^{*} \\
(0.0751)\end{array}$ \\
\hline$\Delta \ln \left(E_{s, t+8}\right)$ & $\begin{array}{l}-0.104 \\
(0.103)\end{array}$ & $\begin{array}{l}0.0873 \\
(0.158)\end{array}$ & $\begin{array}{c}0.119 \\
(0.0722)\end{array}$ \\
\hline$\Delta \ln \left(E_{s, t+6}\right)$ & $\begin{array}{l}-0.0359 \\
(0.169)\end{array}$ & $\begin{array}{c}0.210 \\
(0.217)\end{array}$ & $\begin{array}{l}0.234^{*} \\
(0.117)\end{array}$ \\
\hline$\Delta \ln \left(E_{s, t+4}\right)$ & $\begin{array}{c}-0.251^{* *} \\
(0.101)\end{array}$ & $\begin{array}{l}0.0347 \\
(0.174)\end{array}$ & $\begin{array}{c}0.0502 \\
(0.0588)\end{array}$ \\
\hline$\Delta \ln \left(E_{s, t+2}\right)$ & $\begin{array}{c}-0.267^{* * *} \\
(0.0968)\end{array}$ & $\begin{array}{l}0.0427 \\
(0.215)\end{array}$ & $\begin{array}{c}0.0478 \\
(0.0877)\end{array}$ \\
\hline $\begin{array}{l}\Delta \ln \left(E_{s, t}\right) \\
\text { (exemption increases) }\end{array}$ & $\begin{array}{c}0.180 \\
(0.181)\end{array}$ & $\begin{array}{l}0.496^{*} \\
(0.270)\end{array}$ & $\begin{array}{c}0.511^{* * *} \\
(0.150)\end{array}$ \\
\hline$\Delta \ln \left(E_{s, t-2}\right)$ & $\begin{array}{c}-0.00479 \\
(0.121)\end{array}$ & $\begin{array}{c}0.346 \\
(0.248)\end{array}$ & $\begin{array}{c}0.339 * * * \\
(0.0964)\end{array}$ \\
\hline$\Delta \ln \left(E_{s, t-4}\right)$ & $\begin{array}{l}-0.111 \\
(0.188)\end{array}$ & $\begin{array}{c}0.260 \\
(0.330)\end{array}$ & $\begin{array}{c}0.233 \\
(0.139)\end{array}$ \\
\hline$\Delta \ln \left(E_{s, t-6}\right)$ & $\begin{array}{l}0.0967 \\
(0.164)\end{array}$ & $\begin{array}{c}0.485 \\
(0.322)\end{array}$ & $\begin{array}{c}0.418^{* * *} \\
(0.135)\end{array}$ \\
\hline$\Delta \ln \left(E_{s, t-8}\right)$ & $\begin{array}{l}0.0179 \\
(0.172)\end{array}$ & $\begin{array}{c}0.445 \\
(0.335)\end{array}$ & $\begin{array}{c}0.271^{* *} \\
(0.108)\end{array}$ \\
\hline$\Delta \ln \left(E_{s, t-10}\right)$ & $\begin{array}{c}0.160 \\
(0.171)\end{array}$ & $\begin{array}{l}0.601^{*} \\
(0.322)\end{array}$ & $\begin{array}{c}0.334^{* * *} \\
(0.117)\end{array}$ \\
\hline $\begin{array}{l}\Delta \ln \left(E_{s, t-12}\right) \\
(12 \text {-month lag })\end{array}$ & $\begin{array}{l}0.0190 \\
(0.137)\end{array}$ & $\begin{array}{l}0.547^{*} \\
(0.319)\end{array}$ & $\begin{array}{c}0.348^{* * *} \\
(0.119)\end{array}$ \\
\hline $\begin{array}{l}\text { Linear state trends } \\
\text { Quadratic state trends }\end{array}$ & & $\mathrm{X}$ & $\begin{array}{l}X \\
X\end{array}$ \\
\hline
\end{tabular}

The sample size consists 4,032 monthly state-level bankruptcy filing rates (per thousand) for 20072013. The dependent variable is the monthly bankruptcy filing rate multiplied by 12 , so the coefficients are comparable to annual estimates. The table reports coefficients on the leads and lags from the event study model in equation (2.5). To reduce the size of the table, the table only shows every other coefficient. Standard errors clustered at the state-level are in parentheses. Observations are weighted by population. All specifications include monthly state unemployment rate, the log of the FHFA quarterly, seasonally adjusted house price index, state fixed effects, and time fixed effects (year $\times$ month). Significance levels: $* 10 \%, * * 5 \%, * * * 1 \%$. 


\section{Pre-BAPCPA}

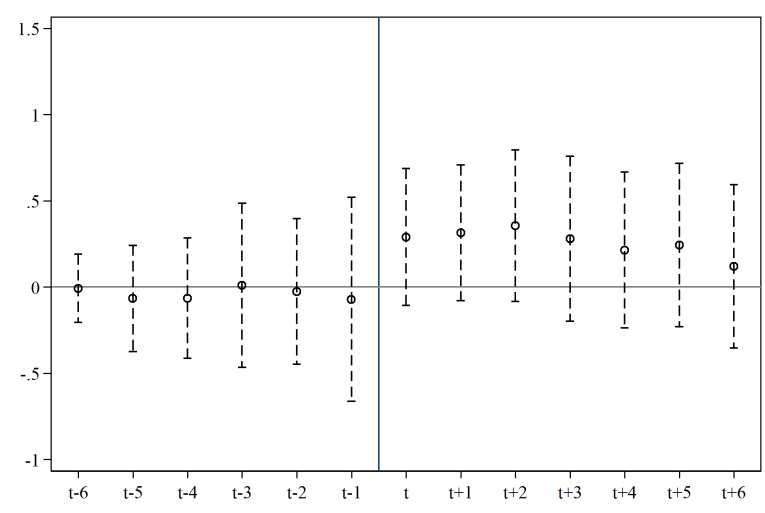

(a) States (1991-2005)

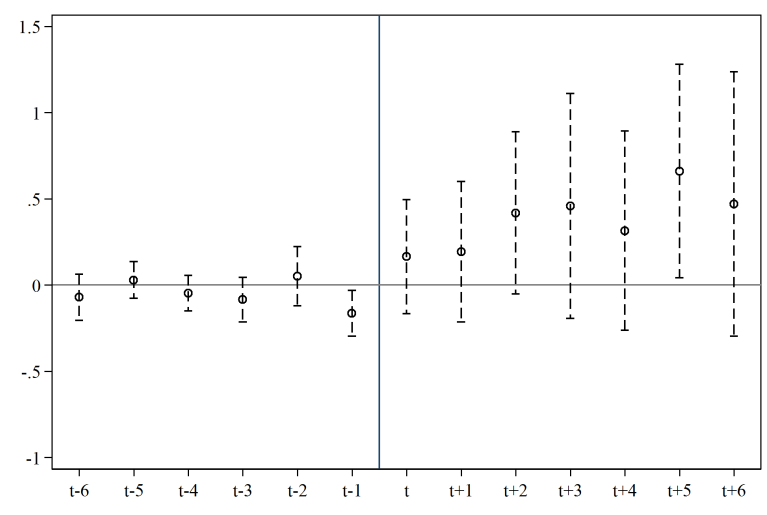

(b) County-pair (1999-2005)

Post-BAPCPA

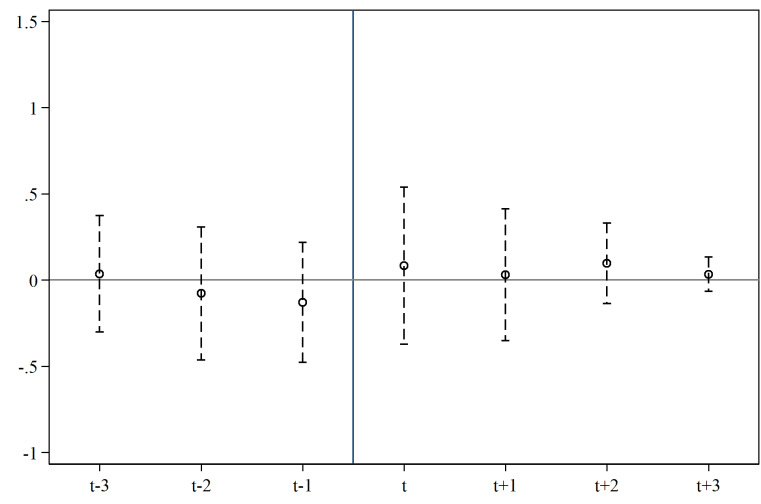

(c) States (2006-2011)

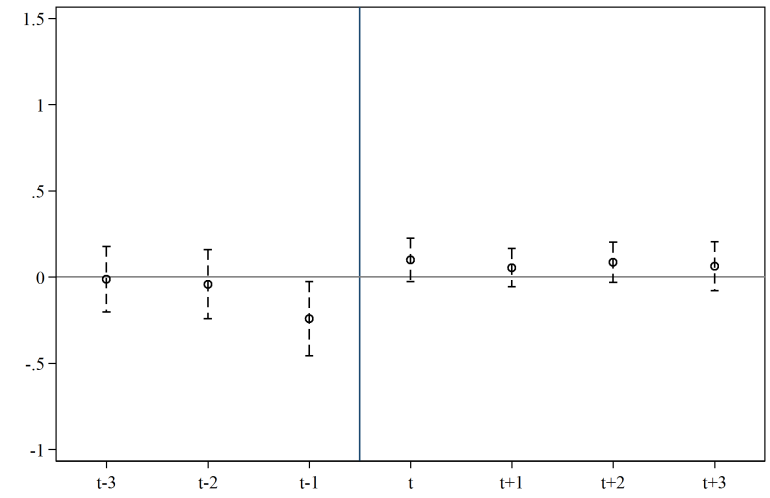

(d) County-pair (2006-2011)

Figure 2.A.1:

Effects of an Exemption Increase in Year $\mathbf{t}$ - Unweighted The figure shows cumulative response of Chapter 7 bankruptcies per thousand with respect to an increase in asset exemptions in period t, estimated from a distributed lag model with six leads and lags using annual data. 95\% confidence intervals for standard errors clustered at the state-level are shown. For the sample of states in panels (a) and (c), the regression includes state and year fixed effects and state economic controls for the unemployment rate, the 25th percentile of the log income distribution, log of median income, and the log of the home price index. For the county pairs in panels (b) and (d), the regression includes county fixed effects, pairspecific year fixed effects, and controls for the county unemployment rate and log of county median income. 


\section{Chapter 3}

Who Benefits from Credit Report Bans? (with Leora

Friedberg and Richard M. Hynes) 


\subsection{Introduction}

Credit reports are used for more than just extending credit. Landlords use credit reports to screen tenants, insurers use them to set premiums, and many employers use them to decide whom to hire (CFPB, 2012). This last use is particularly controversial. Eleven states and several cities now limit the use of credit reports in employment (NCSL, 2015), and Senators Bernie Sanders and Elizabeth Warren have co-sponsored legislation that would impose a national ban.

Supporters of the limits argue that the information in credit reports is unrelated to job performance and that their use imposes significant costs on vulnerable populations. It may hinder the financial recovery of consumers who have suffered adverse events such as illness or job loss that caused them to default on financial obligations. ${ }^{1}$ It can also have a disparate impact on minority employment because minorities tend to have worse credit histories. ${ }^{2}$ It can even deter qualified workers from applying for jobs for which they believe that a bad credit history will disqualify them. Prohibiting the use of credit reports can help those with bad credit by allowing them to pool with those with good credit. On the other hand, this pooling can harm people in the pool who are observably similar to those with bad credit, as employers may use the observable variable as a proxy for credit history, resulting in statistical discrimination. Therefore, the social welfare effects of credit report bans depend on their impact on both those with bad credit and others who look similar to them.

The existing literature focuses on the effect of credit report bans or other exogenous changes in credit reports on people who either are likely to suffer from bad credit (and

\footnotetext{
${ }^{1}$ See https://www.warren.senate.gov/?p=press_release\&id=917, where it is argued that "research has shown that an individual's credit rating has little to no correlation with his or her ability to be successful in the workplace," and also that, "[a] bad credit rating is far more often the result of unexpected medical costs, unemployment, economic downturns, or other bad breaks than it is a reflection on an individual's character or abilities."

${ }^{2}$ The EEOC used this theory to sue a series of companies for employment discrimination, but it was largely unsuccessful. See, e.g., EEOC v. Kaplan Higher Education Corp, 748 F.3d 749 (6th Cir. 2014).
} 
may benefit from the law) or who may resemble those who do (and may be harmed by the law). Papers focusing on possible beneficiaries differ in how precisely they can pinpoint such groups. Some papers analyze the effect of negative credit information dropping off of credit reports after a fixed duration of time and find mixed evidence of labor market effects (Dobbie et al., 2016, Herkenhoff, Phillips, and Cohen-Cole, 2016, Bos, Breza, and Liberman, 2016). While those papers focus on individual-specific credit information, other papers like ours analyze recent credit reporting policies. Clifford and Shoag (2016) find positive effects and Cortés, Glover, and Tasci (2016) find negative effects on employment resulting from credit report bans, but they do not observe people with bad credit; rather, they consider locations (Census tracts and counties, respectively) where people with bad credit are concentrated, so their results may reflect outcomes for people with bad credit or for people who get pooled together with those with bad credit.

Several papers focus on employment effects of credit report bans for groups of people who resemble those with bad credit, and here the findings are negative. Clifford and Shoag (2016) find worse outcomes for residents of tracts with moderately low average scores. They also find worse outcomes for black individuals in states that passed bans, as do Bartik and Nelson (2016). ${ }^{3}$ These findings of possible statistical discrimination are consistent with papers that examine the use or limits on the use of other types of applicant information in labor markets, including Wozniak (2015) on employment-related drug testing, Doleac and Hansen (2016) on recent "ban the box" laws that prohibit questions about criminal history on job applications, and Holzer, Steen, and Stoll (2006) on the availability of criminal background information. On the other hand, Finlay (2009) presents some contrary evidence regarding questions about criminal history, and Autor and Scarborough (2008) find no measurable impact of job testing

\footnotetext{
${ }^{3}$ Clifford and Shoag (2016), further, find a decline in the number of requests for a credit report submitted by an employer to one of the three national credit bureaus after a state enacts a limit, but the size of the effect is extremely small. One year after enactment, the number of credit checks fell by a little more than one per thousand unemployed individuals.
} 
on minority hiring. Some of the most recent papers noted above are able to focus, as we do, on worker flows, job flows, or job search, rather than on overall employment for entire groups of the population. ${ }^{4}$ Since the laws govern the applicant screening process, observing who is looking for a job is a critical advantage.

We use the Survey of Income and Program Participation (SIPP), which offers several advantages. The SIPP follows individuals for up to four years, allowing us to observe partial or full unemployment spells for respondents who are unemployed. Moreover, the SIPP asks respondents if they have had recent trouble meeting all of their essential expenses, which is the case for $28 \%$ of our sample of the unemployed. We confirm in the FINRA National Financial Capability Study that people who report having difficulty covering their expenses also tend to have low credit scores. Therefore, we can target a group more likely than others to benefit from credit report bans.

Because we can focus on a narrow group of people within each state, we can employ quasi-experimental strategies that rule out many concerns that might invalidate broader comparisons across states and years. ${ }^{5}$ We estimate weekly hazard models on the likelihood of finding a job using two related identification strategies. We estimate a double-difference specification that compares unemployed people who have trouble meeting their expenses in states with and without credit report bans. Because our observations of financial distress precede almost all the credit report bans, we are not concerned that the bans themselves could alter the likelihood of experiencing financial distress. This strategy avoids the necessity in

\footnotetext{
${ }^{4}$ Dobbie, Goldsmith-Pinkham, Mahoney \& Song (2016), Herkenhoff, Phillips \& Cohen-Cole (2016), and Bos, Breza, and Liberman (2016) follow individuals over time in administrative data; Doleac \& Hansen (2016) and Bartik \& Nelson (2016, for some of their results) follow individuals in the CPS, although the CPS is designed to follow housing units rather than individuals. Clifford \& Shoag (2016, for their main results) and Bartik \& Nelson (2016, for their main results) use different aggregates of LEHD data that report worker and job flows by geographic location but do not follow the individuals over time. All of these data sets allow researchers to focus on employment flows rather than stocks in various ways.

${ }^{5}$ By focusing on Census tracts, Clifford and Shoag are able to use within-state -year variation, as we are. In some specifications, Clifford and Shoag focus further on Census tracts in commuting areas that cross state lines, where they find that when a state enacts a ban, it increases jobs held by people who live outside of the state but are within commuting distance.
} 
studies of statistical discrimination of distinguishing between treatment and controls using broad demographic classifications (for example, race or age). Aggregate employment patterns for these large and visible groups may be related to law changes. If the broader group of unemployed do serve as useful controls, we can use people who do not have trouble meeting their essential expenses as a within-state control group to formulate a triple-difference specification. We show that the latter group is not significantly affected by credit report bans, so we use them to control for changes in labor markets within states that are correlated with the passage of credit report bans.

We find that credit report bans reduce the unemployment duration of those with bad credit by about twenty-five percent, with quite similar results in both estimation strategies. The double-difference strategy indicates a $24.7 \%$ decline, and the triple-difference strategy indicates a $28.3 \%$ decline in the duration of unemployment, measured at the weekly level. Lastly, we fail to find evidence of harm to people who might now be pooled in the labor market together with those with bad credit; we do not estimate a statistically significant effect of the laws on unemployment durations of people who have not had trouble meeting their expenses or on blacks or Hispanics relative to whites.

\subsection{Background}

This paper focuses on statutes that explicitly limit the use of credit reports. In the absence of a statute, an employer's use of credit reports may risk litigation, as the EEOC has argued that their use has a disparate impact on minority employment and is therefore prohibited by Title VII. However, the EEOC's litigation efforts have been largely unsuccessful, in part because at least one court noted that the EEOC itself used credit reports to screen applicants for most of its positions. ${ }^{6}$

\footnotetext{
${ }^{6}$ EEOC v. Kaplan Higher Education Corp, 748 F.3d 749 (6th Cir. 2014).
} 
Most states have considered legislation that would ban the use of credit reports, and Senators Sanders \& Warren have co-sponsored a national prohibition on the use of credit reports in employment. As shown in Table 3.2, eleven states (along with several cities) have enacted a ban. However, all existing bans include exceptions. Common exceptions include positions at financial institutions, positions with access to money, confidential information or proprietary information, managerial positions, and positions where a credit report is substantially job related or a bona fide occupation qualification (Phillips and Schein, 2015). The ban imposed by one state, Connecticut, may have little effect as it permits the use of credit reports if the applicant consents. ${ }^{7}$ These exceptions may limit the impact of the laws, especially if the credit reporting industry is correct in arguing that the reports are primarily used for managerial or financial positions. ${ }^{8}$ However, consumer advocates argue that credit reports are used much more broadly (Traub, 2013), ${ }^{9}$ and even when they are not used, applicants may feel deterred from applying for jobs for which they believe that a bad credit history will disqualify them.

As noted earlier, the existing literature focuses on the effect of restricting credit report information on people who either are likely to suffer from bad credit (and may benefit from the law) or who may resemble those who do (and may be harmed by the law). Previous research that seeks to measure the benefits differs by what types of restrictions are analyzed, what groups are studied, and what employment outcomes are considered. Some studies have data on exactly who has bad credit and focus on the disappearance of old information from credit reports. The evidence suggests little to no effect on employment when bankruptcy

\footnotetext{
${ }^{7}$ We include Connecticut's credit report ban, but when we drop Connecticut from the sample, the magnitude and significance of our estimates remain similar.

${ }^{8}$ www.shrm.org/hr-today/trends-and-forecasting/research-and-surveys/pages/creditbackgroundchecks.aspx

${ }^{9}$ According to Traub, "Our survey of low- and middle-income households carrying credit card debt finds that approximately 1 in 7 of these households recall being asked by an employer or prospective employer to authorize a credit check. About the same proportion say they don't know whether they've ever been asked for an employment credit check" (Bartik and Nelson, 2016). Notably, the national ban proposed by Senators Sanders \& Warren would only exempt positions that require national security clearance or where a credit check is otherwise required by law.
} 
information that is quite old disappears in the U.S. (Dobbie, Goldsmith-Pinkham, Mahoney \& Song 2016, Herkenhoff, Phillips \& Cohen-Cole 2016), and substantial positive effects on pawnshop borrowers in Sweden when the information is more recent (Bos, Breza \& Liberman 2016).

Studies on credit reporting bans that come closest to focusing on people with bad credit consider locations where people with bad credit are concentrated. Clifford \& Shoag (2016) find an increase in jobs held by residents of Census tracts with the lowest credit scores, using the Longitudinal Employer-Household Dynamics (LEHD) data set, while in contrast Cortés, Glover, \& Tasci (2016) find an increase in unemployment rates in counties with high subprime populations. The job increases that Clifford \& Shoag find are concentrated in the government sector and require increased education and experience, and perhaps the job holders are new residents in these locations. More generally, the outcomes in areas where people with bad credit are concentrated may reflect both direct effects on people with bad credit and indirect effects on people who get pooled together with those with bad credit.

Other recent research focuses on broader disadvantaged groups, for example youth and minorities as a whole, who have worse credit on average than other groups, and finds that restricting credit information may worsen employment outcomes. This implies, first, that members of the group with poor credit either do not benefit or are too small in number to affect outcomes for the whole group and, second, that those who resemble people with poor credit are directly harmed through statistical discrimination. Some papers use survey data to examine current employment (Clifford \& Shoag, in their analysis of the American Community Survey) or worker flows (Bartik \& Nelson, in their analysis of the Current Population Survey panel, although the CPS is designed to follow housing units, not individuals), and some use administrative data on worker flows (Bartik \& Nelson, in their use of the LEHD Job-to-Job data and Clifford \& Shoag, in their use of the LEHD data for residents in Census tracts with moderately low average credit scores). 
We use the SIPP in this paper, which offers several advantages. First, we are able to observe people who have trouble meeting their essential expenses. This allows us to target directly a group very likely to benefit from credit report bans, unlike the focus in Clifford \& Shoag on neighborhoods. We are also able to examine job finding in a worker-level panel data set. While the SIPP is considerably smaller than the CPS, ACS, or LEHD, we gain power by focusing on groups and outcomes of direct interest. Lastly, we can make use of a within-state control group comprised of people who do not have trouble meeting essential expenses, so in some specifications we include state-by-year fixed effects that capture changes in labor markets within states that might be correlated with the passage of credit report bans.

\subsection{Empirical Strategy}

We estimate hazard models to investigate how employment credit report bans affect unemployment durations for individuals who are unemployed and who have trouble paying their bills. Our double-difference identification strategy estimates how the enactment of a credit report ban affects the employment hazard rate for unemployed people with recent trouble meeting essential expenses (whom we refer to as "financially distressed"), compared to financially distressed people in states without bans as a control group. After showing that individuals who did not have trouble meeting essential expenses (the "non-distressed") are not similarly affected by credit report bans, we combine the samples in a triple-difference specification that uses non-financially distressed people as a within-state comparison group. This allows us to control for unobserved time-varying state shocks that affect the unemployment durations of all individuals within a state.

We use a Cox proportional hazard model to estimate the probability that an unemployed 
individual will find a job after $\tau$ weeks, conditional on being unemployed for $\tau-1$ weeks. ${ }^{10}$ Our double-difference specification follows the set-up of Kroft and Notowidigdo (in press) and Chetty (2008), who also estimate unemployment durations with state and year fixed effects.

The key explanatory variable in our model is whether the unemployed individual lives in a state that has enacted a credit report ban, Ban. We model the weekly unemployment exit hazard $h$ for person $i$ who has been unemployed in state $s$ for $\tau$ weeks, beginning at time $t$, as

$$
\log \left(h_{i s t}(\tau)\right)=\log \left(h_{0}(\tau)\right)+\beta \operatorname{Ban}_{s t}+X_{i s t} \gamma+\delta_{s}+\tau_{y(t)}
$$

where $\mathrm{Ban}_{\mathrm{st}}$ is an indicator for an employment credit check ban being in effect in state $s$ at time $t, X_{\text {ist }}$ represents controls for individual characteristics, and $\delta_{s}$ and $\tau_{y(t)}$ are state and year (or higher frequency) fixed effects. In the baseline specifications, $X_{\text {ist }}$ consists of age, sex, years of education, and marital status. Additionally, following Chetty (2008), we include a dummy to adjust for the "seam" effect of panel surveys. ${ }^{11}$ In all specifications, standard errors are clustered at the state level.

The inverse $-\beta$ of the coefficient on Ban represents the change in the log of the unemployment duration when credit is banned, after controlling for individual characteristics $X_{\text {ist }}$ and state and year fixed effects. ${ }^{12}$ The causal interpretation of our estimates of $\beta$ rely on the

\footnotetext{
${ }^{10}$ We use a continuous time Cox proportional hazard model, but our estimates are substantively unchanged if we instead use a complementary log-log specification, as in Bartik \& Nelson (2016) and Meyer (1990), which accounts for the fact that the data are observed at discrete, weekly intervals.

${ }^{11}$ In panel surveys in which respondents are interviewed every few months about events in the intervening months, the respondents tend to report fewer changes within an interview than across interviews. In the SIPP, the interviews occur every 4 months and the seam effect leads to artificial spikes in job-finding rates during the $4^{\text {th }}$ and $8^{\text {th }}$ month.

${ }^{12}$ This interpretation, which is used in Kroft and Notowidigdo (in press), relies on the fact that the log of the unemployment duration $\mathrm{D}$ is approximately equal to the inverse hazard ratio:

$$
\log (D) \approx \log \left(\frac{1}{h}\right)=-\log (h)
$$
}


identification assumption that, in the absence of the credit ban, there would be no significant difference in the unemployment durations for financially distressed individuals between the treatment and control states (after conditioning on other covariates). ${ }^{13}$ This identification assumption would also be violated if unemployment durations changed over time in a way that is correlated with the passage of credit bans.

We can make use of the sample of non-financially distressed individuals to relax this assumption. If the broader group of unemployed people experience the same labor market conditions but are unaffected by credit report bans, we can exploit them to formulate a triple-difference specification that uses the non-distressed sample as a within-state control group. We show that the non-distressed are not themselves affected significantly by credit report bans.

The more demanding triple-difference specification, still formulated as a Cox proportional hazard model, estimates the difference in weekly hazard rates among financially distressed individuals (indicated by $F D$ ) before and after a state enacts a credit ban, relative to the difference in hazard rates among non-distressed individuals living in the same state and year:

$$
\log \left(h_{\text {ist }}(\tau)\right)=\log \left(h_{0}(\tau)\right)+\alpha \mathrm{FD}_{i} \times \operatorname{Ban}_{\text {st }}+X_{\text {st }} \gamma+\delta_{s} \times F D_{i}+\tau_{y(t)} \times \mathrm{FD}_{i}+\delta_{s, y(t)} .
$$

Equation (3.2) includes second-order state $\times$ distressed fixed effects (that allow for different unemployment durations for financially distressed people in states that ever pass a credit report ban), year $\times$ distressed fixed effects (that allow for changing unemployment durations nationwide among financially distressed people), and state $\times$ year fixed effects (that allow for different unemployment durations in a state that has passed a credit report ban or in

\footnotetext{
${ }^{13}$ We do not face the problem that credit report bans may cause more financial distress, altering the composition of the treatment and control groups. As explained below, we measure instances of financial distress that occur in 2009 or 2010, when only three smaller states had a credit report ban in effect at that time. For the large majority of individuals in our sample, the financial distress occurred before their state enacted a ban.
} 
any other state-year combination).

Because the SIPP is relatively small, it helps that we can focus on a group (those who are likely to have bad credit) and an outcome (successful job search) that are more likely to be affected by credit report bans. In the spirit of other papers, we also estimate whether the bans impact unemployment duration of minorities. To do this we focus on samples of black, Hispanic, and white (not Hispanic) unemployed individuals.

\subsection{Data}

\subsubsection{State Laws}

Information on state bans of employment credit checks come from the National Conference of State Legislatures. Table 3.1 lists the ten states that enacted bans during our sample period. ${ }^{14}$ For an unemployment spell that begins in state $s$ at time (year-month) $t$, we assign a variable Ban that equals one if credit checks are banned in state $s$ at time $t{ }^{15}$

\subsubsection{SIPP Data}

We use data on individuals from the 2008 Survey of Income and Program Participation (SIPP), which surveyed 42,030 households in May 2008 and followed them every four months through December 2013. The advantages of the SIPP are that it reports weekly employment status, and also asked twice whether households were suffering financial hardship. A further advantage is that the SIPP oversamples people with low income, increasing the size of the sample in which we are interested.

\footnotetext{
${ }^{14}$ Delaware enacted its ban in 2014, after our sample period ended. This information is identical to that used by Cortés, Glover, \& Tasci (2016). It is nearly identical to Bartik \& Nelson (2016), except for a minor difference in the timing of the Oregon law. The Oregon law was scheduled to go into effect on July 1, 2010, but the Governor of Oregon declared it effective immediately on March 29, 2010.

${ }^{15}$ If we considered bans that passed during an unemployment spell, it would artificially skew the sample of treated spells towards longer durations.
} 
We focus our analysis on the duration of unemployment spells, measured in weeks, and build our sample in much the same way as Chetty (2008) did using the SIPP. Starting from all job separations that begin during the SIPP, we restrict the sample to prime-age individuals who have at least 3 months of work history in the survey, who are not on temporary layoff, and who report searching for a job. Details on sample construction are provided in the Appendix. ${ }^{16}$ These restrictions leave 10,249 separate unemployment spells in the sample, with a total of 270,439 weekly observations. ${ }^{17}$ The unemployment spell ends when an individual reports working for at least one month. Following Chetty, we censor unemployment durations at 50 weeks to reduce the influence of outliers and focus on job-finding rates during the first year of unemployment.

The first two columns of Table 3.2 present summary statistics for the full sample of unemployment spells. The average unemployment duration is 26 weeks; this includes observations that are right-censored at fifty weeks or due to sample attrition. The next sets of columns show statistics for borrowers residing in the control states and in the ban states (those that have passed or will pass bans on employment credit checks). The populations in the states are generally similar; for example, pre-unemployment monthly earnings are $\$ 2,305$ in control states and $\$ 2,489$ in ban states. The only exception is that unemployed individuals in states that pass credit bans are less likely to be black; $15 \%$ are black in control states, and $8.5 \%$ are black in treatment states.

Information on financial hardship comes from the Adult Well-Being interviews, which were conducted between May and August of 2010. These interviews ask households whether they had trouble meeting their essential expenses, such as rent or mortgage payments or

\footnotetext{
${ }^{16}$ Compared to Chetty, we broaden the sample to include women and those who do not receive unemployment benefits.

${ }^{17}$ Note that our observations are unemployment spells, not individuals, and many individuals suffer more than one unemployment spell. If we drop individuals with more than one unemployment spell (about half the sample), our coefficients are larger but are statistically insignificant. If we drop individuals with more than two unemployment spells, our coefficients remain larger than those presented and are statistically significant. If we cluster standard errors at the individual level, our results remain unchanged.
} 
utility payments. We code an individual as financially distressed if they answer "Yes" to the most general question: "During the past 12 months, has there been a time when (you/anyone in hour household) did not meet all of your essential expenses?" This results in 2,888 unemployment spells and 77,487 weekly observations for the financially distressed sample. In the next subsection, we show that there is a high correlation in another data set between having trouble meeting essential expenses and having negative information on one's credit report. We chose to use information on financial hardship from as early as possible in the SIPP sample, although the same questions were asked again in late 2011-early 2012, so as to minimize the possibility that unemployment spells caused financial distress. This conservative choice means that we miss some episodes of financial distress. ${ }^{18}$

Table 3.3 shows the financial hardship questions and the share of unemployed respondents answering "Yes" to each. We use the broadest indicator of financial distress (failing to meet essential expenses) in our analysis. $28 \%$ of the unemployed respond that they are not able to meet all of their essential expenses, compared to $18 \%$ of the full SIPP sample. In the specific questions that follow, the most common missed payment involves gas, oil, or electricity bills (19\% of everyone who is unemployed), and then rent or mortgage (15\%). We use this broad indicator as a proxy for negative information on a credit report, rather than the specific SIPP questions, for three reasons. First, the specific questions do not cover delinquent credit card, auto or medical debt, which are important components of credit reports. Second, many people answer yes to multiple specific questions and these responses will likely be correlated with unobservable missed payments, so we cannot isolate the impact of missing specific payment types on job-finding rates. Third, using a comparable measure of financial

\footnotetext{
${ }^{18}$ In robustness checks we show that our estimates are similar if we limit the sample to individuals who report financial distress prior to the beginning of their unemployment spell. If unemployment causes financial distress, then financial distress might in turn affect how intensively someone searches for a job or someone's reservation wage for accepting a job offer. This would get netted out in our differences-in-differences strategy, unless the credit report bans undoes some of those effects; if it does, that would lead to longer unemployment spells, but we find a reduction in spell length.
} 
distress in the FINRA data below, we show that difficulty meeting essential expenses is quite positively correlated with having a low credit score.

Table 3.4 presents the same summary statistics as earlier for the distressed and nondistressed samples. As one might expect, the group that has had difficulty paying its bills has lower pre-unemployment monthly wages ( $\$ 1,920$ versus $\$ 2,520)$, a slightly lower level of education and more black, Hispanic and female members. This group also has a slightly longer average unemployment duration (27 versus 26 weeks). Lastly, the share of unemployed respondents in Table 3.2 who have trouble paying their bills is slightly (and significantly) higher in control states (29\%) than in treatment states (26\%).

\subsubsection{Corroborating Information on Financial Distress}

The FINRA Investor Education Foundation provides information and educational tools to promote financial literacy. As part of this effort, it undertakes the National Financial Capability Study (NFCS), a periodic survey of the financial situation of over 20,000 Americans, representative of each U.S. state. We use the 2009 State-by-State Survey to investigate credit information for people who report having trouble meeting their regular expenses.

As shown in Table 3.5, 17\% of NFCS respondents find it very difficult to "cover your expenses and pay all your bills", and $44 \%$ find it somewhat difficult. ${ }^{19}$ The $17 \%$ is quite close to the $18 \%$ of all SIPP respondents who report not having been able to meet their essential expenses, suggesting these two measures are comparable. Another question asks about respondents' credit scores for the $42 \%$ of respondents who have checked their credit score within the last 12 months. Credit scores of 620 or less were reported by $57 \%$ of respondents who found it very difficult to cover their expenses, compared to $29 \%$ and $8 \%$ of those who found it somewhat difficult or not difficult, respectively. While not everyone

\footnotetext{
${ }^{19}$ These statistics are computed using surveys weights to make them nationally representative.
} 
had checked their credit scores, many more answered questions about recent bankruptcies and late mortgage or credit card payments. Once again, individuals who had difficulty covering their expenses were more likely to report negative credit information. Therefore, the information in the NFCS suggests that the SIPP financial distress responses proxy poor credit histories quite well. ${ }^{20}$

\subsection{Estimation Results}

We estimate a series of hazard models to investigate how employment credit report bans affect unemployment durations for individuals who have trouble paying their bills. Our double-difference identification strategy compares the employment hazard rate for those who are financially distressed in states with and without bans. Our triple-difference specification includes the non-distressed sample as well, providing a within-state control group. We cluster all standard errors at the state level. ${ }^{21}$

\subsubsection{Baseline Results}

Table 3.6 reports the main results from the Cox proportional hazard models, estimated for the weekly job-finding hazard rate. Column 1 reports the coefficients from equation (3.1), the double-difference specification for the sample of financially distressed individuals, while column 2 reports the same specification for non-distressed individuals, and column 3 reports the coefficients from equation (3.2), the triple-difference specification that includes both the financial distressed and non-distressed.

\footnotetext{
${ }^{20} \mathrm{Hsu}$, Matsa, and Melzer (2016) validate another measure of financial distress in the SIPP, about mortgage delinquency, by showing that the frequency and geographic distribution of mortgage delinquency in the SIPP is highly correlated with the measure from the Mortgage Banker's Association's National Delinquency Survey over the same period.

${ }^{21}$ This approach follows Chetty (2008) and Kroft and Notowidigdo (forthcoming). If we cluster standard errors at the individual level, our main estimates are less precise, but remain statistically significant.
} 
In column 1, the coefficient on Ban is 0.247 and statistically significant at the $5 \%$ level. It indicates that financially distressed individuals living in a state with a credit report ban have unemployment durations that are $25 \%$ lower, on average, than those living in states without a credit report ban, after controlling for state fixed effects, year fixed effects, and individual characteristics. To interpret this as the causal effect of banning credit checks, there must be no other changes affecting unemployment durations that are correlated with the enactment of credit report bans.

The non-distressed sample provides a way to investigate this identification assumption. If our results are driven by statewide shocks to unemployment durations, such as unobserved labor market conditions, that are correlated with bans, then these may affect financially distressed and non-distressed individuals similarly, and so the coefficient on $B a n_{s t}$ will be similar when estimated on the sample of non-distressed individuals. Other possibilities that may invalidate the non-distressed as a control group - such as statistical discrimination or crowd-out from jobs now taken by the financially distressed - would result in a negative estimated effect of Ban. Column 2 reports the coefficients from equation (3.1) estimated on the sample of non-distressed individuals. Consistent with the identification assumption, the coefficient on Ban is estimated to be close to zero, at 0.048 , and is statistically insignificant, indicating little difference in the unemployment durations of (and no apparent harm to) non-distressed individuals living in ban and non-ban states.

The triple-difference specification in equation (3.2) relaxes the assumption that changes in labor markets within states over time must be uncorrelated with the credit report bans. Now, the identifying assumption is that broad labor market shocks that are correlated with credit report bans affect distressed and non-distressed individuals similarly. Combining the distressed and non-distressed samples allows us to include state and year fixed effects interacted with an indicator for financial distress, as well as state-by-year fixed effects that control for state-level time-varying unobserved shocks to unemployment duration. The re- 
sults are presented in Column 3 of Table 3.6. The key coefficient in this specification is the interaction of financial distress FD with Ban. The estimate of 0.284 (significant at the $1 \%$ level) indicates that upon the enactment of a credit ban, unemployment durations of financially distressed individuals fall by $28 \%$ relative to non-distressed individuals in the same state and year (after conditioning on all other covariates). The state-by-year fixed effects are jointly statistically significant, indicating different patterns in employment hazards within states over time, and the state-distressed fixed effects are jointly significant, indicating fixed differences across states in the employment hazards of the financially distressed as opposed to the non-distressed; the year-distressed fixed effects are not jointly significant.

Overall, the results in Table 3.6 show that credit check bans reduce the unemployment durations of the financially distressed by about twenty-five percent, while having little effect on the unemployment durations of those who are not distressed. Besides mandating the pooling of distressed and non-distressed job applicants in the employment screening process, the laws may also change the job-seeking behavior of those who are financially distressed. The relatively large effect that we estimate could arise because banning the use of credit

reports may encourage people with bad credit to apply for some jobs that they would not have otherwise.

\subsubsection{Additional Estimates}

We implement several checks on the robustness of our estimation results in Tables 3.7 and 3.8, and the estimated effect of the bans remains quite similar. We include additional individual controls and state-level economic controls, we alter our sample selection, and we report pre-ban event study coefficients. In Table 3.9, we examine the effect of bans on broader groups.

Column 1 repeats the baseline estimate of 0.247 on Ban from equation (3.1). One po- 
tential concern is that year fixed effects do not fully control for time-varying differences in unemployment duration, which is measured at the weekly level. Column 2 adds year-bymonth fixed effects, and the estimated effect on durations remains similar. A second concern is that the questions about financial distress, which we use to proxy bad credit, were collected in wave 6 , two years after the 2008 SIPP survey began, and unemployment may cause financial distress. Column 3 restricts the sample to individuals with unemployment spells that began after the financial distress questions were asked. With this restriction, the coefficient on the effect of the credit ban remains similar at 0.222 , though it is now only significant at the $10 \%$ level. Column 4 includes additional individual-level controls for a five-piece log linear spline in pre-unemployment wages and dummies for occupation and industry; this increases the coefficient to $0.285 .{ }^{22}$ Column 5 controls for geographic variation in both labor markets and unemployment benefits during the Great Recession by including the state-level unemployment rate and maximum allowable weeks of unemployment insurance, and Column 6 includes both the individual and state-level controls. Including these controls raises the coefficient to 0.324 in Column 5 and 0.361 in Column $6 .{ }^{23}$ The coefficients in Columns 4 through 6 are all significant at the $1 \%$ level.

In Table 3.8, we investigate the timing of the changes in unemployment durations by estimating a version of equation (3.1) that includes leads, which indicate that Ban will be implemented in one or two years:

$$
\log \left(h_{i s t}(\tau)\right)=\log \left(h_{0}(\tau)\right)+\beta_{-2} \operatorname{Ban}_{s, t+2}+\beta_{-1} \operatorname{Ban}_{s, t+1}+\beta \operatorname{Ban}_{s t}+X_{i s t} \gamma+\delta_{s}+\tau_{y(t)} .
$$

\footnotetext{
${ }^{22}$ The occupation dummies are for the five high-level SOC occupation classifications for the individual's pre-unemployment occupation (and a dummy for missing). There are twelve industry classifications and a dummy for missing. "Mining, quarrying, and oil and gas extraction" was combined with "Agriculture, forestry, fishing, and hunting" because of the small number of observations. Pre-unemployment (monthly) wages, occupation, and industry are the values for the last month worked prior to the unemployment spell.

${ }^{23}$ We use the unemployment insurance coding from Mueller, Rothstein \& von Wachter (2016), which includes data through 2012. For this reason, we drop the unemployment spells beginning in 2013 from the regressions reported in Columns 5 and 6 . In unreported results, we also control for the state-year level home price index, and the estimates remain very similar.
} 
The coefficients $\beta_{-2}$ and $\beta_{-1}$ capture the difference in unemployment durations between states that will pass a ban in the next 1 or 2 years and the control states. If our identification strategy is reasonable and the passage of the bans are uncorrelated with trends in unemployment durations, the coefficients $\beta_{-2}$ and $\beta_{-1}$ should be around zero. If, however, the treatment states follow different pre-trends than the control states, $\beta_{-2}$ and $\beta_{-1}$ could be non-zero. The main concern is that unemployment durations were already lower in states that passed bans.

Table 3.8 reports results from this specification. In general, the results indicate that unemployment durations may have been higher in 1-2 years preceding the bans, primarily for the non-distressed sample. Columns 1-4 report the double difference specification for the financially distressed, and Columns 5-8 report the double difference specification for the non-distressed. Column 1 includes the one-year lead. Consistent with our identification assumption, the coefficient is small and statistically insignificant, and the coefficient on Ban remains almost identical in magnitude and significance. Column 2 includes one- and twoyear leads, and Column 3 adds the state unemployment rate as well. The coefficient on the 2-year leading indicator of -0.124 (standard error 0.160) is insignificant but somewhat large in magnitude in Column 2, and it shrinks a little to -0.090 (0.154) in Column 3, while the coefficient on Ban shrinks slightly to 0.229 and remains significant in Column 3. Column 4 drops unemployment spells that begin less than three months before the enactment of a ban (because they may be partially affected by the ban), and this causes the coefficients on the 1-year lead to become negative, which is consistent with the dropped spells being shortened by the ban. The coefficient on the Ban indicator increases in Column 4, while the cumulative change (equal to the sum of the three Ban coefficients) is 0.27 , similar to earlier estimates.

Columns 5-8 estimate these specifications on the non-distressed sample, which might indicate whether credit report bans responded to broader labor market conditions. Again, the concern is that unemployment durations were shorter in states that instituted bans, 
making it look like bans caused shorter durations; and again, these estimates show weak evidence that durations may have been longer, not shorter, in ban states. The coefficients on the one-year Ban lead and the Ban policy variables are statistically insignificant but somewhat large in magnitude, at -0.124 (standard error 0.0969) for the lead and 0.115 (0.081) for Ban in Column 7); the cumulative effect is close to zero, as we found earlier. Dropping the unemployment spells that begin less than 3 months before the enactment of the ban shrinks the magnitude of the 1-year lead coefficient. Overall, these results suggest a possible story in which worsening unemployment durations perhaps led to pressure for the bans, which shortened durations for the financially distressed. If the imprecisely measured improvement for the non-distressed includes an element of mean reversion in unemployment durations, then the twice-as-large estimate for the distressed continues to indicate that they benefited from the bans, even if the estimate partly reflects mean reversion.

Lastly, Table 3.9 formally tests whether banning employment credit checks affected jobfinding rates overall or for disadvantaged groups that have higher rates of poor credit. In contrast to other studies, we do not find that the bans have a statistically significant effect on minority employment outcomes. The signs of the coefficients in Columns 2 and 3 suggest that African-Americans had shorter unemployment spells and Hispanics had longer unemployment spells after the enactment of a ban, but these estimates fall well short of statistical significance. Whites had $18.3 \%$ shorter unemployment spells, and the estimate is significant at the $10 \%$ confidence level. To compare the estimates to each other, we ran two triple-difference specifications, either pooling the samples of Black with non-Hispanic White individuals or Hispanic with non-Hispanic White individuals. These specifications follow those in equation (3.2), except the financial distress indicator $F D$ is replaced with either and indicator for Black status (in the first regression) or Hispanic status (in the second regression). The coefficient on the interaction of the race indicator with the Ban variable is statistically insignificant in both regressions, which indicates that there are no statistically 
significant differences in the impact of the law on minority groups relative to non-Hispanic White individuals. However, the population sizes limit the power of our tests, and we cannot rule out economically meaningful effects. ${ }^{24}$

\subsection{Conclusion}

Employers' use of credit reports is controversial. Prominent national politicians, including Senators Sanders and Warren, have introduced legislation that would ban their use, and nearly every state has considered its own limits. A key motivation for the bans is a desire to help individuals who experience financial hardship. We use double- and triple-difference specifications and find a substantial improvement in job search outcomes of people who are likely to have bad credit - with about a $25 \%$ decline in the duration of unemployment for people who have had having trouble paying their bills. These results suggest that employers treat such information as a negative signal of productivity and that people with bad credit may be deterred from applying for jobs for which they believed a bad credit history would disqualify them.

Another motivation for the bans is a desire to help members of minority groups, but the existing literature suggests that credit report bans may depress minority employment as a result of statistical discrimination. We fail to confirm this finding in our data, but our standard errors are large enough that we cannot rule out economically meaningful effects.

It is worth noting that these effects occurred during the high-unemployment period of the Great Recession, and perhaps banning the use of negative information may be more important during slack labor markets. In future research, it may be possible to use long-

\footnotetext{
${ }^{24}$ Unsurprisingly, when we pool together the financially distressed sample (who comprise $28 \%$ of the unemployed in the SIPP and experience around a $25 \%$ reduction in unemployment duration) and the nondistressed (who experience a small and insignificant increase) in Column 1, the overall effect of credit report bans is to reduce unemployment durations by $9.7 \%$.
} 
term employment outcomes from matched employee-employer data to look for longer-lasting effects, either positive or negative, of eliminating the use of credit reports. 
Table 3.1: State Employment Credit Check Bans

\begin{tabular}{cc}
\hline State & Effective Date \\
\hline WA & $7 / 22 / 2007$ \\
HI & $7 / 15 / 2009$ \\
OR & $7 / 10 / 2010$ \\
IL & $1 / 1 / 2011$ \\
CT & $10 / 1 / 2011$ \\
MD & $10 / 1 / 2011$ \\
CA & $1 / 1 / 2012$ \\
VT & $7 / 1 / 2012$ \\
CO & $7 / 1 / 2013$ \\
NV & $10 / 1 / 2013$ \\
DE & $5 / 8 / 2014$ \\
\hline
\end{tabular}

Information on the states that enacted credit bans is from the National Conference of State Legislatures, and the dates that the bans went into effect were obtained from a combination of articles, press releases, and industry reports. The information in this table is identical to that in Cortés, Glover, \& Tasci (2016). 
Table 3.2: Summary Statistics for the Sample of Unemployment Spells by States

\begin{tabular}{lcccccc}
\hline & \multicolumn{2}{c}{ Full Sample } & \multicolumn{2}{c}{ Control States } & \multicolumn{2}{c}{ Ban States } \\
\hline & Mean & Std. Dev. & Mean & Std. Dev. & Mean & Std. Dev. \\
Duration & 26.4 & 18.2 & 26.0 & 18.1 & 27.4 & 18.2 \\
Bad credit & 0.28 & 0.45 & 0.29 & 0.45 & 0.26 & 0.44 \\
Pre-unemp. monthly wage & 2,351 & 2,487 & 2,305 & 2,506 & 2,489 & 2,423 \\
Education & 12.7 & 2.5 & 12.8 & 2.3 & 12.5 & 3.0 \\
Age & 36.5 & 13.1 & 36.5 & 13.1 & 36.7 & 13.2 \\
Female & 0.47 & 0.50 & 0.47 & 0.50 & 0.48 & 0.50 \\
Married & 0.42 & 0.49 & 0.41 & 0.49 & 0.46 & 0.50 \\
Black & 0.14 & 0.34 & 0.15 & 0.36 & 0.09 & 0.28 \\
Hispanic & 0.16 & 0.37 & 0.12 & 0.33 & 0.28 & 0.45 \\
Obs. & \multicolumn{2}{c}{10,249} & & 7,697 & & 2,552 \\
\hline
\end{tabular}

The data are individual-level unemployment spells from the 2008 SIPP, covering 2008-2013. Control States and Ban States show the means and standard deviations for unemployment spells in states that never enacted a credit report ban (control states) and the states in Table 3.1 that eventually enact a ban (ban states). Unemployment durations are censored at 50, and the means include censored observations. Financially distressed indicates the percentage answering yes to the question, "During the past 12 months, has there been a time when (you/anyone in hour household) did not meet all of your essential expenses?" This question was asked in the Adult Well-Being interview in Wave 6, May-August 2010. 
Table 3.3: Financial Hardship in the SIPP

\begin{tabular}{lcc}
\hline Financial Hardship Questions & Mean Full SIPP & Mean Unemployed \\
\hline $\begin{array}{l}\text { Did you not meet all of your essential } \\
\text { expenses? }\end{array}$ & 0.19 & 0.28 \\
$\begin{array}{l}\text { Did you not pay the full amount of the } \\
\text { rent or mortgage? }\end{array}$ & 0.1 & 0.15 \\
$\begin{array}{l}\text { Were you evicted? } \\
\text { Did you not pay the full amount of the } \\
\text { gas, oil, or electricity bills? }\end{array}$ & 0.00 & 0.01 \\
$\begin{array}{l}\text { Did the gas or electric company turn off } \\
\text { service, or the oil company not deliver } \\
\text { oil? }\end{array}$ & 0.02 & 0.19 \\
$\begin{array}{l}\text { Did you need to see a dentist but not } \\
\text { go? }\end{array}$ & 0.05 & 0.04 \\
$\begin{array}{l}\text { Did you need to see a doctor or go to } \\
\text { the hospital but not go? }\end{array}$ & 0.09 & 0.07 \\
$\begin{array}{l}\text { Did the telephone company discon- } \\
\text { nect service because payments were not } \\
\text { made? }\end{array}$ & 0.11 & 0.15 \\
\begin{tabular}{l} 
Observations \\
\hline
\end{tabular} & 80,650 & 0.18 \\
\hline
\end{tabular}

This table shows the incidence of financial distress, based on questions in the Adult Well-Being interview in Wave 6, May-August 2010, among SIPP respondents and the subsample of SIPP respondents with unemployment spells. 
Table 3.4: Summary Statistics for the Sample of Unemployment Spells by Financially Distressed and Non-Distressed

\begin{tabular}{lcccccc}
\hline & \multicolumn{2}{c}{ Full Sample } & \multicolumn{2}{c}{ Distressed } & \multicolumn{2}{c}{ Non-Distressed } \\
\hline & Mean & Std. Dev. & Mean & Std. Dev. & Mean & Std. Dev. \\
Duration & 26.4 & 18.2 & 26.8 & 18.2 & 26.2 & 18.1 \\
Ban & 0.09 & 0.29 & 0.09 & 0.28 & 0.10 & 0.30 \\
Pre-unemp. monthly wage & 2,351 & 2,487 & 1,920 & 1,707 & 2,520 & 2,714 \\
Education & 12.7 & 2.5 & 12.2 & 2.3 & 12.9 & 2.5 \\
Age & 36.5 & 13.1 & 36.4 & 12.4 & 36.6 & 13.4 \\
Female & 0.47 & 0.50 & 0.49 & 0.50 & 0.46 & 0.50 \\
Married & 0.42 & 0.49 & 0.40 & 0.49 & 0.43 & 0.50 \\
Black & 0.14 & 0.34 & 0.17 & 0.38 & 0.12 & 0.33 \\
Hispanic & 0.16 & 0.37 & 0.19 & 0.39 & 0.15 & 0.36 \\
Obs. & \multicolumn{2}{c}{10,249} & & 2,888 & & 7,361 \\
\hline
\end{tabular}

The data are individual-level unemployment spells from the 2008 SIPP. Distressed and NonDistressed show the means and standard deviations for unemployment spells among individuals answering yes or no, respectively, to the question, "During the past 12 months, has there been a time when (you/anyone in hour household) did not meet all of your essential expenses?" This question was asked in the Adult Well-Being interview in Wave 6, May-August 2010. Unemployment durations are censored at 50, and the means include censored observations. 


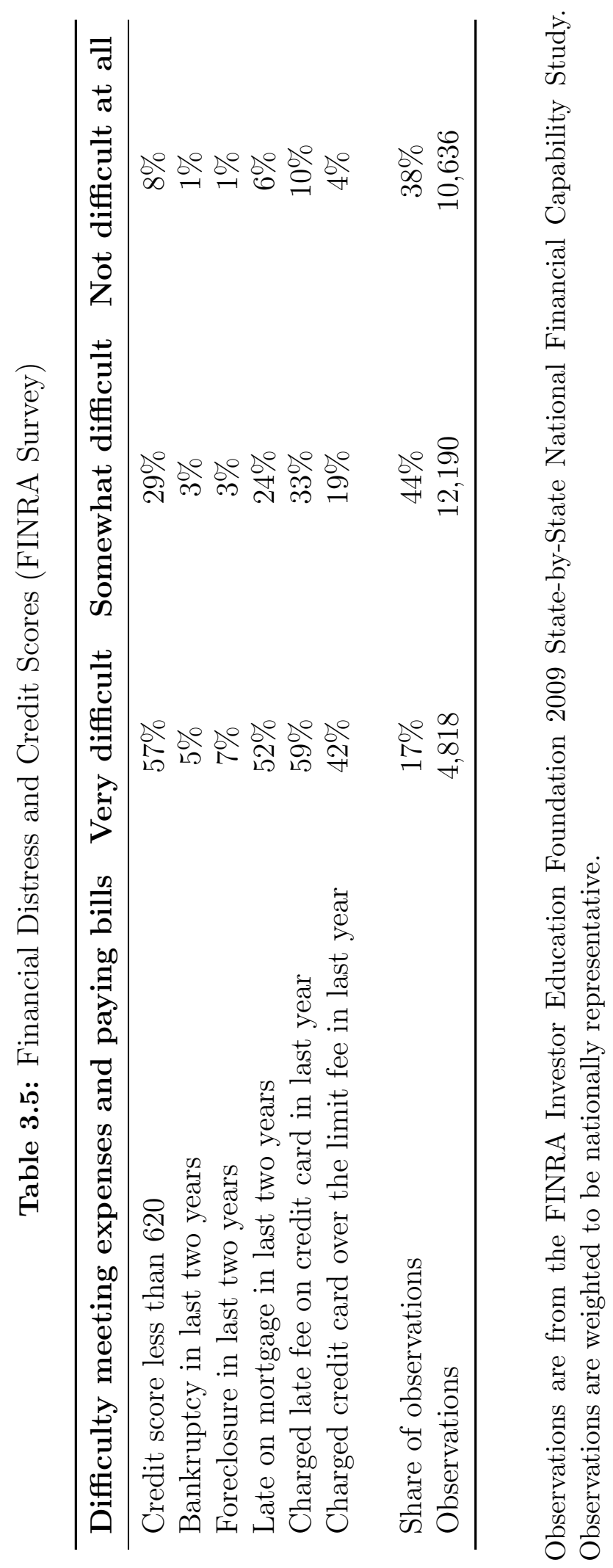


Table 3.6: The Impact of Credit Check Bans on Weekly Job-Finding Hazards

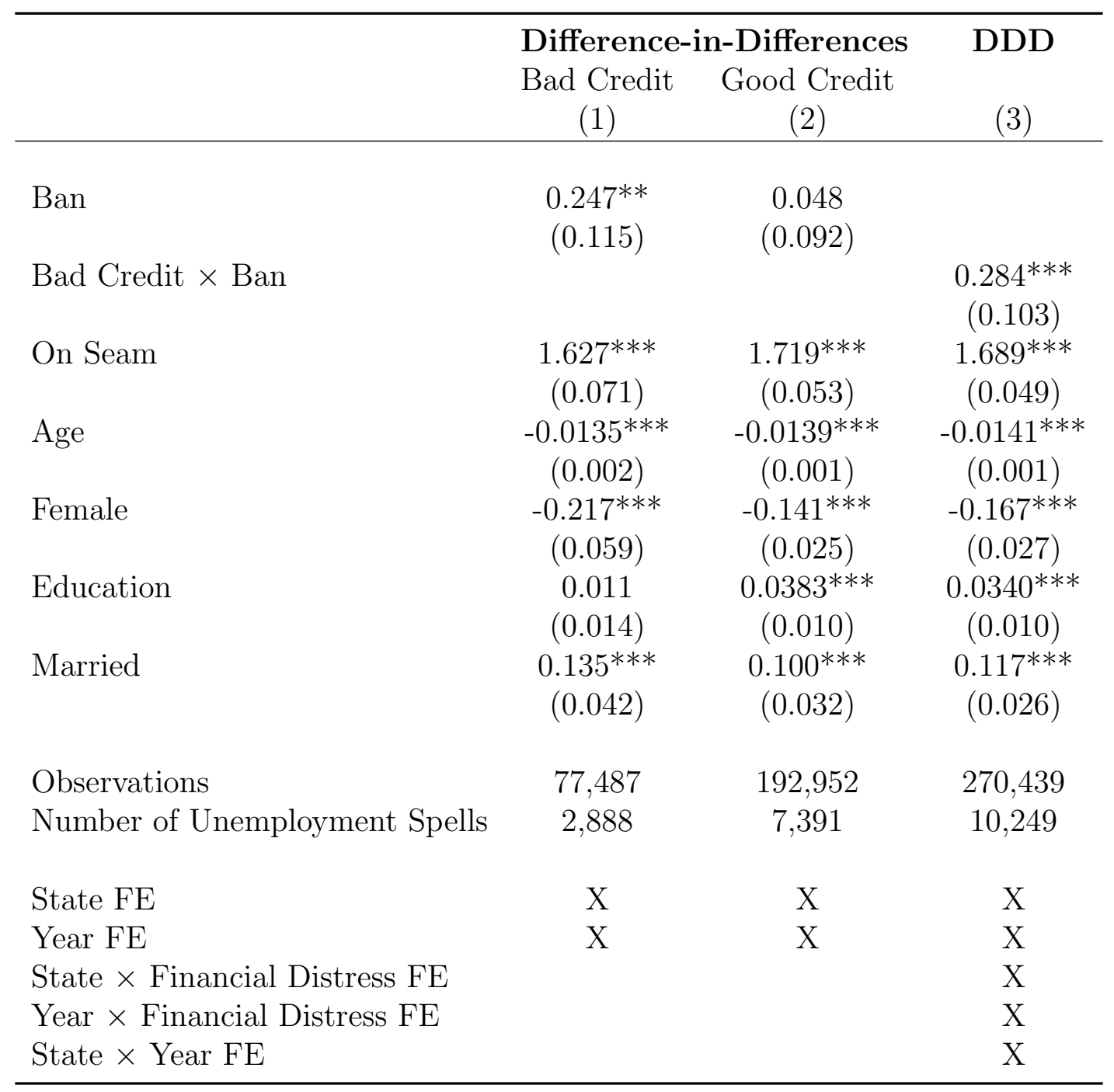

The data are individual-level unemployment spells from the 2008 SIPP. All columns report estimates from semiparametric Cox proportional hazard models. Ban equals 1 if credit checks were banned in state $\mathrm{s}$ at the start of the unemployment spell, and Financial Distress equals 1 if the individual answers "Yes" to the question "During the past 12 months, has there been a time when (you/anyone in hour household) did not meet all of your essential expenses?" in the Wave 6 AdultWellbeing questionnaire. Columns 1 and 2 report coefficients from equation (3.1) estimated on the Distressed and Non-Distressed samples, respectively. Column 3 reports coefficients from equation (3.2) estimated on the pooled sample of Distressed and Non-Distressed unemployment spells. On Seam is an indicator for being on the seam between interviews to adjust for the seam effect. Standard errors are clustered at the state level. Significance levels: ${ }^{*}=.1, * *=.05$ and ${ }^{* * *}=.01$ 


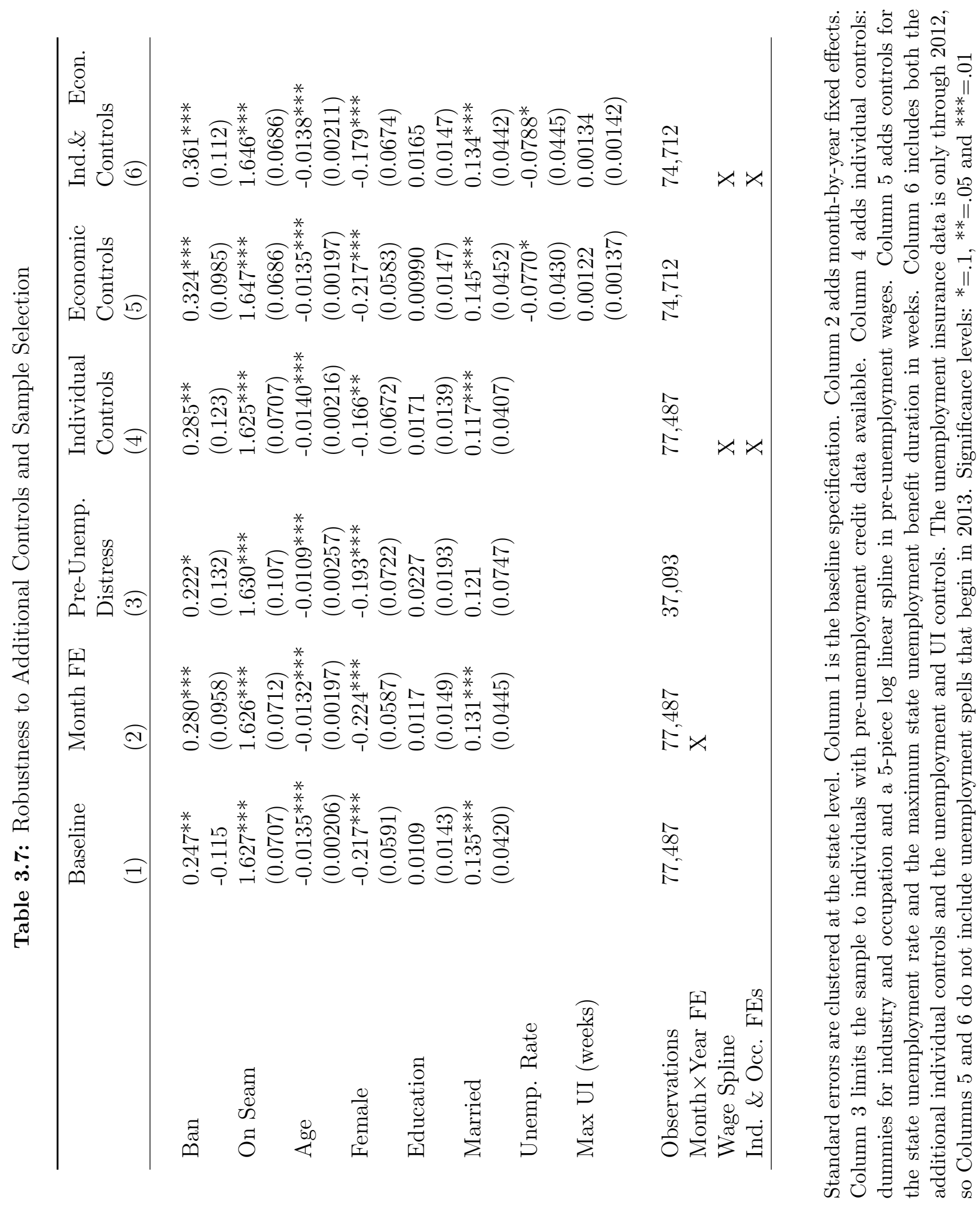



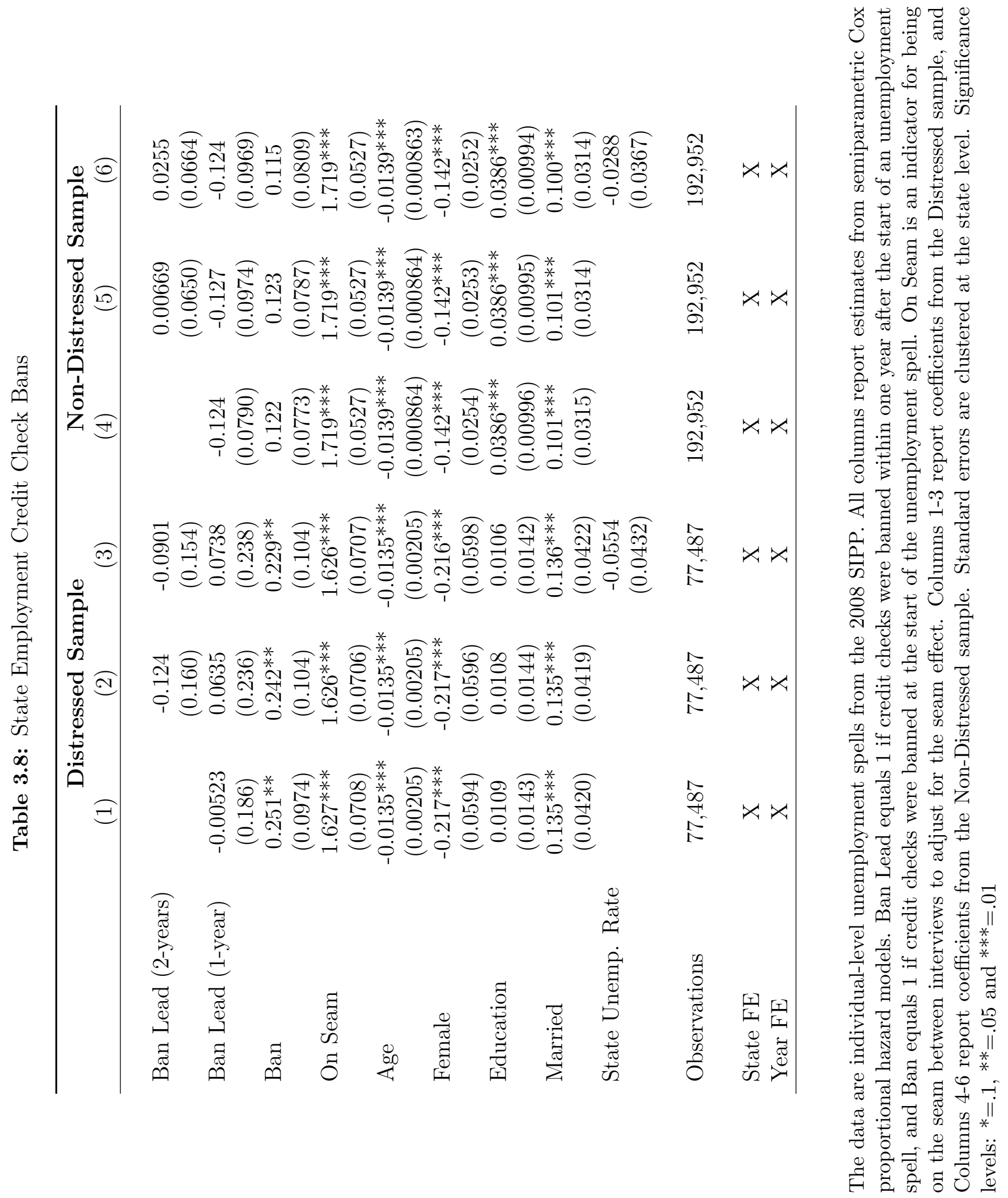
Table 3.9: State Employment Credit Check Bans

\begin{tabular}{|c|c|c|c|c|}
\hline & $\begin{array}{c}\text { All } \\
(1)\end{array}$ & $\begin{array}{c}\text { Black } \\
(2)\end{array}$ & $\begin{array}{c}\text { Hispanic } \\
(3)\end{array}$ & $\begin{array}{c}\text { Non-Hispanic White } \\
(4)\end{array}$ \\
\hline Ban & $\begin{array}{c}0.0969 \\
(0.0853)\end{array}$ & $\begin{array}{c}0.122 \\
(0.245)\end{array}$ & $\begin{array}{l}-0.162 \\
(0.171)\end{array}$ & $\begin{array}{l}0.183^{*} \\
(0.103)\end{array}$ \\
\hline Onseam & $\begin{array}{l}1.694^{* * *} \\
(0.0488)\end{array}$ & $\begin{array}{c}1.809^{* * *} \\
(0.094)\end{array}$ & $\begin{array}{c}1.903^{* * *} \\
(0.087)\end{array}$ & $\begin{array}{c}1.611^{* * *} \\
(0.047)\end{array}$ \\
\hline Age & $\begin{array}{r}-0.0137^{* * *} \\
(0.000773)\end{array}$ & $\begin{array}{c}-0.00966^{* *} \\
(0.004)\end{array}$ & $\begin{array}{c}-0.0148 * * * \\
(0.002)\end{array}$ & $\begin{array}{c}-0.0158 * * * \\
(0.001)\end{array}$ \\
\hline Female & $\begin{array}{c}-0.168^{* * *} \\
(0.0264)\end{array}$ & $\begin{array}{l}(0.103) \\
(0.085)\end{array}$ & $\begin{array}{c}-0.400^{* * *} \\
(0.066)\end{array}$ & $\begin{array}{c}-0.127^{* * *} \\
(0.035)\end{array}$ \\
\hline Education & $\begin{array}{c}0.0324^{* * *} \\
(0.00953)\end{array}$ & $\begin{array}{c}0.0861^{* * *} \\
(0.019)\end{array}$ & $\begin{array}{l}-0.009 \\
(0.008)\end{array}$ & $\begin{array}{l}0.0491^{* * *} \\
(0.011)\end{array}$ \\
\hline Married & $\begin{array}{l}0.113^{* * *} \\
(0.0251)\end{array}$ & $\begin{array}{c}0.073 \\
(0.128)\end{array}$ & $\begin{array}{c}0.202^{* * *} \\
(0.050)\end{array}$ & $\begin{array}{l}0.0795^{* * *} \\
(0.027)\end{array}$ \\
\hline $\begin{array}{l}\text { Observations } \\
\text { Number of Spells }\end{array}$ & $\begin{array}{c}270,439 \\
10,249\end{array}$ & $\begin{array}{c}40,241 \\
1,397\end{array}$ & $\begin{array}{c}44,514 \\
1,661\end{array}$ & $\begin{array}{c}165,271 \\
6,467\end{array}$ \\
\hline $\begin{array}{l}\text { State FE } \\
\text { Year FE }\end{array}$ & $\begin{array}{l}X \\
X\end{array}$ & $\begin{array}{l}X \\
X\end{array}$ & $\begin{array}{l}X \\
X\end{array}$ & $\begin{array}{l}X \\
X\end{array}$ \\
\hline
\end{tabular}

The data are individual-level unemployment spells from the 2008 SIPP. All columns report estimates from semiparametric Cox proportional hazard models in equation (3.1), with the samples restricted to all individuals (both distressed and non-distressed), Black individuals, Hispanic individuals, and non-Hispanic White individuals. On Seam is an indicator for being on the seam between interviews to adjust for the seam effect. Standard errors are clustered at the state level. Significance levels: $*=.1, * *=.05$ and $* * *=.01$ 


\section{Appendix}

\section{A Appendix}

Measuring unemployment duration

Weekly employment status (ES) in the SIPP can take the following values:

1. With a job - working

2. With job - not on layoff, absent

3. With job - on layoff, absent

4. No job - looking for work or on layoff

5. No job - not looking for work and not on layoff

We define a job separation as a switch from $\mathrm{ES}=1,2$ to $\mathrm{ES}=3,4,5$. The duration of the unemployment spell is the number of weeks with $\mathrm{ES}=3,4,5$, starting at the date of the job separation and ending when the individual reports a full month of work $(\mathrm{ES}=1$ or $\mathrm{ES}=2)$. The unemployment spell is considered a temporary layoff if the individual reports $\mathrm{ES}=3$ at any point in the spell. An individual is considered to be actively searching for a job if $\mathrm{ES}=4$ at any point during the spell. Our sample construction below will focus on unemployment durations of active job searchers. 


\section{Sample construction}

Our sample construction largely follows Chetty (2008), though we include women and individuals who are not receiving unemployment benefits. The 2008 Survey of Income and Program Participation starts with a sample of 105,663 individuals in 40,030 households. Of these, 31,570 individuals experienced at least one job separation during the sample period. Restricting the sample to individuals between the ages of 18 and 65, who are observed for at least three months, and have at least three months of wage history leaves 19,865 individuals. We drop individuals on temporary layoff, since they may not have been searching for a job, which leaves 16,385 individuals. We then keep only those actively searching for a job for at least one week, to eliminate people who dropped out of the labor force, leaving 10,054 individuals. Of these, we keep the 7,829 who have information on financial distress in the Wave 6 Adult Well-Being topical module. The final core sample consists of 7,829 individuals who experience 10,249 unemployment spells. 


\section{Bibliography}

Agarwal, Sumit, Chunlin Liu, and Lawrence Mielnicki. 2003. "Exemption Laws and Consumer Delinquency and Bankruptcy Behavior: An Empirical Analysis of Credit Card Data." The Quarterly Review of Economics and Finance 43 (2):273-289.

Akerlof, George A and Robert J Shiller. 2015. Phishing for phools: The economics of manipulation and deception. Princeton University Press.

Albanesi, Stefania and Jaromir Nosal. 2015. "Insolvency After the 2005 Bankruptcy Reform." Federal Reserve Bank of New York Staff Reports .

Alper, Elijah M. 2007. "Opportunistic Informal Bankruptcy: How BAPCPA May Fail to Make Wealthy Debtors Pay Up." Columbia Law Review :1908-1943.

AOUSC. 2014. "2014 Report of Statistics Required by the Bankruptcy Abuse Prevention and Consumer Protection Act of 2005." Tech. rep., Administrative Office of the United States Courts, Washington D.C.

Athreya, Kartik. 2006. "Fresh Start or Head Start? Uniform Bankruptcy Exemptions and Welfare." Journal of Economic Dynamics and Control 30 (11):2051-2079.

Autor, David H. and David Scarborough. 2008. "Does job testing harm minority workers? Evidence from retail establishments." The Quarterly Journal of Economics 123 (1):219277. 
Avery, Robert B, Paul S Calem, Glenn B Canner, and Raphael W Bostic. 2003. "Overview of consumer data and credit reporting, an." Fed. Res. Bull. 89:47.

Baily, Martin Neil. 1978. "Some aspects of optimal unemployment insurance." Journal of Public Economics 10 (3):379-402.

Bartik, Alexander Wickman and Scott Nelson. 2016. "Credit Reports as Résumés: The Incidence of Pre-Employment Credit Screening." .

Berger, Allen N, Geraldo Cerqueiro, and María F Penas. 2011. "Does Debtor Protection Really Protect Debtors? Evidence from the Small Business Credit Market." Journal of Banking \& Finance 35 (7):1843-1857.

Berkowitz, Jeremy and Richard Hynes. 1999. "Bankruptcy Exemptions and the Market for Mortgage Loans." The Journal of Law and Economics 42 (2):809-830.

Berkowitz, Jeremy and Michelle J White. 2004. "Bankruptcy and Small Firms' Access to Credit." RAND Journal of Economics 35 (1):69-84.

Bos, Marieke, Emmily Breza, and Andres Liberman. 2016. "The Labor Market Effects of Credit Market Information." Working Paper .

Boustanifar, Hamid. 2015. "Personal Bankruptcy Reform, Credit Availability, and Financial Distress." .

Bronchetti, Erin Todd. 2012. "Workers' compensation and consumption smoothing." Journal of Public Economics 96 (5):495-508.

Brown, Meta, Andrew Haughwout, Donghoon Lee, and Wilbert van der Klaauw. 2011. "Do We Know What We Owe? A Comparison of Borrower- and Lender-Reported Consumer Debt." Federal Reserve Bank of New York Staff Reports (523). 
Browning, Martin and Thomas F Crossley. 2001. "Unemployment insurance benefit levels and consumption changes." Journal of public Economics 80 (1):1-23.

Buckley, F. H. and Margaret F. Brinig. 1998. "The Bankruptcy Puzzle." The Journal of Legal Studies 27 (1).

CFPB. 2012. "Key Dimensions and Processes in the US Credit Reporting System." CFPB White Paper (December) .

Chetty, Raj. 2006. "A general formula for the optimal level of social insurance." Journal of Public Economics 90 (10):1879-1901.

—. 2008. "Moral Hazard versus Liquidity and Optimal Unemployment Insurance." Journal of Political Economy 116 (2):173-234.

Clifford, Robert and Daniel Shoag. 2016. "No More Credit Score: Employer Credit Checks and Signal Substitution." Working Paper .

Cochrane, John H. 1991. "A simple test of consumption insurance." Journal of political economy :957-976.

Cornwell, Christopher and Bing Xu. 2014. "Effects of the BAPCPA on the Chapter Composition of Consumer Bankruptcies." Economics Letters 124 (3):439 - 442.

Cortés, Kristle Romero, Andrew S Glover, and Murat Tasci. 2016. "The unintended consequences of employer credit check bans on labor and credit markets." .

Dávila, Eduardo. 2016. "Using Elasticities to Derive Optimal Bankruptcy Exemptions." .

Dawsey, Amanda E and Lawrence M Ausubel. 2004. "Informal Bankruptcy." Unpublished Working Paper . 
Dawsey, Amanda E, Richard M Hynes, and Lawrence M Ausubel. 2013. "The Regulation of Non-Judicial Debt Collection and the Consumer's Choice Among Repayment, Bankruptcy and Informal Bankruptcy." American Bankruptcy Law Journal .

Dobbie, Will and Paul Goldsmith-Pinkham. 2015. "Debtor Protections and the Great Recession." .

Dobbie, Will, Paul Goldsmith-Pinkham, Neale Mahoney, and Jae Song. 2016. "Bad Credit, No Problem? Credit and Labor Market Consequences of Bad Credit Reports." Credit and Labor Market Consequences of Bad Credit Reports (September 27, 2016) .

Dobbie, Will and Jae Song. 2015. "Debt Relief and Debtor Outcomes: Measuring the Effects of Consumer Bankruptcy Protection." American Economic Review 105 (3):1272-1311.

Doleac, Jennifer L and Benjamin Hansen. 2016. "Does "ban the box" help or hurt low-skilled workers? Statistical discrimination and employment outcomes when criminal histories are hidden." Tech. rep., National Bureau of Economic Research.

Dube, Arindrajit, T. William Lester, and Michael Reich. 2010. "Minimum Wage Effects Across State Borders: Estimates Using Contiguous Counties." The Review of Economics and Statistics $92(4): 945-964$.

East, Chloe N and Elira Kuka. 2015. "Reexamining the consumption smoothing benefits of Unemployment Insurance." Journal of Public Economics 132:32-50.

Eaton, Jonathan and Mark Gersovitz. 1981. "Debt with potential repudiation: Theoretical and empirical analysis." The Review of Economic Studies 48 (2):289-309.

Edmiston, Kelly D. 2006. "A New Perspective on Rising Nonbusiness Bankruptcy Filing Rates: Analyzing the Regional Factors." Economic Review-Federal Reserve Bank of Kansas City 91 (2):55. 
Elias, Stephen, Albin Renauer, and Robin Leonard. 1996-2013. How to File for Bankruptcy. Berkeley: Nolo Press.

Ernst \& Young. 2014. "The Impact of Third-Party Debt Collection on the National and State Economies in 2013." Tech. rep., ACA International.

Fay, Scott, Erik Hurst, and Michelle J White. 2002. "The Household Bankruptcy Decision." American Economic Review 92 (3):706-718.

Fedaseyeu, Viktar. 2015. "Debt collection agencies and the supply of consumer credit." Tech. rep., Citeseer.

Fedaseyeu, Viktar and Robert M Hunt. 2014. "The economics of debt collection: enforcement of consumer credit contracts." .

Filer, Larry H and Jonathan D Fisher. 2005. "The consumption effects associated with filing for personal bankruptcy." Southern Economic Journal :837-854.

Finlay, Keith. 2009. "Effect of Employer Access to Criminal History Data on the Labor Market Outcomes of Ex-Offenders and Non-Offenders." Studies of Labor Market Intermediation .

Finlay, Steven. 2010. The management of consumer credit: theory and practice. Springer.

Flynn, Ed, Gordon Bermant, and Suzanne Hazard. 2003. "Chapter 7 Asset Cases Part II." American Bankruptcy Institute Journal .

Furletti, Mark. 2003. "Credit card pricing developments and their disclosure." Federal Reserve Bank of Philadelphia Payment Cards Center Discussion Paper (03-02). 
Goodman, Paul. 1993. "The Emergence of Homestead Exemption in the United States: Accommodation and Resistance to the Market Revolution, 1840-1880." The Journal of American History :470-498.

Grant, Charles. 2010. "Evidence on the insurance effect of bankruptcy exemptions." Journal of Banking 83 Finance 34 (9):2247-2254.

Grant, Charles and Winfried Koeniger. 2009. "Redistributive Taxation and Personal Bankruptcy in US States." Journal of Law and Economics 52 (3):445-467.

Gropp, Reint, John Karl Scholz, and Michelle J White. 1997. "Personal Bankruptcy and Credit Supply and Demand." The Quarterly Journal of Economics 112 (1):217-251.

Gross, Tal and Matthew J Notowidigdo. 2011. "Health insurance and the consumer bankruptcy decision: Evidence from expansions of Medicaid." Journal of Public Economics 95 (7):767-778.

Gruber, Jonathan. 1997. "The Consumption Smoothing Benefits of Unemployment Insurance." The American Economic Review 87 (1):192-205.

Hendren, Nathaniel. 2015. "Knowledge of Future Job Loss and Implications for Unemployment Insurance." Tech. rep., National Bureau of Economic Research.

Herkenhoff, Kyle, Gordon Phillips, and Ethan Cohen-Cole. 2016. "The Impact of Consumer Credit Access on Employment, Earnings and Entrepreneurship." Working Paper .

Hintermaier, Thomas and Winfried Koeniger. 2016. "Debt Portfolios and Homestead Exemptions." American Economic Journal: Macroeconomics 8 (4):103-41.

Holzer, Harry J., Raphael Steen, and Michael A. Stoll. 2006. "Perceived Criminality, Crim- 
inal Background Checks, and the Racial Hiring Practices of Employers." Journal of Law and Economics 49:451-480.

Hsu, Joanne W, David A Matsa, and Brian T Melzer. 2016. "Positive externalities of social insurance: Unemployment insurance and consumer credit." Tech. rep., National Bureau of Economic Research.

Hynes, Richard M. 1998. Three Essays on Exemptions and Consumer Bankruptcy. Ph.D. thesis, Ph. D. thesis, University of Pennsylvania.

— 2008. "Broke But Not Bankrupt: Consumer Debt Collection In State Courts." Fla. L. Rev. 60:1.

Hynes, Richard M, Anup Malani, and Eric A Posner. 2004. "The Political Economy of Property Exemption Laws." Journal of Law and Economics 47 (1):19-43.

Hynes, Richard M and Eric A Posner. 2002. "The law and economics of consumer finance." American Law and Economics Review 4 (1):168-207.

Jiménez, Dalié. 2009. "Distribution of Assets in Consumer Chapter 7 Bankruptcy Cases, The." American Bankruptcy Law Journal 83:795.

Kroft, Kory and Matthew J Notowidigdo. forthcoming. "Should unemployment insurance vary with the unemployment rate? Theory and evidence." Review of Economics and Statistics .

Lefgren, Lars and Frank McIntyre. 2009. "Explaining the Puzzle of Cross-State Differences in Bankruptcy Rates." The Journal of Law and Economics 52 (2):367-393.

Lehnert, Andreas and Dean M Maki. 2002. "Consumption, Debt and Portfolio Choice." .

Leonard, Robin. 2015. Solve Your Money Troubles: Debt, Credit $\& 3$ Bankruptcy. Nolo. 
Li, Wenli and Pierre-Daniel Sarte. 2006. "US Consumer Bankruptcy Choice: The Importance of General Equilibrium Effects." Journal of Monetary Economics 53 (3):613-631.

Li, Wenli, Michelle J. White, and Ning Zhu. 2011. "Did Bankruptcy Reform Cause Mortgage Defaults to Rise?" American Economic Journal: Economic Policy 3 (4):123-47.

Lin, Emily Y and Michelle J White. 2001. "Bankruptcy and the Market for Mortgage and Home Improvement Loans." Journal of Urban Economics 50 (1):138-162.

Livshits, Igor. 2015. "Recent developments in consumer credit and default literature." Journal of Economic Surveys 29 (4):594-613.

Loftsgordon, Amy. n.d. "Can a judgment creditor foreclose on my home?" http://www.nolo.com/legal-encyclopedia/can-judgment-creditor-foreclose-home.html. Accessed: 2016-06-16.

Lupica, Lois R. 2012. "The Consumer Bankruptcy Fee Study: Final Report." American Bankruptcy Institute Law Review 20.

Mahoney, Neale. 2015. "Bankruptcy as Implicit Health Insurance." The American Economic Review 105 (2):710-746.

Mankart, Jochen. 2014. "The (Un-)importance of Chapter 7 Wealth Exemption Levels." Journal of Economic Dynamics and Control 38:1-16.

Miller, Michelle M. 2011. "Who Files for Bankruptcy? State Laws and the Characteristics of Bankrupt Households." .

Mitman, Kurt. 2015. "Macroeconomic Effects of Bankruptcy \& Foreclosure Policies." .

—. 2016. "Macroeconomic Effects of Bankruptcy and Foreclosure Policies." American Economic Review 106 (8):2219-55. 
Morgan, Donald P, Benjamin Iverson, and Matthew Botsch. 2012. "Subprime Foreclosures and the 2005 Bankruptcy Reform." Economic Policy Review 18 (1).

NBRC. 1997. "Bankruptcy: The Next Twenty Years. Final Report of the Bankruptcy Review Commission." Tech. rep.

NCLC. 2016. Guide to Surviving Debt. National Consumer Law Center.

NCSL. 2015. "Use of Credit Information in Employment 2015 Legislation." Tech. rep., National Conference of State Legislatures.

NCUA. 2002. "Financial Trends in Federally Insured Credit Unions: January 1,2002 to September 30,2002." .

Pattison, Nathaniel. 2016. "New Evidence on Asset Exemptions and Consumer Bankruptcies." .

Pavan, Marina. 2008. "Consumer Durables and Risky Borrowing: The Effects of Bankruptcy Protection." Journal of Monetary Economics 55 (8):1441-1456.

Phillips, James D and David D Schein. 2015. "Utilizing Credit Reports for Employment Purposes: A Legal Bait and Switch Tactic." Rich. JL \& Pub. Int. 18:133.

Sandler, Danielle H and Ryan Sandler. 2014. "Multiple Event Studies in Public Finance: A Simulation Study with Applications." Journal of Economic and Social Management .

Severino, Felipe, Meta Brown, and Brandi Coates. 2015. "Personal Bankruptcy Protection and Household Debt." Working paper .

Stavins, Joanna. 2000. "Credit card borrowing, delinquency, and personal bankruptcy." New England Economic Review :15. 
Traczynski, Jeff. 2011. "Divorce Rates and Bankruptcy Exemption Levels in the US." Journal of Law and Economics .

Traub, Amy. 2013. "Discredited: How Employment Credit Checks Keep Qualified Workers Out of a Job." Demos .

Weiss, Lawrence A, Jagdeep S Bhandari, and Russell Robins. 2000. "An Analysis of StateWide Variation in Bankruptcy Rates in the United States." Bankruptcy Developments Journal 17:407.

White, Michelle J. 1987. "Personal Bankruptcy under the 1978 Bankruptcy Code: An Economic Analysis." Indiana Law Journal 63:1.

—. 2009. "Bankruptcy: Past Puzzles, Recent Reforms, and the Mortgage Crisis." American Law and Economics Review 11 (1):1-23.

Wozniak, Abigail. 2015. "Discrimination and the effects of drug testing on black employment." Review of Economics and Statistics (3):548-566.

Yang, Crystal Siming, Will Dobbie, and Paul Simon Goldsmith-Pinkham. 2015. "Consumer Bankruptcy and Financial Health." .

Zeldes, Stephen P. 1989. "Consumption and liquidity constraints: an empirical investigation." The Journal of Political Economy :305-346.

Zinman, Jonathan. 2014a. "Consumer Credit: Too Much or Too Little (or Just Right)?" Journal of Legal Studies 43 (3):9.

—. 2014b. "Household Debt: Facts, Puzzles, Theories, and Policies." Tech. rep., National Bureau of Economic Research. 